Final Report

FHWA/IN/JTRP-2003/23

\title{
UPGRADING THE INDOT PAVEMENT FRICTION TESTING PROGRAM
}

\author{
By \\ Shuo Li \\ Research and Pavement Friction Engineer \\ Transportation, safety, and Pavement Management Systems \\ Samy Noureldin \\ Section Manager \\ and \\ Karen Zhu \\ Senior System Analysts \\ Pavement, Materials, and Accelerated Testing Section \\ Division of Research \\ Indiana Department of Transportation \\ Joint Transportation Research Program \\ Project No. C-36-31Q \\ File No. 2-11-17 \\ SPR-2821 \\ Prepared in Cooperation with the \\ Indiana Department of Transportation and the \\ U.S. Department of Transportation \\ Federal Highway Administration
}

The contents of this report reflect the views of the author who is responsible for the facts and the accuracy of the data presented herein. The contents do not necessarily reflect the official views or policies of the Indiana Department of Transportation or the Federal Highway Administration at the time of publication. This report does not constitute a standard, specification, or regulation.

Purdue University

West Lafayette, Indiana 47907

October 2003 
TECHNICAL REPORT STANDARD TITLE PAGE

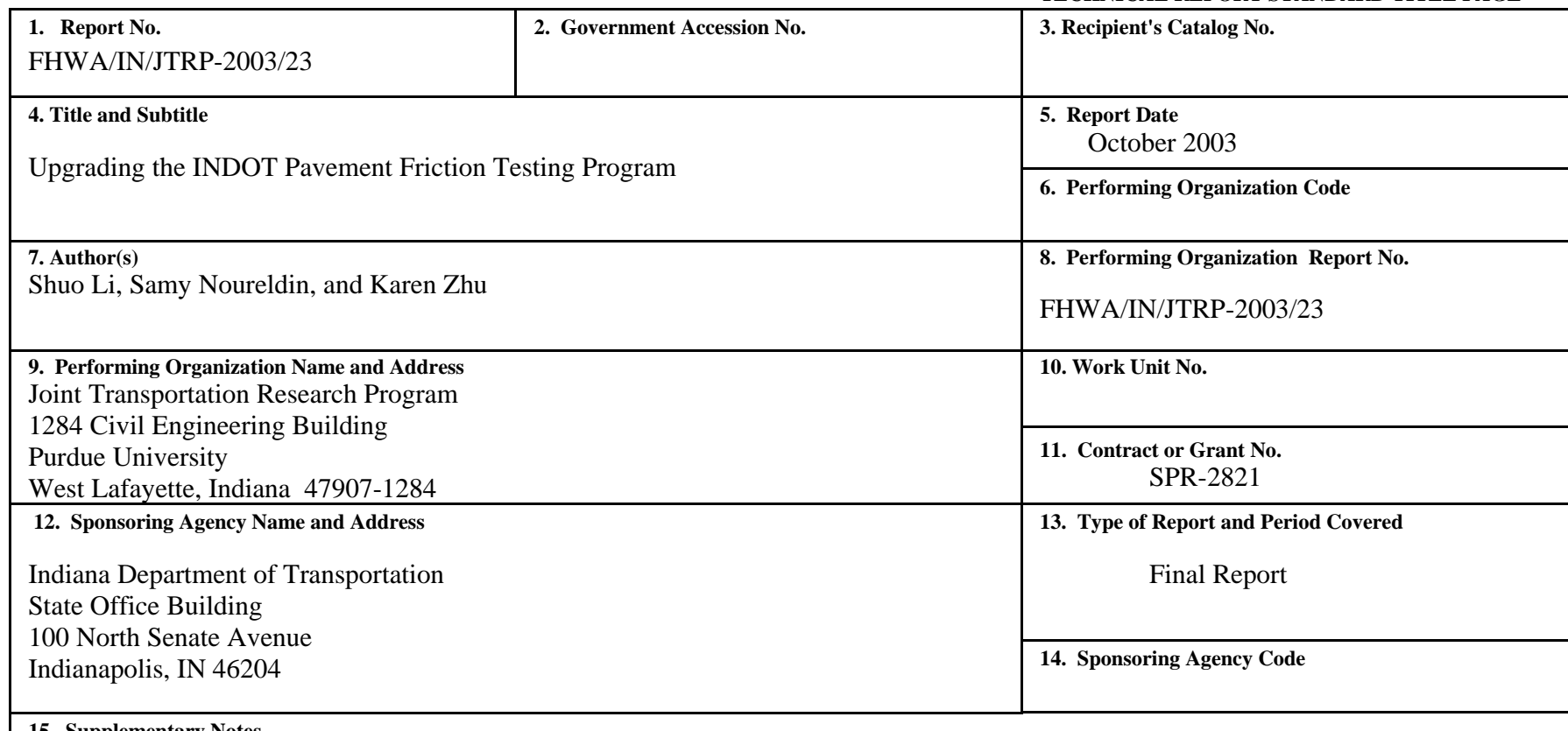

\section{Supplementary Notes}

Prepared in cooperation with the Indiana Department of Transportation and Federal Highway Administration.

\section{Abstract}

This study investigated many important issues associate with pavement surface friction testing, in particular using the smooth tire. This study utilized 3-D FEM program to investigate the fundamental friction phenomenon in light of energy dissipation during friction process. It was demonstrated that the pavement friction depends on many factors such as test tire, test speed, surrounding conditions, pavement surface texture, and pavement type. A great amount of friction data has been collected so as to investigate variations involved in pavement friction measurements. System variations depend on the feature of pavement surface. The standard deviations due to system errors are usually less than 5 . The smooth tire tends to provide greater variations than the ribbed tire. As air temperature increases, the friction number does not necessarily decrease. No consistent relations were identified between friction measurements and test seasons. Seasonal friction variations are negligible. The largest directional variation is 16 with the smooth tire on a State road. The State and U.S. roads tend to produce greater directional variations than the interstates. Driving lane usually has lower friction than other lanes. The greatest lateral variation arose due to the effect of wheel track. Longitudinal friction variations depend on traffic distribution, pavement type, and surrounding conditions. Friction measurements taken at 1.0-mile spacing can provide realistic network pavement friction information. Pavement frictions on interstates decreased faster than those on State and US roads. INDOT conducts pavement inventory friction test every year on interstates and every three years on State and US roads.

The force transducers should be calibrated every month and the whole system performance verified every week so as to identify potential significant performance changes. A minimum of three to five test runs must be conducted for system verification. The standard smooth tire is recommended for INDOT network pavement inventory friction test. In general, the friction number measured with the ribbed tire is greater than that with the smooth tire. However, the differences decrease as the surface texture becomes rougher. The average friction difference is about 20 on highway pavements. Friction test speed should be determined in light of the traffic conditions. Three test speeds of $30 \mathrm{mph}, 40 \mathrm{mph}$, and $50 \mathrm{mph}$ are recommended for network pavement inventory friction testing. Determination of the minimum friction requirement should consider its impact on wet-pavement accidents and agency's budgets. Taking into account the minimum friction requirement recommended by NCHRP Report-37 and the differences between the ribbed and smooth tires, a friction number of 20 with the smooth tire at $40 \mathrm{mph}$ is recommended as the minimum friction requirement for network pavement inventory friction testing. It was found that this requirement is economically reasonable in light of the network pavement maintenance and resurfacing. No good correlations were identified between pavement friction and wet-pavement accidents.

\section{Key Words}

18. Distribution Statement

Pavement friction, tire-pavement interaction, energy dissipation, 3-D simulation, smooth tire, frictional variations, friction No restrictions. This document is available to the public through the National Technical Information Service, Springfield, VA 22161 requirement, network pavement

\begin{tabular}{|c|c|c|c|}
\hline $\begin{array}{c}\text { 19. Security Classif. (of this report) } \\
\text { Unclassified }\end{array}$ & $\begin{array}{c}\text { 20. Security Classif. (of this page) } \\
\text { Unclassified }\end{array}$ & $\begin{array}{c}\text { 21. No. of Pages } \\
94\end{array}$ & 22. Price \\
\hline
\end{tabular}




\section{TECHNICAL Summary}

INDOT Research

Technology Transfer and Project Implementation Information

TRB Subject Code: 24-7 Pavement Surface Property

Publication No.: FHWA/IN/JTRP-2003/23, SPR-2821

October 2003

Final Report

\section{Upgrading the INDOT Pavement Friction Testing Program}

\section{Introduction}

A cost-effective network pavement friction testing program plays a great role in enhancing wet-pavement travel safety. Because of the many advantages with the smooth test tire, INDOT started to use it in the network pavement inventory friction testing in 1996. Each year, INDOT conducts approximately 6,500 lane-miles inventory friction testing. In the past 7 years, a great amount of pavement friction data has been measured on the INDOT friction test track, interstates, State roads, and US highways with the smooth tire. This study addressed those issues associated with pavement friction testing. This study investigated the complicated friction phenomenon during the process of tire-pavement interaction using 3-D FEM simulation. This study also investigated the primary frictional variations such as system variations, seasonal variations, spatial variations, and temporal variations. Based on the results, this study has finalized test frequencies, test tire, test speed, friction correction, and friction requirement for INDOT network pavement inventory friction testing program.

\section{Findings}

3-D FEM simulation may be a useful tool for researchers to investigate tire-pavement friction phenomenon in light of energy dissipation. Pavement friction is the result of tire-pavement interaction and depends on many factors. The frictional variations due to testing system errors are less than 5 measured in friction number. No consistent trend was observed in the seasonal variations of friction. It is difficult but not necessary to apply seasonal corrections to friction measurements. The largest lateral friction variation occurred due to the effect of wheel track. Pavement friction varies in time and the interstate pavements experienced more significant friction variations than pavements on other highways. The friction differences between smooth and ribbed tires vary with pavement surface texture. On average, the pavement friction number measured with the smooth tire is 20 less than that with the ribbed tire. Speed gradient curves vary with the type of test tire and surface texture. It is advisable to test interstate pavements every year and other highway pavements at least every three years. A test spacing of one-mile is reasonable. A friction requirement of 20 is justified with respect to the smooth tire at 40 mph.

\section{Implementation}

The findings will be employed to upgrade the existing INDOT network pavement friction testing program so as to provide realistic pavement friction information to INDOT individual districts and Program Development Division. 
Contacts

For more information:

Dr. Shuo Li

Indiana Department of Transportation

Division of Research

1205 Montgomery Street

P.O. Box 2279

West Lafayette, IN 47906

Phone: (765) 463-1521, Ext. 247

Fax: (765) 497-1665

Dr. Samy Noureldin

Indiana Department of Transportation

Division of Research

1205 Montgomery Street

P.O. Box 2279

West Lafayette, IN 47906

Phone: (765) 463-1521, Ext. 250

Fax: (765) 497-1665

\section{Dr. Karen Zhu}

Indiana Department of Transportation

Division of Research

1205 Montgomery Street

P.O. Box 2279

West Lafayette, IN 47906

Phone: (765) 463-1521, Ext. 241

Fax: (765) 497-1665

\section{Purdue University}

Joint Transportation Research Program

School of Civil Engineering

West Lafayette, IN 47907-1284

Phone: (765) 494-9310

Fax: (765) 496-7996 


\section{TABLE OF CONTENTS}

Chapter 1 Introduction $\quad 1$

1.1 Background and Problem Statement 1

1.2 Primary Objectives 3

1.3 Research Scope and Approach 4

Chapter 2 Pavement Surface Friction Testing and Evaluation: Literature Review 7

2.1 Pavement Surface Friction 7

$\begin{array}{ll}\text { Fundamentals of Tire-Pavement Friction } & 7\end{array}$

Primary Factors Involved in Tire-Pavement Friction Interaction 8

2.2 Pavement Friction Testing 10

2.3 Pavement Friction Modeling 15

Fundamental Relationship between Velocity, Temperature, and Friction 15

$\begin{array}{ll}\text { The Penn State Models } & 16\end{array}$

$\begin{array}{ll}\text { The PIARC Model } & 17\end{array}$

2.4 The Use of Friction Data by Highway Agencies 19

2.5 Pavement Friction Requirements 21

Chapter 3 Simulation of Tire-Pavement Friction Interaction Using 3-D FEM Program 23

3.1 Mechanical Behavior of Tire-Pavement Friction Interaction 23

Energy Dissipation during Sliding $\quad 23$

Temperature and Speed Dependencies $\quad 24$

3.2 3-D FEM Modeling Tire-Pavement Friction Interaction Process 26

The ABAQUS/Explicit Program 26

Simplified Tire-Pavement Friction Interaction Model 27

3.3 Simulation Results and Analysis $\quad 29$

Smooth Tire versus Ribbed Tire $\quad 30$

Energy Dissipation and Resultant Friction 31

Variations of Energy Dissipation with Sliding Speed 31

Concrete Pavement versus Asphalt Pavement 33

3.4 Summary 33 
4.1 System Variations 35

Friction Measurements $\quad 35$

System Variations on Different Pavement Surfaces 36

4.2 Seasonal Variations 41

Variations of Friction with Air Temperature $\quad 41$

Significant Test of Air Temperature Effect $\quad 42$

4.3 Spatial Variations 45

Lateral Friction Variations $\quad 45$

Longitudinal Friction Variations $\quad 47$

4.4 Temporal Variations $\quad 48$

Variations of Friction with Time in New Pavements 51

Variations of Friction with Time in Old Pavements 52

Chapter 5 The INDOT Network pavement Inventory Friction Test Program 55

5.1 Friction Testing System Calibration and Performance Verification 55

Calibration of Transducers and Subsystems 55

System Performance Verification 56

5.2 Test Frequencies and Test Locations 58

Test Frequencies $\quad 58$

Test Locations $\quad 61$

5.3 Test Tires 63

Differences between the Ribbed and Smooth Tires 63

Use of the Ribbed and Smooth Tires 66

$\begin{array}{lll}5.4 & \text { Test Speeds } & 68\end{array}$

$\begin{array}{lll}\text { Chapter } 6 \text { Network Pavement Friction Data management } & 71\end{array}$

$\begin{array}{lll}6.1 & \text { Friction Requirements } & 71\end{array}$

$\begin{array}{ll}\text { The Friction Flag Value } & 71\end{array}$

Effect of Friction Requirement on Pavement Maintenance and Resurfacing $\quad 73$ Impact of Pavement Friction on Wet-Pavement Accidents 75

$\begin{array}{lll}6.2 & \text { Friction Data Reporting } & 77\end{array}$

6.3 Friction Data Management 81 
Chapter 7 FINDINGS AND RECOMMENDATIONS

7.1 Findings

83

$\begin{array}{lll}7.2 & \text { Recommendations } & 87\end{array}$

$\begin{array}{ll}\text { Recommendations for Implementation } & 87\end{array}$

Recommendations for Further Research $\quad 89$

$\begin{array}{lr}\text { References } & 91\end{array}$ 


\section{List Tables and Figures}

Table 4.1 Results of Pearson Correlation Analysis

Table 5.1 Surface Features of the Three Test Sections

Table 6.1 Summary of Friction Differences between Ribbed and Smooth Tires

Table 6.2 Illustration of Low Friction Report

Table 6.3 Illustration of Summary of Inventory Friction Test for Individual Districts

Table 6.4 Illustration of Inventory Friction Test Report for Individual Districts

Figure 2.1 Texture Wavelengths and Tire-Pavement Interaction

Figure 2.2 Dependences of Friction Force Components on Sliding Speed

Figure 2.3 ASTM E-274 Friction Test Trailer

Figure 2.4 British Pendulum Tester (BPT)

Figure 2.5 Dynamic Friction Tester (DFTester)

Figure 2.6 Surveys on Use of Friction Data by State Highway Agencies

Figure 2.7 Friction Requirements by State DOTS

Figure 3.1 Principal Friction Force Components

Figure 3.2 Frictional Characteristics of Rubbers during Sliding

Figure 3.3 Typical Temperature Dependence of Friction

Figure 3.4 Dimensions of Tire-Pavement Model

Figure 3.5 Illustrations of Meshes

Figure 3.6 Tire-Pavement Stress Contour Plot Created Using ABAQUS/CAE

Figure 3.7 Energy Dissipations with the Smooth and Ribbed Rubbers

Figure 3.8 Energy Dissipations vs. Coefficient of Friction

Figure 3.9 Energy Dissipations vs. Sliding Speed

Figure 3.10 Energy Dissipations with Smooth Rubber Block on Asphalt and Concrete Pavements

Figure 4.1 Standard Deviations of Friction Measurements on the Test Track

Figure 4.2 Coefficients of Variations of Friction Measurements on the Test Track

Figure 4.3 Standard Deviations with Smooth and Ribbed Tires

Figure 4.4 Coefficients of Variations with Smooth and Ribbed Tires

Figure 4.5 Friction Measurements in Different Seasons

Figure 4.6 Variations of Air Temperature, Solar Radiation, and Wind Speed with Time in West Lafayette

Figure 4.7 Directional Friction Variations

Figure 4.8 Friction Variations due to Test Location

Figure 4.9 Friction Variations on Asphalt and Concrete Pavements

Figure 4.10 Longitudinal Friction Variations on Interstates

Figure 4.11 Longitudinal Friction Variations on State and US Roads

Figure 4.12 Frictional Variations on New HMAt Pavements

Figure 4.13 Frictional Variations on New Concrete Pavements

Figure 4.14 Frictional Variations in Asphalt Pavement with Rutting

Figure 4.15 Frictional Variations in Asphalt Pavement with Cracking and Raveling

Figure 4.16 Variations of INDOT Network Pavement Friction Conditions

Figure 5.1 INDOT In-House Force Plate Calibration Platform

Figure 5.2 The INDOT Friction Test Track

Figure 5.3 Effect of Sample Size on System Verification Test with the Smooth Tire 
Figure 5.4 Effect of Sample Size on System Verification Test with the Ribbed Tire

Figure 5.5 Friction Measurements Taken in Indiana SHRP Friction Test Site 20

Figure 5.6 Friction Measurements with Smooth and Ribbed Tires on INDOT Friction Test Track

Figure 5.7 Frictional Differences Measured on SR-37

Figure 5.8 Frictional Differences in the Pavement Network

Figure 5.9 Speed Gradients with Smooth and Ribbed Tires on Different Surfaces

Figure 6.1 Friction-Failed Pavements vs. Minimum Friction Requirement

Figure 6.2 Wet-Pavement Accidents

Figure 6.3 Correlations between Network Wet-Pavement Accidents and Pavement Frictions

Figure 6.4 INDOT Network Pavement Inventory Friction Data Query Program 


\section{ACKNOWLEDGMENTS}

This research project was sponsored by the Indiana Department of Transportation in cooperation with the Federal Highway Administration through the Joint Transportation Research Program (JTRP). The authors would like to thank the study advisory committee members, Dave Kumar, Flora William, Isenhower Steve, Victor Lee Gallivan, and Walker Ronald, for their valuable assistance and technical guidance in the course of performing this study. Sincere thanks are extended to David Hinshaw and Aaron Ping for their assistance in data collection. The authors also acknowledge the effort made by our former colleagues, Sedat Gulen and Larry Batman, in developing the pavement friction test program. 


\section{Chapter 1}

\section{INTRODUCTION}

\subsection{Background and Problem Statement}

Indiana Department of Transportation (INDOT) initiated pavement friction testing in the early 1960s. However, the existing INDOT pavement friction testing program was established in 1975 as part of the Skid Accident Reduction Program and has been upgraded several times by following American Society for Testing and Materials (ASTM) standards and American Association of State Highway and Transportation Officials (AASHTO) and Federal Highway Administration (FHWA) guidelines (1). The INDOT pavement friction testing program includes network inventory friction testing, warranty project friction testing, and special project friction testing. The inventory friction testing is conducted routinely on all interstates and toll roads each year, and on all US and State roads in a three-year cycle. The four main purposes for inventory friction testing are given below

a) To identify potential slippery pavement locations

b) To provide the INDOT Program Development Division and Districts with friction data which may be used in planning pavement maintenance and rehabilitation activities

c) To provide the INDOT Legal Division and Attorney General's Office with friction data at accident sites, and

d) To establish and maintain a network pavement friction database

Warranty project friction testing is conducted for warranty projects to ensure sufficient skid-resistance during a five-year warranty period. Special project friction testing is usually conducted for research purposes so as to evaluate the skid-resistance of a specific mix or aggregate materials. Also, special project friction testing may be conducted in response to public inquiry so as to examine the pavement skid-resistance at certain locations. All pavement friction 
tests are conducted in accordance with ASTM E-274 (2). Prior to 1996, INDOT conducted pavement friction testing using the standard ribbed tire (3). Since 1996, the standard smooth tire (4) has been employed in all pavement friction tests considering the good correlation between pavement friction numbers measured using the standard smooth tire and wet-pavement accidents. The ribbed tire is only used to measure the surface macrotexture when the pavement friction is less than the minimum requirement.

It has been reported by Henry (5), that the standard smooth tire has some important advantages over the standard ribbed tire. With the smooth tire, the friction measurement is sensitive to both surface microtexture and macrotexture. However, the standard ribbed tire has six straight grooves which provide channels much larger than surface macrotexture for water flow. Therefore, the ribbed tire may generate friction measurements which are insensitive to surface macrotexture but dominated by surface microtexture. In addition, a study by Connecticut DOT shows that a good correspondence between low smooth-tire skid numbers and accident experience were observed but ribbed-tire correspondence was quite poor (6). Henry further pointed out that agencies are reluctant to use the smooth tire possibly because the friction number with the smooth tire is much lower and because the ribbed tire is the original standard tire for friction test, changing to the smooth tire would produce data that could not be compared with historical data.

INDOT is one of the very few state highway agencies in the country currently using the standard smooth tire in pavement friction testing. At the time that INDOT started to use the smooth tire in pavement friction test, no friction data with the smooth tire was available. Many issues associated with the use of the smooth tire, such as test system calibration, seasonal correction, and minimum friction requirement, remained not addressed. Since 1996, a tremendous volume of data has been collected with the smooth tire on INDOT highways and friction test track. Also, all test system calibration data, such as force plate calibration data, monthly in-house system calibration data, and weekly test track system calibration data, has been recorded electronically and is ready to be used to upgrade the system calibration procedures. 
Pavement surface friction is a sophisticated phenomenon. The dynamic nature of tirepavement friction interaction is fundamentally a molecular-kinetic process due to the thermal motion of the molecular chains in sliding or rolling on the contacting surface. While many models have been developed to evaluate pavement friction (7-10), it is widely accepted that the true pavement friction is hard to determine due to the many complex factors involved in the tirepavement interaction process. Recently, friction theory and computation techniques have witnessed great advancement $(11,12)$. This brought investigators a step closer to understanding the friction phenomenon and makes it possible for investigators to characterize tire-pavement friction interaction in terms of the energy dissipation. Sound theory is a solid foundation for pavement friction testing and evaluation.

\subsection{Primary Objectives}

Pavement surface friction is an important measure of pavement performance related to travel safety. It is also a basic element of the long-term pavement performance (LTPP) study conducted in the North America (13). While the accidents related to pavement friction may only account for a small portion of all accidents on roadways, it does represent actual human injuries, fatalities, and multiple dollars in property damage. Recognizing the importance of pavement friction, the INDOT Research Division has made great efforts to upgrade the pavement friction testing program with the emerging technologies and is committed to provide realistic pavement friction data. Since 1996, the INDOT Research Division has conducted pavement friction tests on approximately 6,600 lane-miles each year. A large amount of friction data is currently electronically accessible. As part of our continuing effort, this study was to fulfill the following four primary objectives.

The first objective was to upgrade the test system calibration procedures. The friction measurement is relevant and conditional because tire-pavement interaction involves many complex factors. Pavement friction depends to a large extent on the test equipment. Therefore, system calibration plays an important role in maintaining consistent system performance. However, system calibration such as force plate calibration and force measuring transducer

calibration is laborious and time-consuming. Currently, the INDOT Research Division has two 
friction testing systems, i.e., ASTM E-274 trailers. This study was to determine an appropriate calibration period so as to minimize the potential errors due to the test equipment and avoid sudden changes in the equipment performance at the lowest cost. Pavement friction varies from location to location and may experience dramatic spatial and temporal variations. Also, field pavement friction testing is relatively expensive and may generate safety concerns in some unfavorable traffic conditions. Therefore, the second objective was to justify the current test spacing, speed, location, and period so as to provide reliable friction data and address cost and safety issues.

The third objective was to address some important issues associated with pavement friction testing using the smooth tire, such as seasonal variations and minimum friction requirement. Currently, most state highway agencies are still using the ribbed tires in pavement friction test. INDOT has used the smooth tire in pavement friction test for about seven years and a large amount of data is now available. The fourth objective was to employ the finite element method (FEM) to explore the dynamic nature of tire-pavement friction interaction in terms of the energy dissipation due to the deformation and relaxation taking place when the tire is sliding or rolling on the pavement. While no theoretical friction model has been fully verified experimentally, theoretical analysis can provide fundamental guidance to the field testing and expand our knowledge so as to further improve the test program. It was believed that after the four objectives were fulfilled, this study could provide more efficient system calibration procedures and more cost-effective friction testing program for locating slippery pavement locations and monitoring network pavement friction variations.

\subsection{Research Scope and Approach}

In order to fulfill the four primary objectives, this study focused all efforts on the following areas:

a) Synthesis study on the technologies, practice and research in pavement friction testing and evaluation

b) Development of an algorithm for validating field calibration tests

c) Investigation of friction variations 

d) Investigation of friction requirements
e) Theoretical studies of tire-pavement friction interaction, and
f) Updating the friction testing manual

The general research approach for the proposed study consisted of three steps. The first step was to undertake synthesis study. An extensive literature review was conducted to examine technologies and research studies associated with pavement friction testing and evaluation. Primary emphasis was given to the latest technologies and current practices nationwide. An intensive review was undertaken to examine other DOTs' friction testing programs including calibration, testing, and friction requirement. The synthesis reviewed the standards and specification published by FHWA, ASTM, and AASHTO for guiding pavement friction testing and evaluation. The synthesis study also reviewed the relevant technical publications by Transportation Research Board (TRB), American Society of Civil Engineers (ASCE), ASTM, and Society of Automotive Engineers (SAE). In addition, the synthesis reviewed the research work conducted by the World Road Association, formerly known as the Permanent International Association of Road Congresses (PIARC).

A second step was to conduct data analysis. INDOT has conducted pavement friction testing for the last 30 years and has used the smooth tire in pavement friction test for the past seven years. A large amount of friction data has been collected on the friction test track and real pavements. However, this study focused on the data measured since 1996 due to three reasons. First, the data was measured using the two existing friction testing systems. Next, all friction test and calibration data collected in these years has been stored electronically and is accessible for use. The third reason is that many pavements have been resurfaced. It was very difficult for us to track down historical information on pavement maintenance and rehabilitation projects. Calibration data was used in assessing the calibration procedures and examining seasonal friction variations in pavement friction measurements. The warranty project pavement friction data was used to examine lateral friction variations and temporal friction variations. Inventory friction test data was used to evaluate network pavement performance. Data collected simultaneously with both the smooth and ribbed tires on the friction test track and real pavements was employed to identify the friction differences between the smooth and ribbed tires. 
The third step was to perform fundamental analysis. This involved statistical analysis of possible correlation between pavement friction and wet-pavement accidents, general analysis of friction requirement and incurred pavement maintenance, and theoretical analysis of the dynamic nature of tire-pavement friction interaction using 3-D FEM simulation. The statistical analysis of pavement friction and wet-pavement accidents was based on the INDOT network pavement inventory friction data and accident data stored in the National Highway Traffic Safety Administration (NHTSA) web-based database, FARS (14). The INDOT network pavement inventory friction data was also employed in the general analysis of pavement friction requirement and maintenance. ABAQUS/Explicit, a 3-D FEM program, was employed to investigate the friction process in terms of the energy dissipation and the inherent differences between the smooth tire and the ribbed tire. Based on the analysis results in conjunction with published information, a minimum friction number with the smooth tire was justified. 


\section{Chapter 2}

\section{PAVEMENT SURFACE FRICTION TESTING AND EVALUATION: LITERATURE REVIEW}

\subsection{Pavement Surface Friction}

\section{Fundamentals of Tire-Pavement Friction}

Friction force arises at the interface due to the interaction between the sliding or rolling tire and the contacting pavement surface. The rubber undergoes all deformation and the mechanism of friction is governed by the behavior of the rubber materials because tires are usually made up of rubber or rubberized materials and pavements are relatively rigid. The dynamic frictional nature of rubber materials is considered as a molecular-kinetic thermal process due to the thermal motion of molecular chains against the contacting surface (15). Therefore, the friction force can be determined by including two main components as follows $(7$, 16)

$$
F_{\mu}=F_{a}+F_{h}
$$

where $\mathrm{F}_{\mu}=$ friction force;

$F_{a}=$ adhesion force depending on the interface shear strength and the contact area; and

$\mathrm{F}_{\mathrm{h}}=$ hysteresis force component generated due to the damping losses within the rubber

When pavement surface is smooth and dry, the friction force is dominated by the adhesion force which is generated due to the molecular bonds between the rubber tread and the contacting surface and the shearing of the rubber taking place just below the surface. When pavement surface becomes wet and rough, the hysteresis force prevails. On wet pavements, the surfaces are lubricated and the adhesion force decreases. When a tire slides over a rough surface, the tread of tire will experience continuing deformation of compression and relaxation. In the compression phase, the deformation energy is stored within the rubber tread. In the relaxation phase, part of 
the stored energy will be recovered and part of the stored energy will be lost in the form of heat which is irreversible and identified with hysteresis losses.

\section{Primary Factors Involved in Tire-Pavement Friction Interaction}

As discussed earlier, the two frictional force components are the results of tire-pavement interaction. These two components depend to a large extent on pavement surface features and the contacting between the tire and pavement surface. Also, the two frictional force components may vary dramatically with temperature and sliding speed because rubber is viscoelastic material. Therefore, any factors which may affect the pavement surface feature, tire properties, and contact will affect surface friction. This section focuses on the primary factors such as pavement surface texture, water, speed, and temperature.

Pavement Surface Texture: Pavement surface feature refers to pavement surface texture which affects the interaction between tire and pavement. Surface feature has a significant effect on tire-pavement contacting, shearing of the tire tread, and molecular bond between tire tread and pavement. As surface texture increases, the adhesion force component decreases and the hysteresis force component increases. Permanent International Association of Road Congress (PIARC) conducted a study to investigate the effect of pavement surface texture on the tirepavement interaction (17). Pavement surface texture was categorized into three groups in terms of texture wavelength by PIARC below

a) Microtexsture: Wavelength $=0.0004$ in. to 0.02 in. $(1 \mu \mathrm{m}$ to $0.5 \mathrm{~mm})$

b) Macrotexture: Wavelength $=0.02$ in. to 2 in. $(0.5 \mathrm{~mm}$ to $50 \mathrm{~mm}$ and

c) Megatexture: Wavelength $=2$ in. to 20 in. $(50 \mathrm{~mm}$ to $500 \mathrm{~mm})$

Wavelengths longer than 20 in. are defined as roughness or evenness. PIARC further proposed the correlation between texture wavelength and its effect on the tire-pavement interaction including wet friction, noise, splash/spray, rolling resistance, and tire wear, which is shown in Figure 2.1. It is demonstrated that microtexture and macrotexture ultimately determine wet-pavement friction. This is because the adhesion force component depends on the microtexture and the hysteresis force component on the macrotexture (7). Also, the surface 
drainage depends mainly on the macrotexture. It is also illustrated that in Figure 2.1, wetpavement friction is independent of pavement roughness. A pavement with large roughness does not necessarily have large surface friction. An attempt to increase pavement friction may result in high noise, splash, and spray problems. Therefore, the design of surface texture requires a compromise among friction, noise, tire wear, and splash/spray.

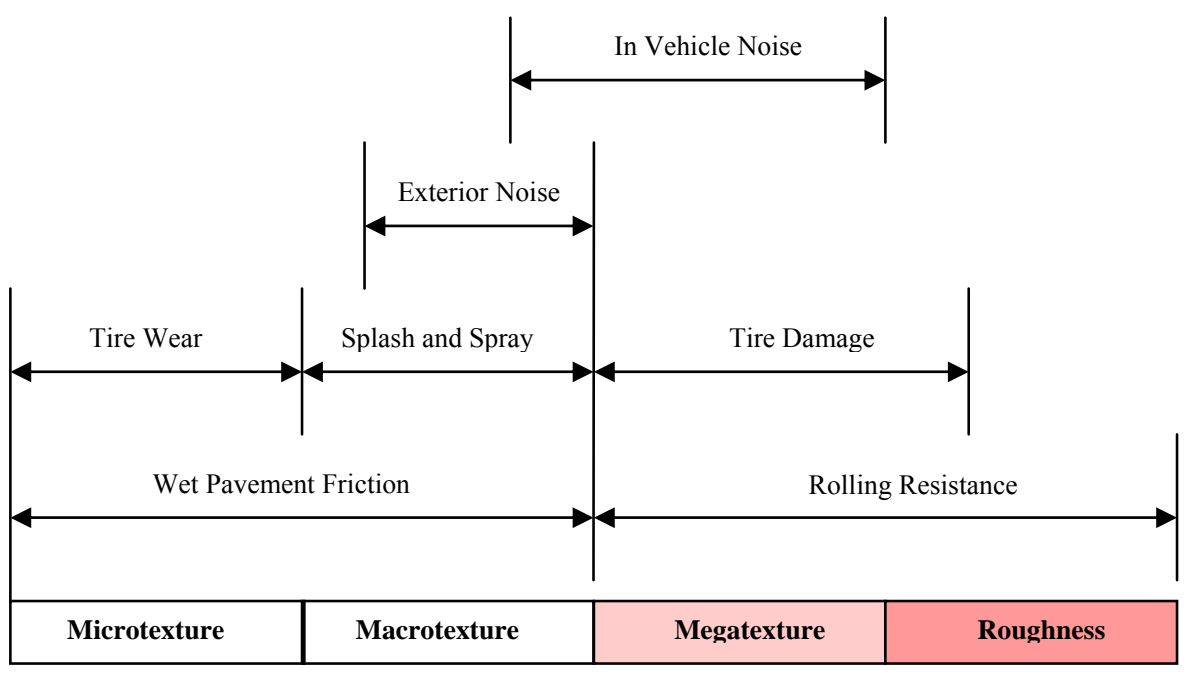

Figure 2.1 Texture Wavelengths and Tire-Pavement Interaction (Modified from PIARC [17])

Water: When pavement is wet, water may be presented in the contact area so that as if vehicle travels on lubricated surfaces. Consequently, the adhesion force component diminishes and friction force decreases. However, the hysteresis force component is little sensitive to water. During the tire-pavement interaction process, bulk water is first removed through open channel provided by the macrotexture. Then, the water film between tire and pavement surface is wiped out in part by the leading edge of tire tread. It is very important to distinguish between wetpavement friction and hydroplaning. The later is a phenomenon which takes place when the tire is lifting from the pavement surface due to the pressure created by the water under the tire. When pavement surface is covered by snow or ice, friction force depends greatly on the design of tire tread such as tread pattern and tread compound.

Effect of Speed and Temperature: Rubber is a viscoelastic material whose damping properties depend strongly on sliding speed and temperature. Kumar and Meyer (18) investigated 
the effect of speed and temperature and concluded that when speed is low (0 to $10 \mathrm{mph}$ ), the adhesion force component shows significant speed dependence. However, the hysteresis force component shows a little speed dependence. When speed is very high $>50 \mathrm{mph}$, the adhesion force component coefficient remains relatively stable and the hysteresis force component begins to increase noticeably, especially after $50 \mathrm{mph}$. Figure 2.2 shows the typical dependences of adhesion and hysteresis force components on sliding speed. As temperature increases, the adhesion force component may increase or decrease. However, the hysteresis force component always decreases as temperature increases.

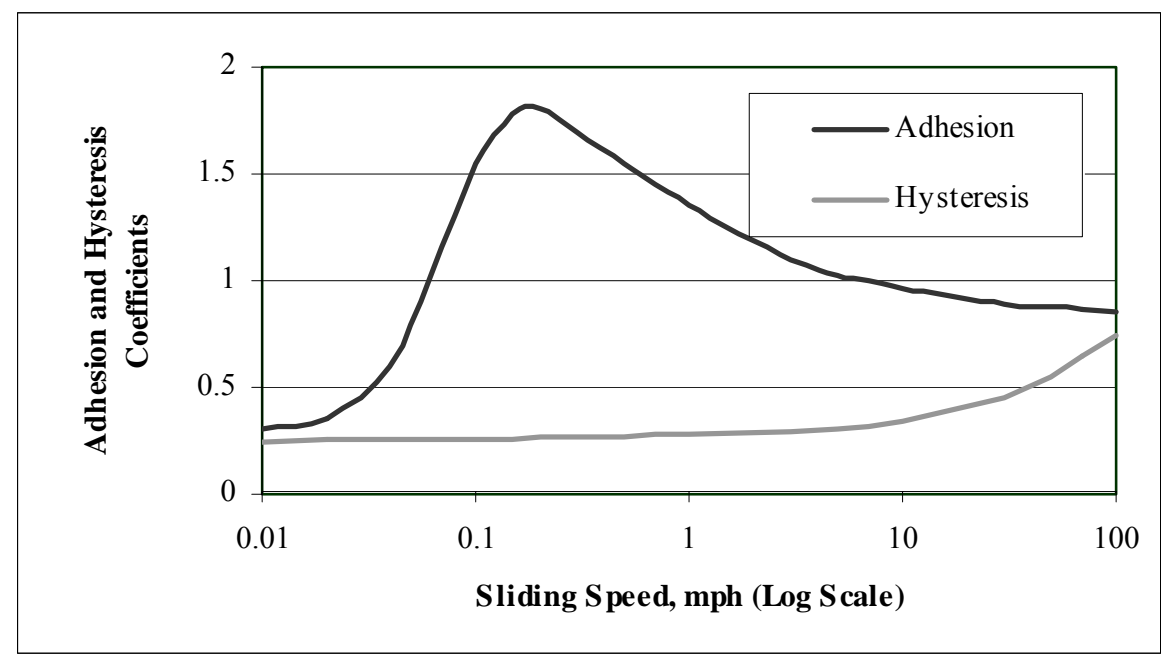

Figure 2.2 Dependences of Friction Force Components on Sliding Speed

(Modified from [18], [19])

\subsection{Pavement Friction Testing}

Friction test includes field friction test and laboratory friction test. There are many types of friction test equipment commercially available. All devices such as pendulum skid resistance tester, rotating disc tester, footwear sliding tester, robotic friction tester, and test vehicles are developed on the basis of the fundamental friction mechanism. For the laboratory friction test, only two types of equipment, i.e., the British pendulum tester (BPT) and the dynamic friction tester (DFTester) are currently available. For field pavement friction test, devices such as locked wheel trailer, side force tester, fixed slip tester, and variable slip tester are widely accepted by highway and airport agencies. Henry conducted a synthesis study and found out that almost all 
state highway agencies are using the locked wheel device in field highway pavement friction testing (20). The primary emphasis is given to discussion of these two devices because the British pendulum tester and the locked wheel tester are the most widely used devices by highway agencies in the United States. In addition, the dynamic friction tester is also briefed because of the fact that it is the latest development in friction equipment and the interest in it is rising.

Locked Wheel Device: This device refers to the ASTM E-274 trailer in the United States as shown in Figure 2.3. It measures the steady-state friction force on a locked wheel as it is sliding over a wetted pavement surface under a constant load and at a constant speed. The device consists of a trailer towed by a vehicle. The apparatus includes force and speed transducers, control system, record system, and pavement wetting system. Test wheels are incorporated into the trailer. The test tire is either a standard ribbed tire or a standard smooth tire. The test tire inflation pressure is set at $24 \mathrm{psi}(165 \mathrm{kPa})$. In the course of testing, the vehicle reaches the desired speed. Then, water is delivered to the pavement, and the test wheel brake is locked 0.5 seconds after beginning of the water delivery.

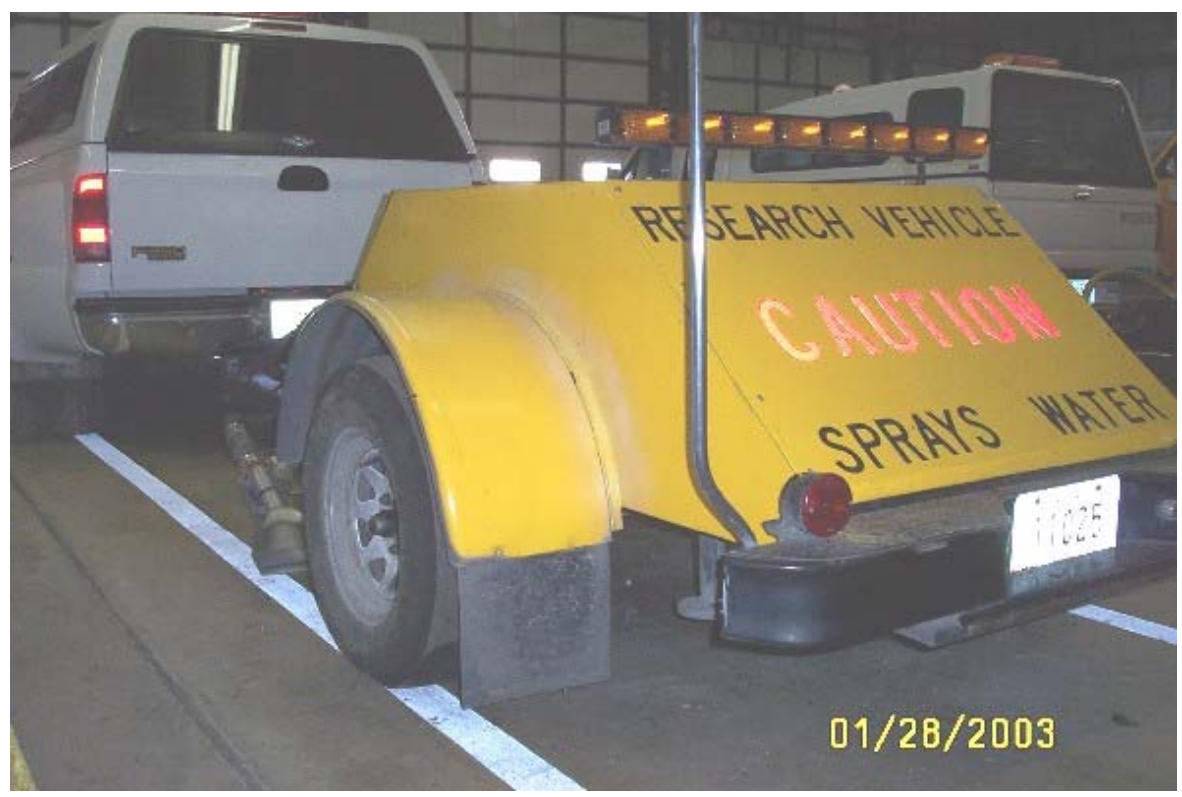

Figure 2.3 ASTM E-274 Friction Test Trailer 
The watering system should provide a water film of 0.02 in. $(0.5 \mathrm{~mm})$. When the test wheel is locked, this device produces a 100 percent slip condition. The relative velocity between the surface of the tire and the pavement surface, i.e., the slip speed, is equal to the vehicle speed. The wheel should remain locked for approximately 1.0 second and the data is measured and averaged. The test result is reported in terms of the classic Coulomb's friction law below

$$
\mu=\frac{F}{N}
$$

where $\mu=$ coefficient of friction;

$\mathrm{F}=$ tractive force or friction force; and

$\mathrm{W}=$ normal force on the test wheel.

The test results are reported as the skid numbers, i.e., friction numbers called in this report, which are the product of 100 and the coefficient of friction. This device can detect the peak friction force because the data measurement is continuous when the test wheel remains locked. With the locked wheel tester, pavement friction testing can be conducted at the traffic speed. At very low speed (approximately less than $15 \mathrm{mph}$ ), however, it is hard to adjust the water delivery. The standard test speed is $40 \mathrm{mph}(64 \mathrm{~km} / \mathrm{h})$. The friction test results at other speeds should be converted into those at $40 \mathrm{mph}(64 \mathrm{~km} / \mathrm{h})$ using speed gradient curves.

The original ASTM E-274 only covered a standard ribbed tire. In 1975, the standard smooth tire was adopted as an alternative for friction testing by ASTM E-501. In 1990, ASTM E-501 and E-524 were developed for both the standard smooth and ribbed tires, respectively. Henry did a survey on the use of test tires in the country and concluded that there is an increased interest in use of the smooth tire (20). The standard ribbed tire has seven 0.66 in. (16.8 mm) wide plain ribs and six $0.2 \mathrm{in} .(5.08 \mathrm{~mm})$ wide grooves. Those grooves in the ribbed tire provide channels much larger than the macrotexture of pavement surface and allow water to flow from the tire-pavement interface. As a result, the friction measurements with a ribbed tire are insensitive to the macrotexture and depend greatly on the microtexture. However, friction testing with the smooth tire is sensitive to both the microtexture and macrotexture. The study by 
Connecticut DOT (6) also shows a good correspondence between low smooth-tire skid numbers and accident experience. Henry pointed out that agencies are reluctant to use the smooth tire possibly because the friction number with the smooth tire is much lower than that with the ribbed tire. Also, changing to the smooth tire would produce data that could not be compared with historical data, because the ribbed tire is the original standard tire for friction testing

British Pendulum Tester: The British pendulum tester, BPT, is a dynamic pendulum impact-type device for measuring surface friction as shown in Figure 2.4. It measures the energy loss when a rubber slider edge is propelled over a test surface. The tester is equipped with a standard rubber slider. During testing, the pendulum is raised to the locked point with a height that is adjusted so that the rubber slider just comes in contact with the pavement surface. When the pendulum is released and reaches the test surface, its potential energy becomes its maximum kinetic energy. As the rubber slider slides over the test surface, the friction reduces the kinetic energy of the pendulum in proportion to the level of friction. When the slider leaves the test surface, the reduced kinetic is converted to potential energy as the pendulum swings to its maximum height. The difference between the height before the release and the recovered height is equal to the loss of the kinetic energy due to the friction.

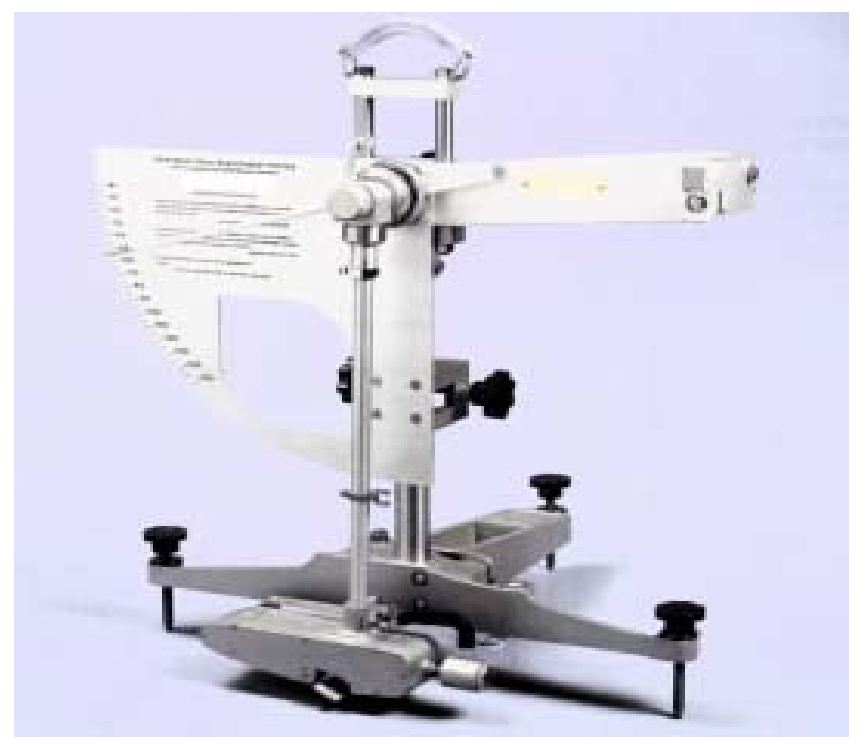

Figure 2.4 British Pendulum Tester (BPT) 
The test method is covered in ASTM E-303 (21). The test result is reported as the British Pendulum Number (BPN). BPN is measured directly using a drag pointer. The greater the friction between the rubber slider and the test surface, the greater the BPN. In reality, this tester is suited for laboratory test. The average slip speed decreases as the friction increases because the average velocity of the slider relative to the test surface is a function of the friction. Usually, the typical slip speed is assumed to be $6 \mathrm{mph}(10 \mathrm{~km} / \mathrm{h})$ for the BPT. BPT is fitted with a scale that measures the recovered height in terms of the BPN over a range of 0 to 140 . BPN mainly depends on the microtexture because the slip speed is very low.

Dynamic Friction Tester: The dynamic friction tester (DFTester), as shown in Figure 2.5, is a portable device for measuring friction. The test procedures are covered in ASTM E-1911 (22). The fundamental principle is the Coulomb's friction law. This device consists of a horizontal spinning disk fitted with three spring-mounted rubber sliders. During testing, the disk is lowered so that the three sliders are in contact with the test surface under a constant force perpendicular to the test surface. The disk is driven by a motor and rotates at a tangential speed varying from 0 to $50 \mathrm{mph}(80 \mathrm{~km} / \mathrm{h})$ which is determined from the rotary speed of the disk. Water is delivered to the test surface by a water supply unit. The horizontal force required to overcome the friction is measured by a transducer. The test result is reported as the coefficient of friction and is plotted against the speed.

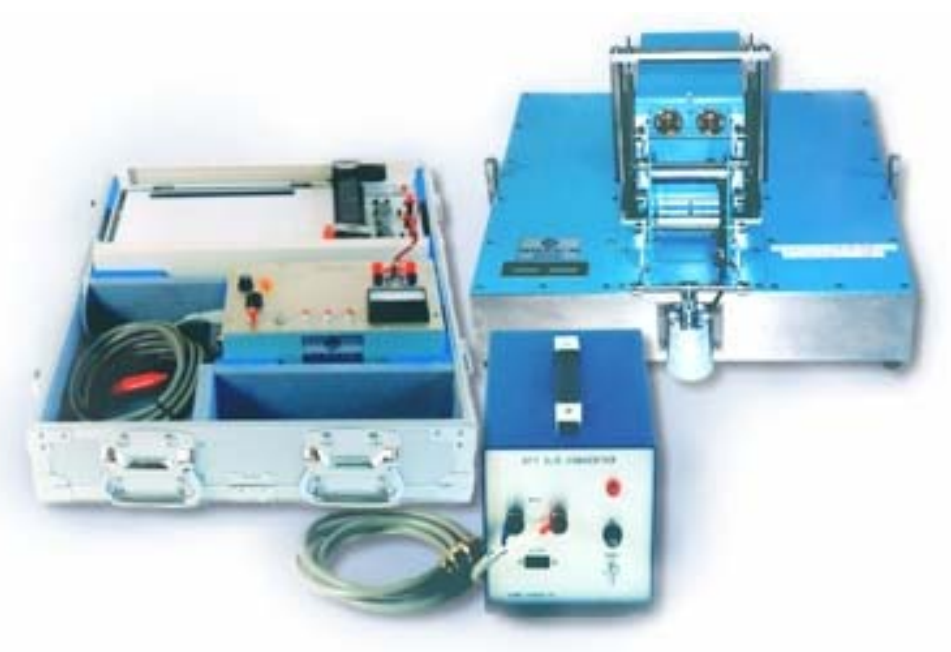

Figure 2.5 Dynamic Friction Tester (DFTester) 
It is reported that by the manufacturer (23), the measurements are a continuous spectrum of dynamic coefficients of friction and are highly reproducible. Data measuring and recording are accomplished simultaneously in a short time period. In addition to easy setup, the DF Tester has the advantage of being able to measure the friction as a function of speed over the range of test speeds. This enables users to create speed gradient curves quickly. Like the British pendulum tester, use of the DF Tester in field pavement friction tests requires traffic control.

\subsection{Pavement Friction Modeling}

\section{Fundamental Relationship between Velocity, Temperature, and Friction}

Rubber is a polymer. For a rubber tire sliding on a rigid surface, the friction between the tire and the rigid surface is definitely not constant and are strongly dependent on temperature and velocity. Schallamach $(24,25)$ investigated the dynamic friction behavior of the rubber materials. He considered the friction as a molecular-kinetic process due to the thermal motion of the molecular chains in the rubber surface and presented an exponential relationship among velocity, temperature, and friction below

$$
V=V_{0} e^{-\frac{E_{a}-\gamma F_{\mu}}{R T}}
$$

where $\mathrm{V}$ = sliding velocity;

$$
\begin{aligned}
& \mathrm{V}_{0}=\text { constant; } \\
& \gamma=\text { constant; } \\
& \mathrm{R}=\text { constant; } \\
& \mathrm{E}_{\mathrm{a}}=\text { activation energy; } \\
& \mathrm{T}=\text { absolute temperature; and } \\
& \mathrm{F}_{\mu}=\text { friction force } .
\end{aligned}
$$

This model indicates that in the sliding process, the dragging force must be large enough to overcome the activation energy which is the energy barrier created due to the molecular bonds. When some molecular bonds are broken, new ones will be formed. As rubber deforms, 
some areas are compressed and some other areas are stretched. All these phenomena such as molecular bond breaking, bond forming, and body deformation and relaxation take energy. Therefore, forces arise at the contacting surfaces. The resultant forces depend on the velocity, temperature; and material properties.

\section{The Penn State Models}

Researchers in Pennsylvania State University have made great effort to investigate the tire-pavement friction phenomenon and develop friction models in the past decades. Based on the fundamentals of rubber friction, Kumar (7) proposed a model to evaluate pavement friction directly using the adhesion and hysteresis components. Other researchers in Pennsylvania State University developed some friction models based on the pavement surface textures because these two components are still not fully understood.

Leu and Henry (8) presented a model to relate the friction to slip speed by an exponential function below

$$
\mu=\mu_{0} e^{-\frac{P N G}{100} S}
$$

where $\mu=$ friction;

$\mu_{0}=$ intercept of friction at zero speed;

$\mathrm{S}=$ slip speed; and

$\mathrm{PNG}=$ percent normalized gradient.

Leu and Henry concluded that PNG is constant with speed and is highly correlated with macrotexture. The intercept of friction at zero speed, $\mu_{0}$, can be predicted from microtexture. Equation 2.4 was modified later by replacing (PNG/100) with a speed constant, $\mathrm{S}_{\mathrm{p}}$. It was also found that Equation 2.4 provides a good estimate of the friction when the locked wheel condition is reached and the braking continues. In order to model the friction taking place while a tire proceeds from the free rolling to the locked wheel condition, Rado (9) presented a model below 


$$
\mu=\mu_{p} e^{-\left[\frac{\ln \left(S / S_{p}\right)}{C}\right]^{2}}
$$

where $\mu_{\mathrm{p}}=$ peak friction;

$\mathrm{S}_{\mathrm{p}}=$ slip speed at the peak (15 percent of the vehicle speed); and

$\mathrm{C}=$ shape factor depending on the harshness of the texture.

\section{The PIARC Models}

In order to relate friction and texture measured by diverse devices, PIARC (26) conducted a large field experiment to measure pavement friction and texture simultaneously in 1992. Fifty-four actual test sites were chosen: twenty-eight sites in Belgium and twenty-six sites in Spain. At each site, measurements were completed by all devices in a short period of time so as to avoid the potential effects of temperature. There were fifty-one different measurements made by sixteen countries. The data was first used to establish correlations between each of the friction measurements and to develop relationships between friction devices. The repeatability was analyzed for the effect of speed and friction level.

A macrotexture parameter is required to harmonize the results so that all systems would produce the same values for these numbers on a given pavement because there are three basic types of friction measuring systems such as locked wheel, slip, and side force. PIARC presented an International Friction Index (IFI) to report friction measurement. The IRI consists of two parameters: the Golden Value Speed Number and the Golden Value Friction Number. The Golden Value Speed Number is proposed to adjust the values of the macrotexture measurement and its predicted value is computed as follows:

$$
S_{p}=a+b \cdot T X
$$

where $S_{p}=$ predicted value of the Golden Value Speed Number;

$\mathrm{TX}=$ texture parameter produced by the macrotexture measuring system; and $a$ and $b=$ constants determined for each type of the macrotexture measurement. 
The Golden Value Friction Number is related to a friction measurement and can be expressed as a function of the friction measurement at any slip speed and the Golden Value Speed Number. In order to predict the Golden Friction Number, the first step is to adjust the friction to that at a common slip speed of $38 \mathrm{mph}(60 \mathrm{~km} / \mathrm{h})$ using the following equation:

$$
F R 60=F R S \cdot e^{\left(\frac{S-60}{S_{p}}\right)}
$$

where FR60 = predicted value of the Golden Value Friction Number;

FRS $=$ adjusted friction value for the system;

$\mathrm{S}=$ slip speed in $\mathrm{km} / \mathrm{h}$; and

$\mathrm{S}_{\mathrm{p}}=$ predicted value of the Golden Value Speed Number.

The Golden Value Friction Number is predicted in terms of the friction and texture measurements below:

$$
F 60=A+B \cdot F R S \cdot e^{\left(\frac{S-60}{s_{p}}\right)}+C \cdot T X
$$

where $\mathrm{A}, \mathrm{B}$ and $\mathrm{C}=$ calibration constants for a particular device; and F60 $=$ prediction of the Golden Value Friction Number.

$\mathrm{A}, \mathrm{B}$, and $\mathrm{C}$ were determined for each measuring system that participated in the experiment using the Mean Profile Depth as the texture measurement. For the locked wheel test method, the value of $\mathrm{C}$ is always zero when the standard smooth tire is used in testing. $\mathrm{S}_{\mathrm{p}}$ and F60 are called the International Friction Index. The inclusion of the texture in reporting friction measurements not only produces better correlation, but also reduces the errors for each device. It is concluded that the IFI provides a universal scale for friction measurements to both highway and airport agencies. The IFI is derived from both friction and texture measurements and can be used in all applications such as accident investigation, maintenance management survey, and airport operation. 


\subsection{The Use of Friction Data by Highway Agencies}

There are multiple uses of pavement friction data by different agencies. For state highway agencies, friction testing is conducted either at the network level or project level or local level. The network level testing is mainly conducted to evaluate the wet-pavement safety by identifying the potential slippery locations and to provide data for planning pavement resurfacing activities, and to establish network friction database. The project level testing is usually conducted to identify friction condition on a specific road for surface treatment decision-making or implement quality control for new construction. The friction testing at the local level is conducted mainly for accident investigations and research studies on paving materials.

This study reviewed three surveys on pavement friction. The first survey was conducted by Sabir et al. and published in 1990 (27). The second survey was conducted by Henry and published in 2000 (5). The third survey was conducted by Tibbles, Office of Pavement Engineering, Ohio Department of Transportation, in 2002 (28). The results regarding the use of friction data by state highway agencies are presented in Figure 2.6. In 1990, forty-four agencies responded that they conducted friction testing for the purpose of wet-pavement accident investigations, forty-two agencies responded that they conducted friction testing for the purpose of pavement inventory, forty-six agencies responded that they conducted friction testing for the purpose of research, and eleven agencies responded that they conducted friction testing for the purpose of new construction acceptance.

In 2000, three agencies started inventory friction testing but thirteen agencies ceased inventory friction testing. Two agencies started to conduct friction testing for accident investigations but nine agencies discontinued this type of friction testing. More agencies started to implement friction requirements for new construction. It is difficult to determine the precise changes in the practices of pavement friction in the country because the three surveys did not include all of the same state agencies. However, it is observed that for state highway agencies, pavement friction testing is primarily conducted for three purposes: pavement inventory, implementation of friction requirements for new construction or resurfacing, and accident investigation. 

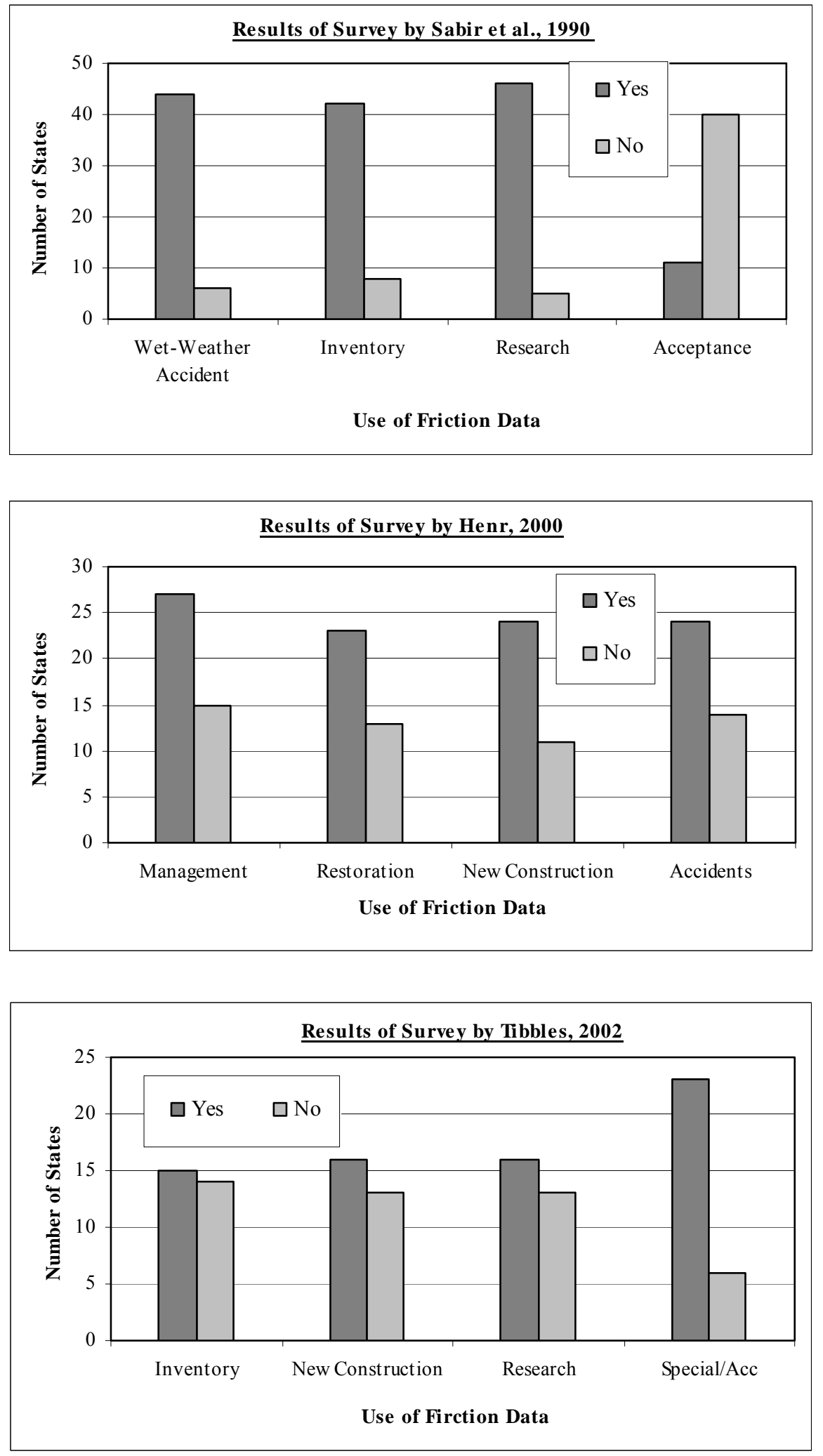

Figure 2.6 Surveys on Use of Friction Data by State Highway Agencies

(Modified from [27], [5] and [28]) 


\subsection{Pavement Friction Requirements}

An extensive literature review was conducted to search for possible friction requirements established by transportation authorities or professional societies. Unfortunately, no such a requirement was located. However, this study has located several publications which have touched this issue $(5,18,27,29-32)$. Determination of the minimum friction requirement is not solely a technical issue and involves safety issues, cost issues, and judgment. On the one hand, wet-pavement accidents tend to decrease as the friction requirement increases. On the other hand, a great friction requirement may incur a large cost to maintain sufficient pavement friction. Therefore, determining the minimum friction requirement requires a compromise between the safety issue and the economic issue.

While there is no national requirement for pavement friction, it appears that the recommended friction requirement of 37 for the standard ribbed tire at $40 \mathrm{mph}$ by Kummer et al. (18) has laid the foundation for state highway agencies to determining the minimum friction requirement. Sabir et al. conducted a survey on wet-pavement safety issues including pavement friction requirement in 1990 (27). Henry conducted another survey on pavement friction approximately 10 years later in 2000 . He also asked highway agencies to respond to the issue of friction requirements. The results from the two surveys are plotted in Figure 2.7. In Sabir's survey (Figure 2.7[a]), the friction requirement for Virginia refers to the smooth tire. The friction requirement for Idaho in Henry's survey (Figure 2.7[b] also refers to the smooth tire. The friction requirement for Arizona is based on a friction tester, MuMeter. All others are based on the locked wheel tester.

It is shown that in 1990, the friction requirements varied from state to state. Florida has the highest friction requirement followed by West Virginia. California and other 9 states have the lowest friction requirement of 30 . The average friction requirement is 34 in 1990. A tendency to reduce the friction requirement has been observed from Figure 2.7. For example, Illinois and West Virginia have lowered its friction requirements from 35 to 30 . There is no doubt that a low friction requirement does not necessarily mean more wet-pavement accidents. With more and accurate data available, it is possible for us to determine a realistic friction requirement. 


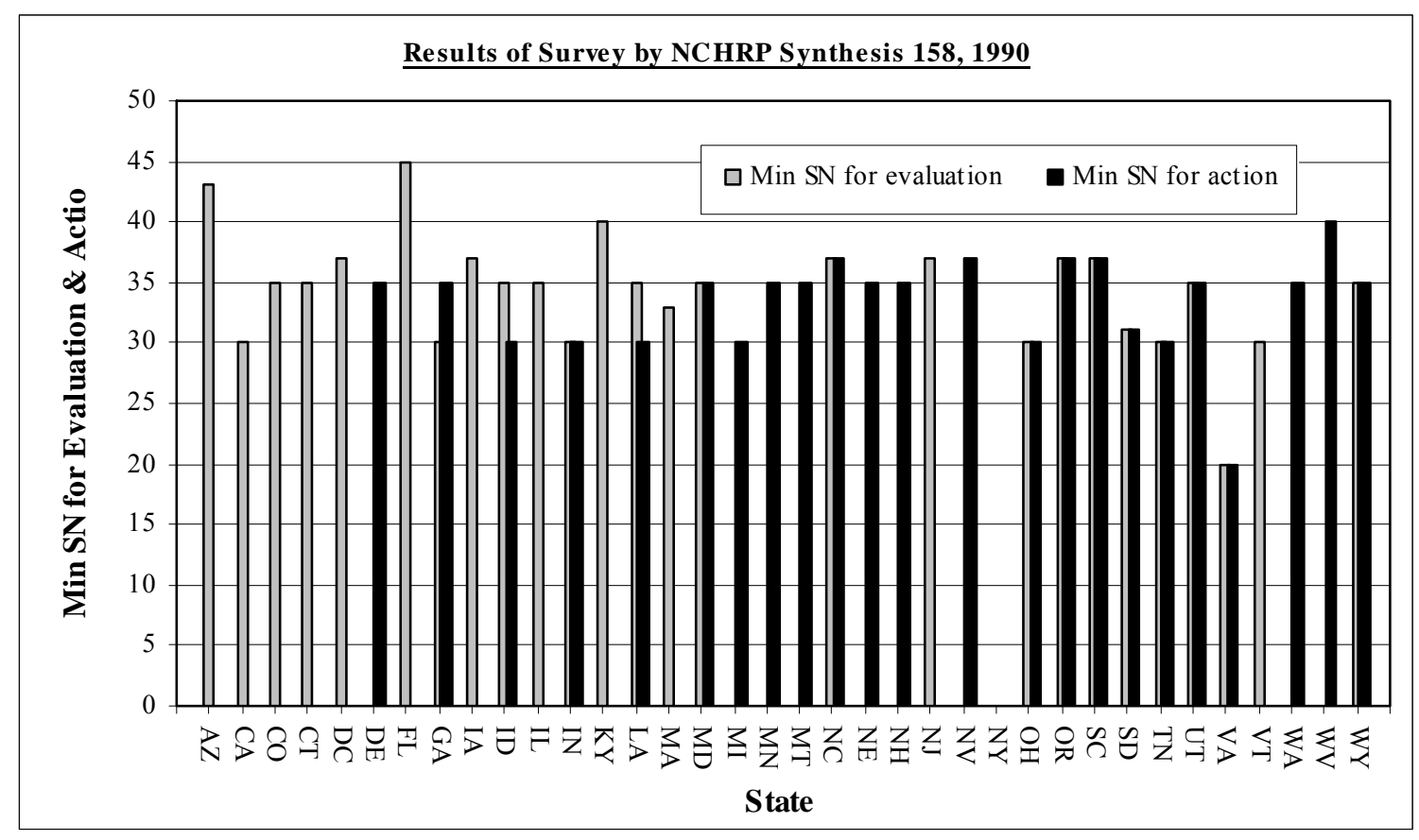

(a) NCHRP Synthesis 158 by Sabir et al. (27)

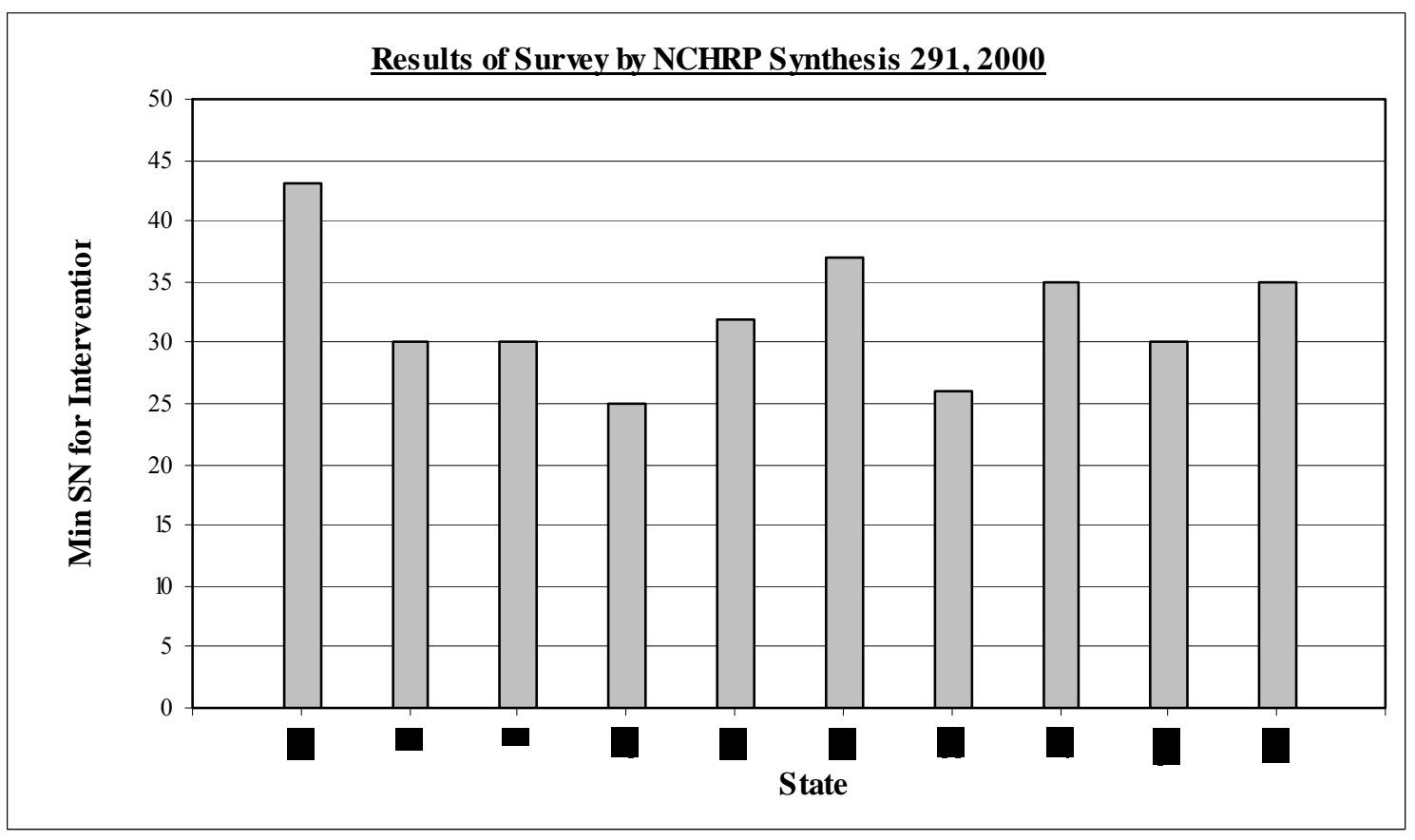

(b) NCHRP Synthesis 291 by Henry (5)

Figure 2.2 Friction Requirements by State DOTS 
Chapter 3

\section{SIMULATION OF TIRE-PAVEMENT FRICTION INTERACTION USING 3-D FEM PROGRAM}

\subsection{Mechanical Behavior of Tire-Pavement Friction Interaction}

\section{Energy Dissipation during Sliding}

Friction arises in the process of tire-pavement interaction while the tire is sliding or rolling over the pavement. The fundamental friction model (Equation 2.1) expresses friction force as the sum of the adhesion force and hysteresis force as shown in Figure 3.1. The adhesion force is significant for dry and smooth surface and is related to the molecular bonds between tread rubber and pavement surface and the shearing of the tread rubber. As the molecular bonds break and form, the rubber molecular chains experience repeated deformation via the internal friction. The hysteresis force arises from the deformation of compression and relaxation due to the asperities of the pavement surface and becomes significant on a wet and rough surface. In the phases of compression and relaxation, the rubber store and dissipate energy via the internal damping within the rubber.

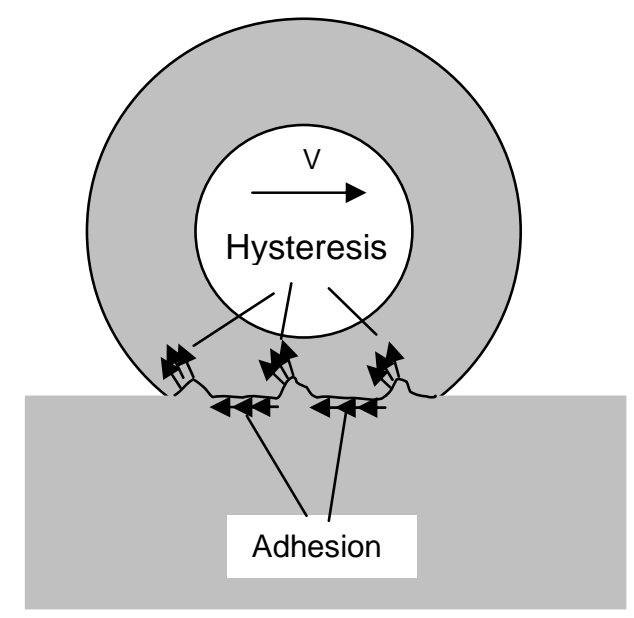

Figure 3.1 Principal Friction Force Components 
Because of the viscoelastic behavior, all deformations will generate energy dissipations which are lost in terms of heat. The energy loss is expressed as follows:

$$
\Delta U=\int F d s
$$

where $\Delta \mathrm{U}=$ energy loss;

$\mathrm{F}=$ acting force; and

$\mathrm{S}=$ sliding distance.

\section{Temperature and Speed Dependencies}

For viscoelastic materials such as rubber, friction is directly related to the internal friction and should have the same temperature dependence as the complex modulus does. Consequently, the coefficient of friction can be evaluated by (33):

$$
\mu \approx-C \frac{\operatorname{Im} E\left(\omega_{0}\right)}{\left|E\left(\omega_{0}\right)\right|}
$$

where $\mu=$ coefficient of friction;

$\mathrm{C}=\mathrm{a}$ number of order unity depending on the nature of the surface asperities;

$\omega_{0}=$ frequency depending on the sliding speed and the wavelength of the surface texture;

$\mathrm{E}\left(\omega_{0}\right)=$ complex modulus of rubber;

$\left|\mathrm{E}\left(\omega_{0}\right)\right|=$ complex modulus of $\mathrm{E}\left(\omega_{0}\right)$; and

$\operatorname{Im} \mathrm{E}\left(\omega_{0}\right)=$ imaginary part of $\mathrm{E}\left(\omega_{0}\right)$

The complex modulus depends on the mechanical stress-strain behavior under dynamic loading. On the real pavement, oscillating forces are applied onto the rubber surface repeatedly by the surface asperities such roughness. For a typical rubber material, it is possible to design a surface texture with respect to a specific sliding speed so as to provide a frequency $\omega_{0}$ to produce the maximum of $\left[-\operatorname{Im} \mathrm{E}\left(\omega_{0}\right) /\left|\mathrm{E}\left(\omega_{0}\right)\right|\right]$, i.e., the maximum of the coefficient of friction. Also, for a specific pavement surface, it is possible to select a tire material so as to produce the 
maximum of $\left[-\operatorname{Im} E\left(\omega_{0}\right) /\left|\mathrm{E}\left(\omega_{0}\right)\right|\right]$. Therefore, Equation 3.2 defines the temperature and velocity dependencies of friction. Kummer (7) conducted experiments which show that the sliding tire has characteristics similar to those of a sliding rubber. He investigated the variations of friction with sliding speed for both natural rubber and butyl rubber, respectively. The results are replotted in Figure 3.2. Both curves demonstrate a similar shape and show clearly the existence of the maximum friction at low speeds. Kummer et al. further demonstrated that the speed dependence was generated by the adhesion force (18).

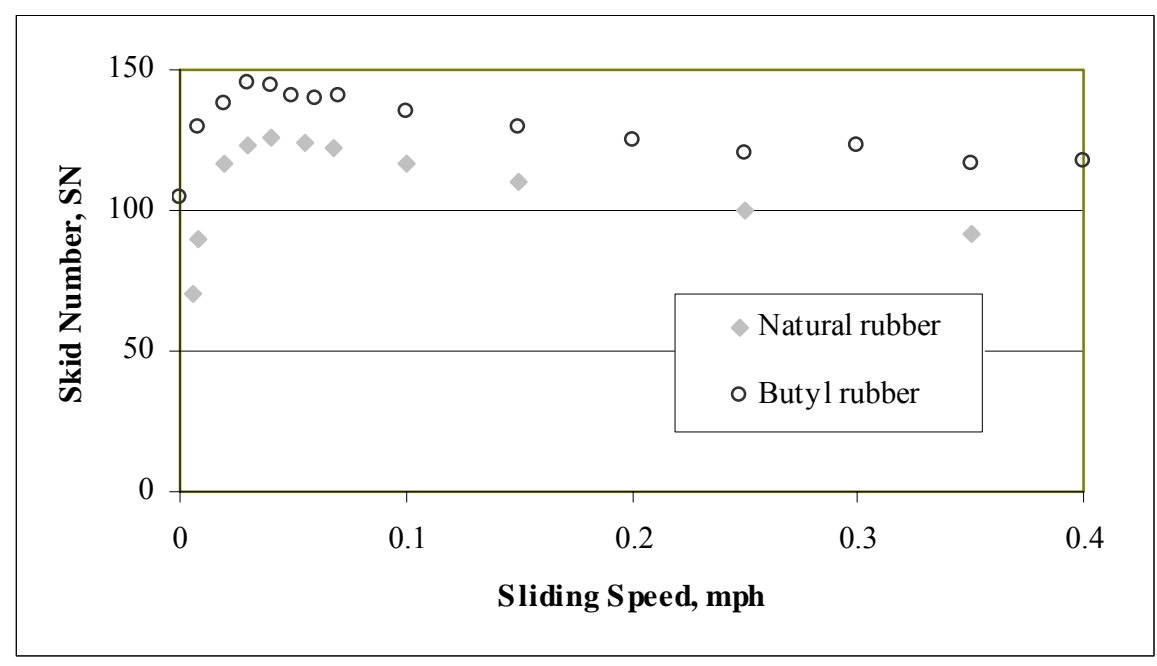

Figure 3.2 Frictional Characteristics of Rubbers during Sliding

(Modified from [7])

The temperature dependence of rubber friction during sliding is due to the variations in the mechanical properties of rubber. For example, the viscosity of rubber varies with the temperature. For a real pavement, the wavelengths of the surface textures vary over a wide range as shown in Figure 2.1. As temperature increases, the rubber becomes soft so that it will deform based on the wavelengths of surface textures. As a result, the contact area increases, leading to an increase in the adhesion force. The temperature dependence of friction has been investigated by means of the William-Landel-Ferry (WLF) transformation or laboratory experiments. A typical temperature dependence of friction is presented in Figure 3.3, which was obtained for a rubber block sliding on a perfect glass surface (15). It is illustrated that the temperature dependence of friction is a complex phenomenon. There is no consistent trend. In some cases, 
the adhesion friction decreases as the temperature increases. In other cases, the adhesion friction increases with increasing temperature.

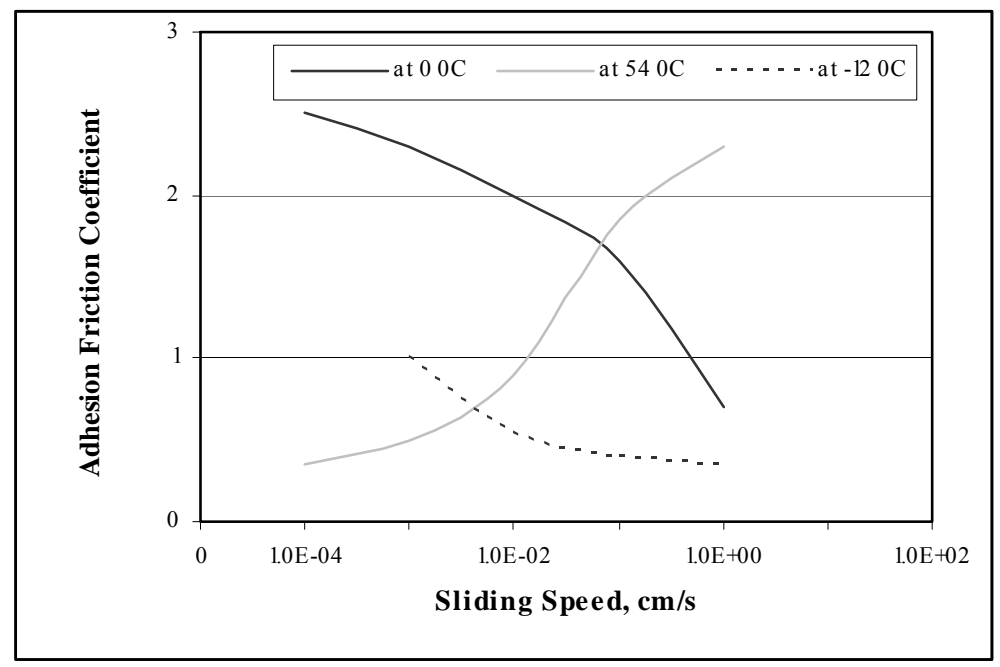

Figure 3.3 Typical Temperature Dependence of Friction

(Source: [15])

\subsection{3-D FEM Modeling Tire-Pavement Friction Interaction Process}

\section{The ABAQUS/Explicit Program}

Because of the sophisticated nature, the friction phenomenon has not been fully understood. While there are many friction models currently available, very few models have been fully verified. Also, because of the complications such as pavement surface asperities and ambient conditions, difficulties and significant deviations may arise when applying a laboratory model to investigation of the tire-pavement friction interaction. The laboratory experiments are usually conducted with a rubber block sliding on a perfect solid surface. However, textures with wide range of wavelength may be presented on the real pavement surfaces. It is very costly to perform laboratory experiments and field tests to include all potential surface textures. Furthermore, tire-pavement friction process is more complicated than that of a rubber sliding on a perfect surface. For example, as temperature increases the tire may become soft. However, the inflation pressure within the tire may increase. It is very difficult to investigate these changes during a field test. As a result, an increased interest in substituting the field test by numerical simulations has been witnessed in the past years $(34,35)$. 
A finite element method (FEM) program, ABAQUS (36), was utilized in numerical simulations. ABAQUS has two analysis modules, ABAQUS/Standard and ABAQUS/Explicit. ABAQUS/Standard is a general purpose module for solving both linear and non-linear problems, including static, dynamic, thermal, and electrical responses. ABAQUS/Explicit is a special purpose module for solving short and transient dynamic events, especially nonlinear problems involving changing contact conditions by means of an explicit dynamic finite formulation. In general, either ABAQUS/Standard or ABAQUS/Explicit can be employed to investigate the tirepavement friction interaction process. This study employed ABQUS/Explicit in analysis simply because of the easy output of energy dissipation by ABAQUS/Explicit.

\section{Simplified Tire-Pavement Friction Interaction Model}

Model, Geometry and Mesh: During friction test with the ASTM E-274 trailer, the rolling wheel is locked for one second and the tire is sliding on the pavement. Only part of the tire is in contact with the pavement surface. Therefore, this study focused on the rubber block in contact with the pavement surface, instead of the entire tire, during sliding. The tire-pavement friction interaction was modeled as a 3-D contact interaction problem. The dimensions of the rubber blocks as shown in Figure 3.4 were determined in light of the physical and operational requirements for the test tire covered in ASTM E-501 and E-504. The rubber block is 7.9 in. $(200 \mathrm{~mm})$ long, 5.9 in. $(150 \mathrm{~mm})$ wide, and $0.5 \mathrm{in}$. $(12.5 \mathrm{~mm})$ thick. The ribbed tire consists of seven 0.66 in. $(16.8 \mathrm{~mm})$ wide ribs and six $0.2 \mathrm{in} .(5.08 \mathrm{~mm})$ grooves. The test pavement block is $11.8 \mathrm{in} .(300 \mathrm{~mm})$ wide and $5.9 \mathrm{in} .(150 \mathrm{~mm})$ thick. The pavement block has a length of 708 in. $(18000 \mathrm{~mm})$ so as to provide a sufficient sliding distance.

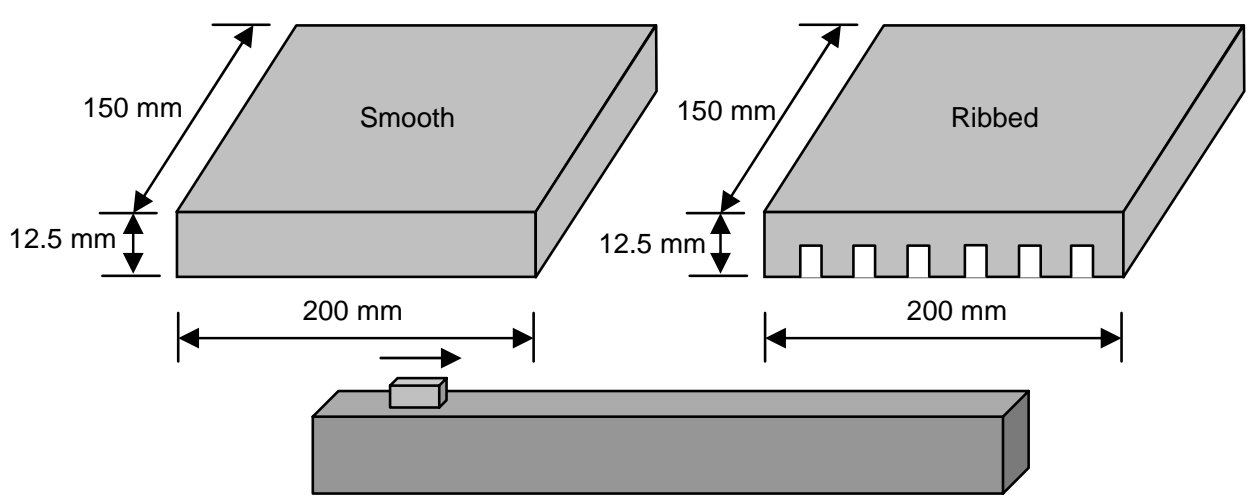

Figure 3.4 Dimensions of Tire-Pavement Model 
The finite element mesh used for the rubber and pavement surface is illustrated in Figure 3.5. The rubber was modeled using 24 C3D8R (continuum, 3 dimensional, eight nodes, and reduced integration) elements, and the pavement using 368 C3D8R elements. The contact pair consists of two contacting surfaces: the master surface and the slave surface. The master surface is the pavement surface and the slave surface is the external surface at the bottom of rubber. Both the master and slave surfaces are element-based surfaces. The Coulomb's friction law is used to govern the relative tangential motions of the contacting surfaces, allowing the interface to transmit shear and normal forces. The sliding speed is applied using the initial condition.

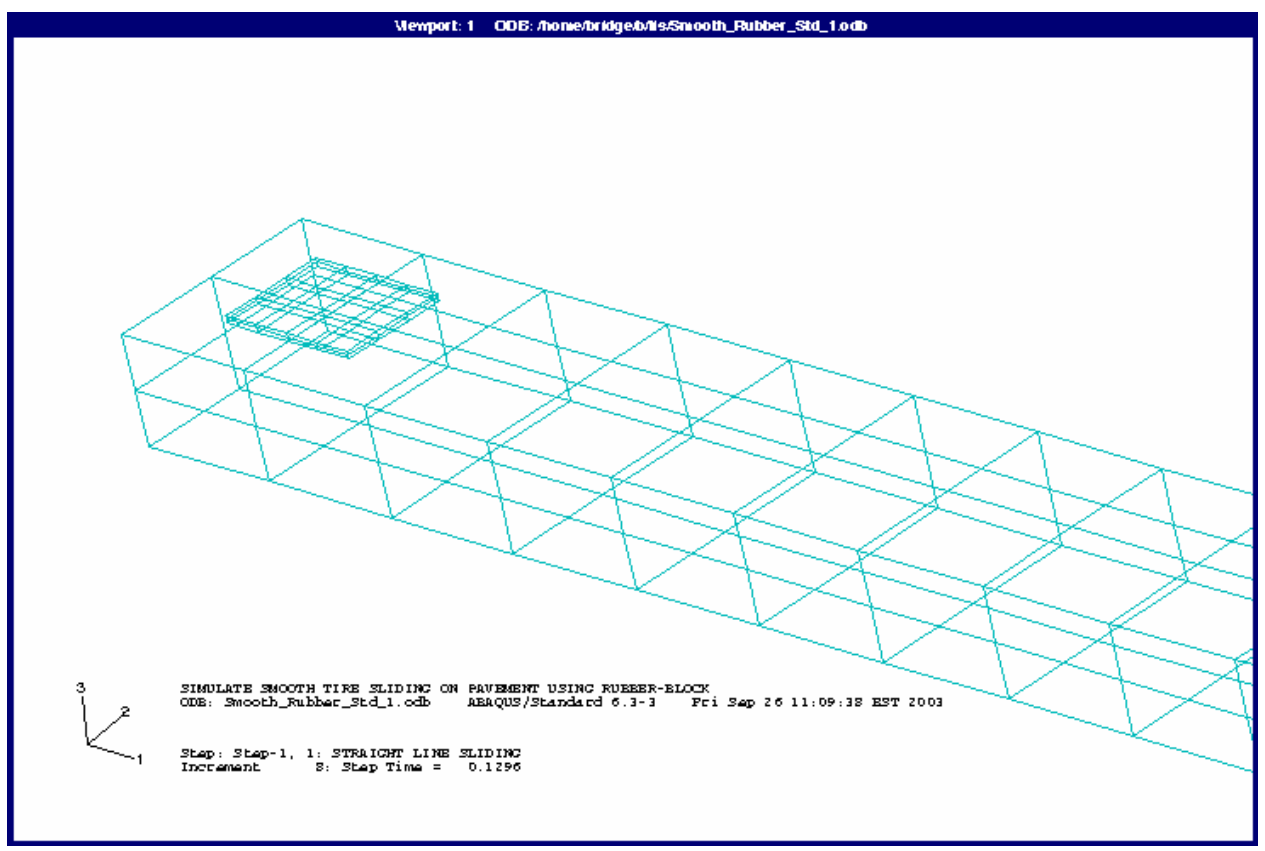

Figure 3.5 Illustrations of Meshes

Materials, Boundary Conditions, Loading, and Initial Conditions: The linear elastic material is used to model the pavement. For concrete pavement, the elastic modulus is $4348 \times 10^{3}$ psi $(30 \mathrm{GPa})$, the Poisson ration is 0.15 , and the density is $150 \mathrm{lb} / \mathrm{ft}^{3}\left(2400 \mathrm{~kg} / \mathrm{m}^{3}\right)$. For asphalt pavement, the elastic modulus is $696 \times 10^{3} \mathrm{psi}(4800 \mathrm{MPa})$, the Poisson ratio is 0.35 , and the density is $144 \mathrm{lb} / \mathrm{ft}^{3}\left(2300 \mathrm{kh} / \mathrm{m}^{3}\right)$ The test tire is modeled using the hyperelastic material which includes a time domain component defined by the *VISCOELASTIC, TIME=PRONY option. The simple model, 1-term Prony series is used. The long term modulus is $145 \mathrm{psi}(1.0 \mathrm{MPa})$ and 
the density is $69 \mathrm{lb} / \mathrm{ft}^{3}\left(1100 \mathrm{~kg} / \mathrm{m}^{3}\right)$. The shear relaxation modulus ratio is 0.30 and its associated relaxation time is 0.1 second. The *Boundary option is used to define boundary conditions such as displacements. Zero displacement is assigned to all nodes on all pavement surfaces, except for the top surface in contact with the rubber block. A uniformly distributed pressure of 24 psi (165 $\mathrm{kPa}$ ) is exerted onto the top surface of the rubber block. The sliding speed is prescribed for all rubber block nodes using the *INITIAL CONDITIONS, TYEP=VELOCITY option. The *AMPLITUDE option is used to define the speed curve for all rubber block nodes. In this case, the sliding speed is defined to be constant during sliding.

\subsection{Simulation Results and Analysis}

In order to run the simulation, two basic input files, one for the smooth tire and the other for the ribbed tire, were developed. The job was done using ABAQUS Version 6.3-3 in the School of Civil Engineering at Purdue University through the Joint Transportation Research Program (JTRP) with the technical assistance provided by the ABAQUS Central, Inc. ABAQUS/CAE was used to view the results of simulation. For example, the Contours tool provided by ABAQUS/CAE can be used to create stress/strain contour plots of the deformed model as shown in Figure 3.6. In this study, the X-Y plotting tool was mainly employed to create viscous energy dissipation history plots for analysis.

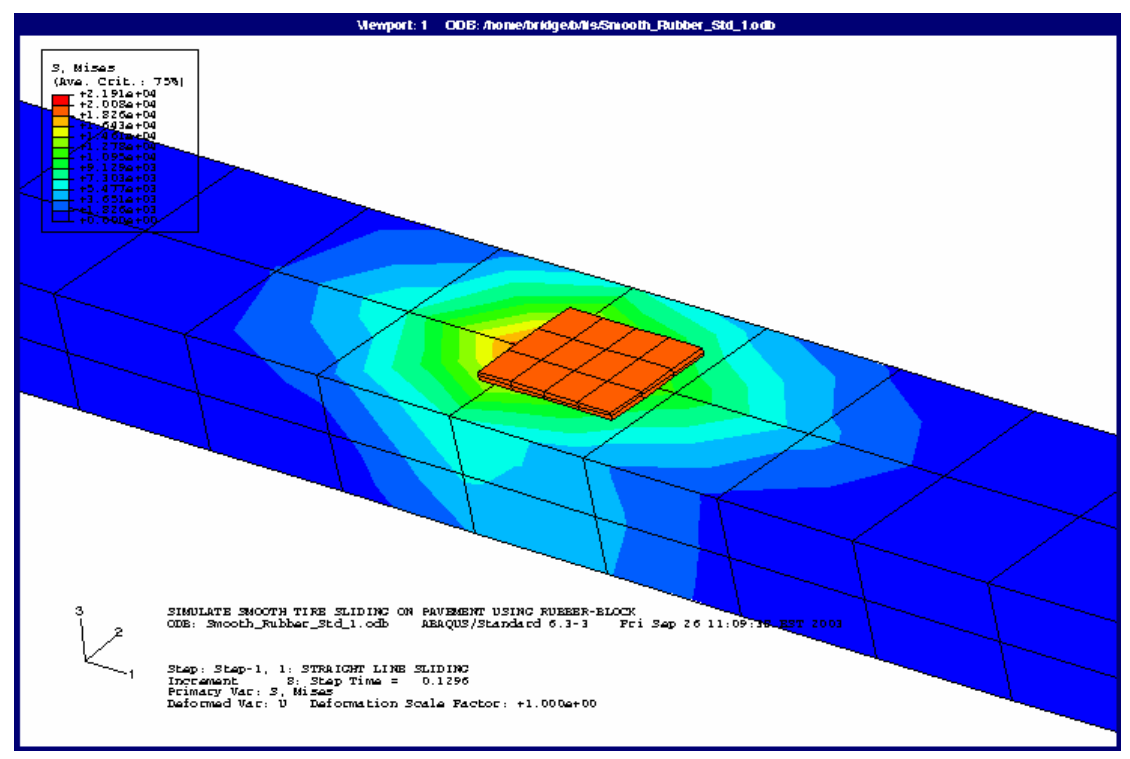

Figure 3.6 Tire-Pavement Stress Contour Plot Created Using ABAQUS/CAE 


\section{Smooth Tire versus Ribbed Tire}

The blocked wheel pavement friction test is conducted with either the standard smooth tire or the standard ribbed tire. The standard smooth tire and the standard ribbed tires have different tread patterns, resulting in different contact areas and contact pressures while the tires are sliding on pavement. Consequently, the two tires may undergo different deformations and relaxations and result in different friction forces. The differences can be characterized by the viscous energy dissipation. To further examine the viscous energy dissipations with the smooth tire and the ribbed tire, respectively, this study conducted simulations of the two standard tires during sliding on the pavement for one second on the basis of models shown in Figure 3.4. Figure 3.7 shows the history plots of the viscous energy dissipations for the rubber blocks sliding on two pavement surfaces with different coefficients of friction at $40 \mathrm{mph}(64 \mathrm{~km} / \mathrm{h})$.

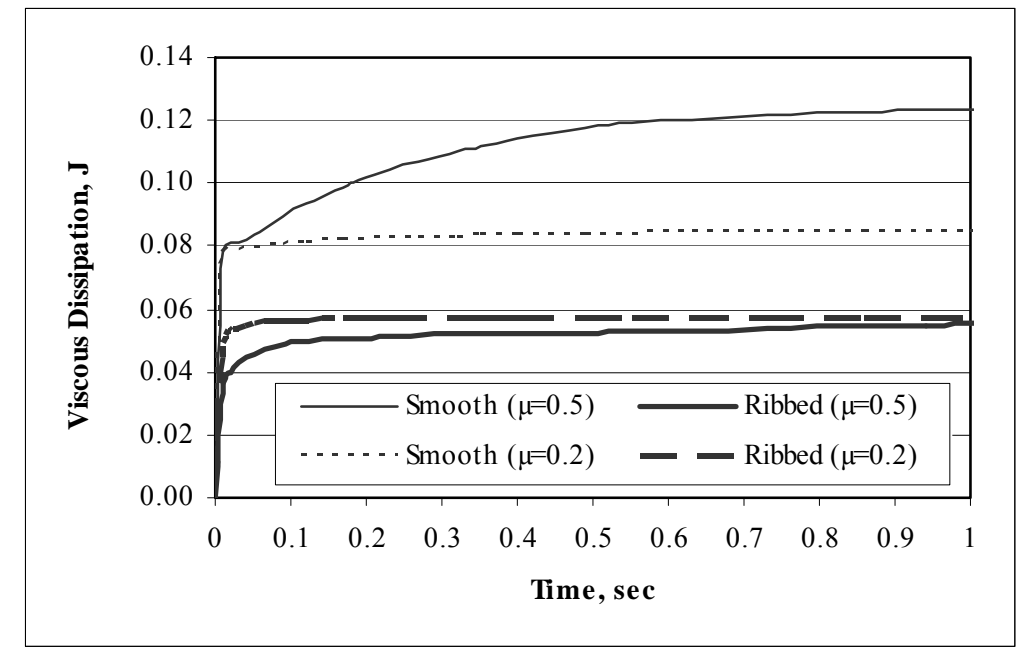

Figure 3.7 Energy Dissipations with the Smooth and Ribbed Rubbers

In general, the smooth rubber block demonstrates greater viscous dissipation than the ribbed rubber block on the two pavement surfaces. It should be noted that this simulation analysis is an inverse or backward analysis, i.e., the energy dissipation is determined by prescribing the coefficient of friction. In reality, the rubber tire generates energy dissipations first; and then, the energy dissipations are presented at the interface in the form of forces. In other words, if the smooth and ribbed tires generate the same energy dissipation, the ribbed tire will result in greater coefficient of friction on a perfect surface than the smooth tire. It is also observed that for the smooth rubber block, the friction process on the pavement surface with a 
coefficient of friction of 0.5 generates much greater viscous dissipation than that on the pavement surface with a coefficient of friction of 0.2 . However, the ribbed rubber block generates only slightly greater energy dissipation on the pavement surface with a coefficient of friction of 0.2 than that on the pavement surface with a coefficient of friction of 0.5 . This can be extended to state that the energy dissipation with the ribbed tire is less sensitive to the pavement surface feature than that with the smooth tire. In other words, when the smooth tire interacts with pavement surfaces of different textures, it will generate very different energy dissipations and result in very different coefficients of friction, i.e., the smooth tire is more sensitive to the surface textures.

\section{Energy Dissipation and Resultant Friction}

In order to further examine the relationship between the energy dissipation and the resultant friction, Figure 3.8 shows the variations of energy dissipation with the coefficient of friction. As the coefficient of friction (frictional interaction) increases, the energy dissipation increases. When the coefficient of friction becomes very large, the viscous energy dissipation with the ribbed rubber block may experience a significant increase. However, the energy dissipation with the smooth rubber block fluctuates and increases slightly as the coefficient of friction increases. Viscous energy dissipation is non-recoverable energy which is converted into heat and lost. The greater the viscous dissipation the more strain energy is lost. The greater the viscous dissipation also indicates a larger frictional force during the sliding process. It is also illustrated that when the friction level is high, the ribbed rubber block tire experiences greater energy dissipation that the smooth rubber block. Otherwise, the smooth rubber block experiences the greater energy dissipation than the ribbed rubber block. This implies that the smooth and ribbed tires may not have consistent trend for energy dissipations.

\section{Variations of Energy Dissipation with Sliding Speed}

As discussed earlier, the sliding speed has an effect on the deformation frequency and temperature within the rubber, resulting in different energy dissipations and furthermore, different friction forces. Figure 3.9 shows the relationship between the energy dissipation and sliding speed. It is demonstrated that as the sliding speed increases, the energy dissipation with the ribbed rubber block increases slowly. After the sliding speed approximately exceeds $60 \mathrm{mph}$ 
$(97 \mathrm{~km} / \mathrm{h})$, the ribbed rubber block may experience dramatic increase in the energy dissipation. The energy dissipation with the smooth rubber block fluctuates as the sliding speed increases and it peaks approximately at $5 \mathrm{mph}(8 \mathrm{~km} / \mathrm{h})$. However, the smooth rubber block demonstrates greater energy dissipations than the ribbed rubber block when the sliding speed is approximately less than $65 \mathrm{mph}(105 \mathrm{~km} / \mathrm{h})$.

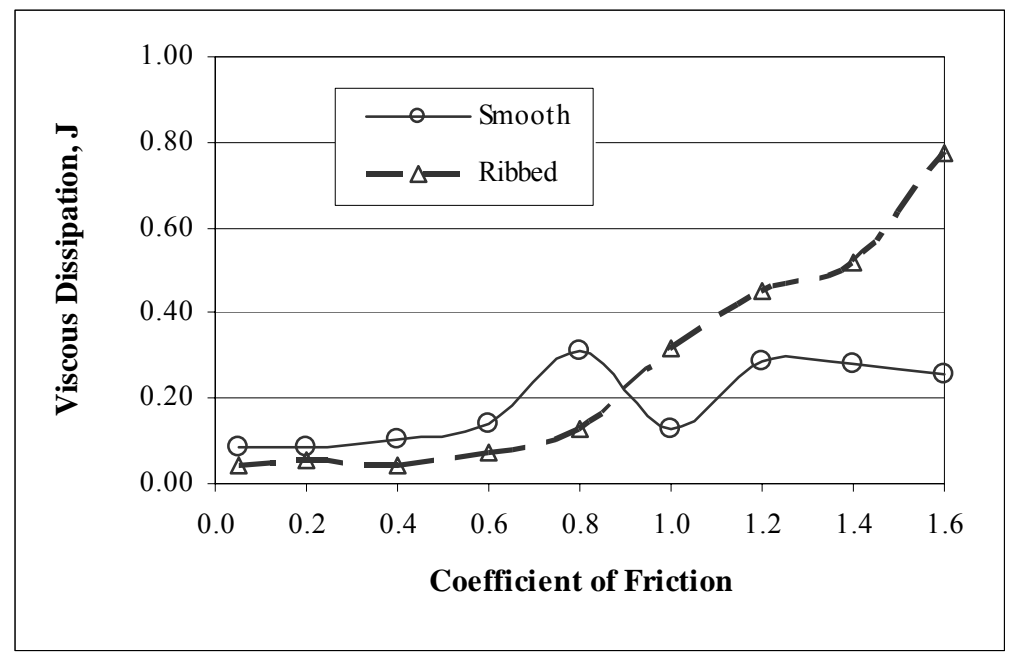

Figure 3.8 Energy Dissipations vs. Coefficient of Friction

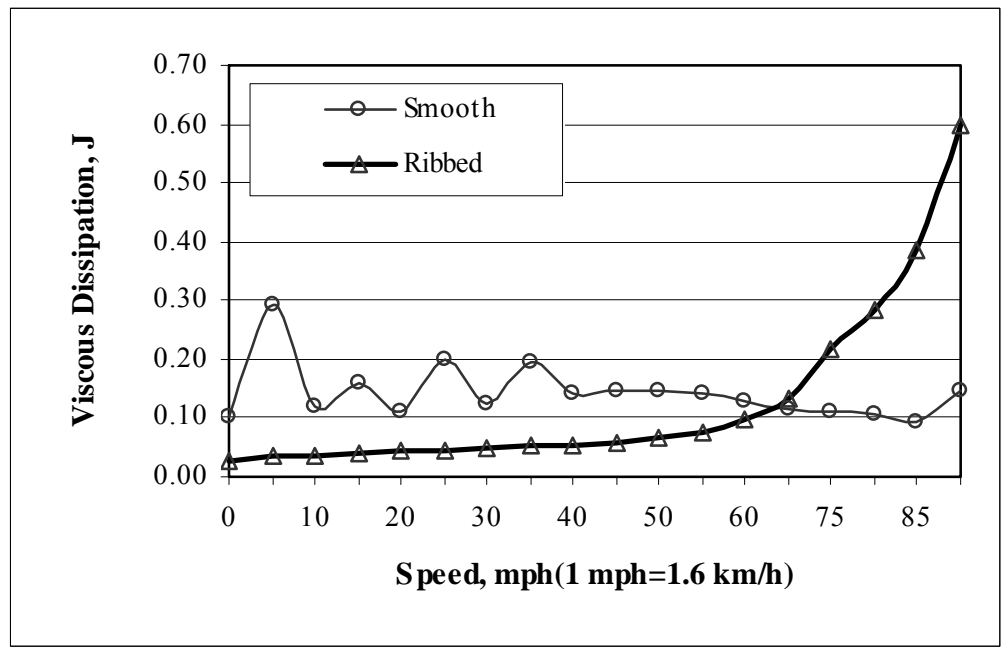

Figure 3.9 Energy Dissipations vs. Sliding Speed 


\section{Concrete Pavement versus Asphalt Pavement}

CONCRETE pavement differs from asphalt pavement mainly on their rigidities. This will affect the frictional interaction between tire and pavement because the pavement rigidity has an effect on the deformation within the rubber. In order to illustrate the energy dissipations on both concrete and asphalt pavements, Figure 3.10 shows the energy dissipation history plots for the smooth rubber block during sliding. It is demonstrated that the two energy dissipation history curves follow a similar trend. However, the energy dissipation on the concrete pavement is slightly greater than that on the asphalt pavement. This indicates that the tire will experience larger deformation and therefore experience greater friction force during sliding on concrete pavement than those during sliding on asphalt pavement.
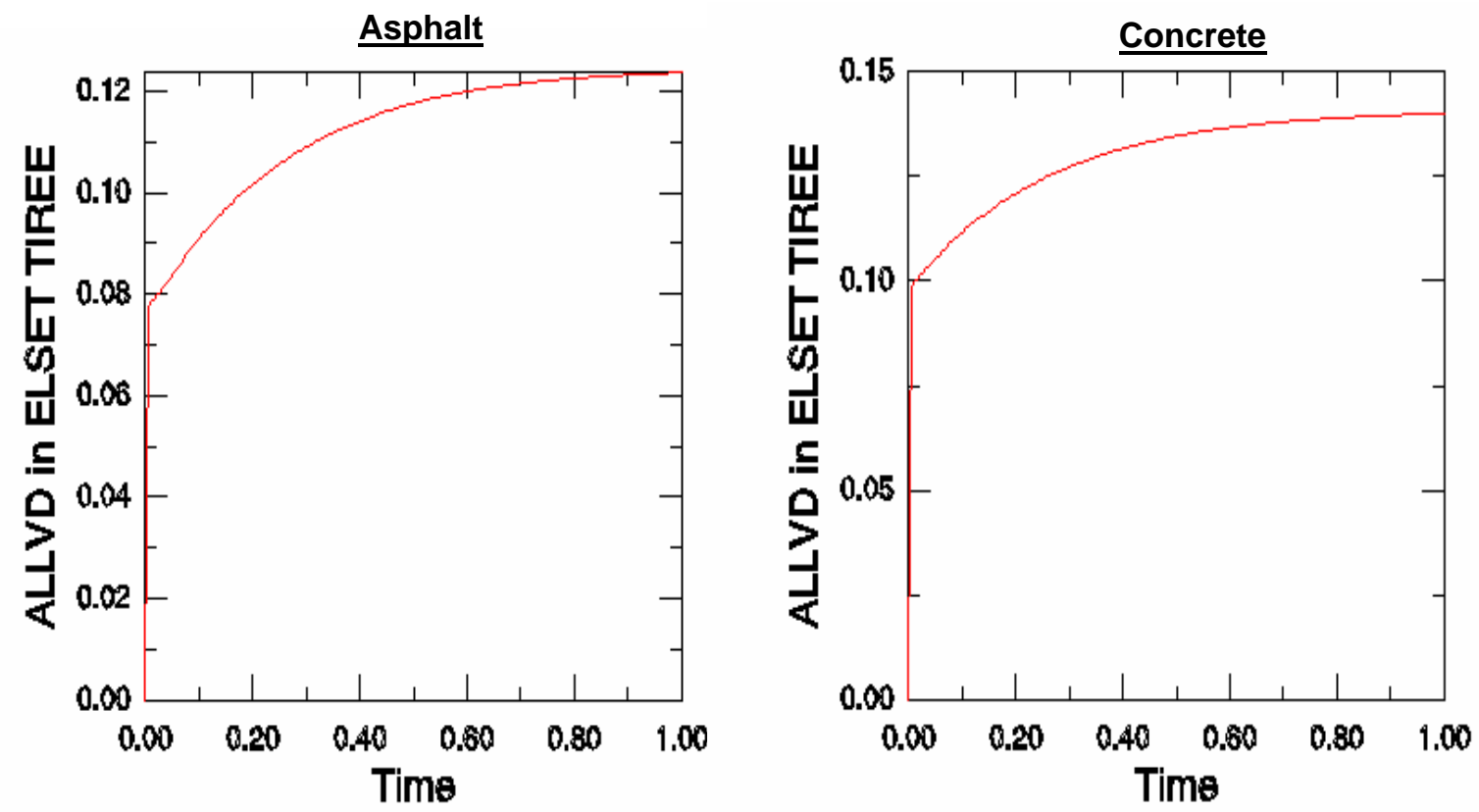

Figure 3.10 Energy Dissipations with Smooth Rubber Block on Asphalt and Concrete Pavements

\subsection{Summary}

BASED on the simulation results and analysis presented in the preceding sections, it can be concluded that the pavement friction is a relative and conditional value, rather than an absolute value. Pavement friction is meant for both the test equipment and test surface. It is the 
result of tire-pavement interaction process and depends on many factors such as test tire, test speed, surrounding conditions, pavement surface texture, and pavement type. Therefore, it is of great significance to maintain the consistency of test so as to make the test results meaningful and comparable. Also, it is difficult to verify the FEM results using field tests because most FEM programs currently available can only perform inverse analysis, i.e., analysis of energy dissipation by assuming a coefficient of friction. However, the FEM simulation technique brought us a step closer to understanding the complicated pavement friction phenomenon. 


\section{Chapter 4}

\section{PAVEMENT FRICTIONAL VARIATIONS}

As demonstrated in the preceding chapters, pavement friction is relevant and the true friction value is not available. Pavement friction is meant for both pavement and rolling tire. For a specific pavement surface, friction measurement may vary with many factors such as test system, surface feature, and surrounding condition. Therefore, it is of great significance to maintain consistent testing environment so as to provide meaningful and comparable friction measurements. This study collected a large amount of data on both the INDOT friction test track and highway pavements so as to investigate the variations involved in pavement friction measurements. This chapter focuses on those primary variations such as testing system variations, spatial variations, temporal variations, and seasonal variations.

\subsection{System Variations}

\section{Friction Measurements}

INDOT has two locked wheel trailers which were assembled by the Research Division in accordance with ASTM E-274. The ASTM E-274 trailer mainly consists of a braking system, standard test tires, force and speed transducers, pavement wetting system, and recorder system. In order to lessen variations associated with test systems, system calibrations shall be performed anytime if necessary. System calibrations will be given in Chapter 5 . This section only discusses the potential variations due to system errors. It is natural that a well-calibrated system may still involve some errors and produce friction measurements with variations. INDOT built a friction test track. The primary purpose of the friction test track is to verify system performance. The secondary purpose is to assess potential frictional variations due to the test system. The test track consists of three 3.0-meter wide sections: slick concrete surface, asphalt surface, and tined (grooved) concrete surface. These three surfaces were prepared so that they could provide distinctive friction features to cover the range of possible friction measurements on highway pavements. For example, pavements with severe rutting usually have very low friction in the 
wheel track and grooved concrete pavements have very high friction. The detailed information about the test track will be provided in Chapter 5 .

As discuss earlier, pavement friction measurements may involve variations due to many factors. The key for evaluating system variations is to distinguish between system variations and other variations. In order to fulfill this, friction measurements made on the friction test track rather than on highway pavements were employed in the analysis of system variations. During testing on the test track, it is possible to make friction measurements on the same spot at the desired speed. Therefore, the lateral variations may be minimized and the frictional variations may be dominated by the system variations. Also, friction measurements were made throughout the test season (from April to October) so as to determine the potential seasonal effect.

\section{System Variations on Different Pavement Surfaces}

During testing, five measurements at the same spot were taken on each of the three surfaces using two trailers, respectively. Figure 4.1 shows the standard deviations of the friction measurements made using smooth tires with the two trailers. In general, the standard deviation is used to measure the variability of a specific property. It is demonstrated that the standard deviations are random. Seasonal effect is not significant. For Trailer 300-4, the average standard deviations are 1.6, 2.46, and 1.53 on the slick concrete surface, asphalt surface, and tined concrete surface, respectively. For Trailer 379-6, the average standard deviations are 0.86, 4.27, and 2.15 on the slick concrete surface, asphalt surface, and tined concrete surface, respectively. The testers tend to produce greater variations on the asphalt surface.

It should be noted that the greater standard deviation does not necessarily imply a worse system performance. The standard deviation depends not only on the variability, but also on the scale of the variable. As an illustration, the average friction numbers with the smooth tire are approximately 10.0, 50.0, and 70.0 for the slick concrete, asphalt, and tined concrete surfaces, respectively. A standard deviation of 2.0 accounts for a coefficient of variation of $20 \%$, 4\%, and $3 \%$ for the three surfaces, respectively. Therefore, the coefficient of variation may be a better measure of the variability involved in the measurements in some cases. The coefficient of variation is also a statistical parameter for measuring the dispersion of random measurements. It 
is defined as the ratio of the standard deviation to the mean and expressed as a percentage. It is usually used as a comparison in assessing relative variability by engineers. Figure 4.2 shows the coefficients of variation in the friction measurements using smooth tires on the three surfaces. It is demonstrated clearly that the two testers produced the least variability on the tined concrete surface and the greatest variability on the slick concrete surface. The overall coefficients of variation with Trailer $300-4$ are $17.7 \%, 5.3 \%$, and $2.2 \%$, and $14.6 \%, 8.2 \%$, and $3.0 \%$ with Trailer 379-6 for the slick concrete, asphalt, and tined concrete surfaces, respectively.
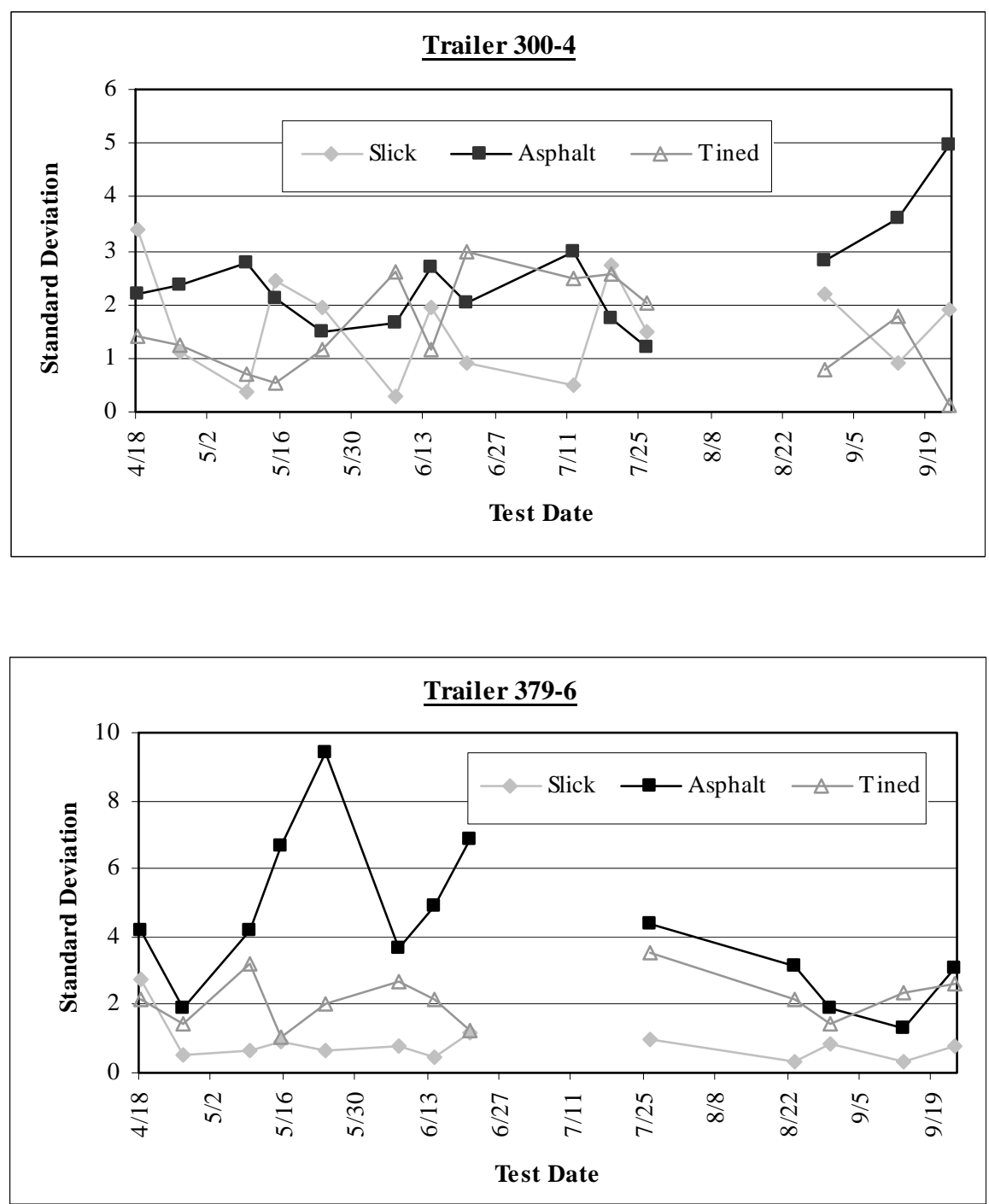

Figure 4.1 Standard Deviations of Friction Measurements on the Test Track 

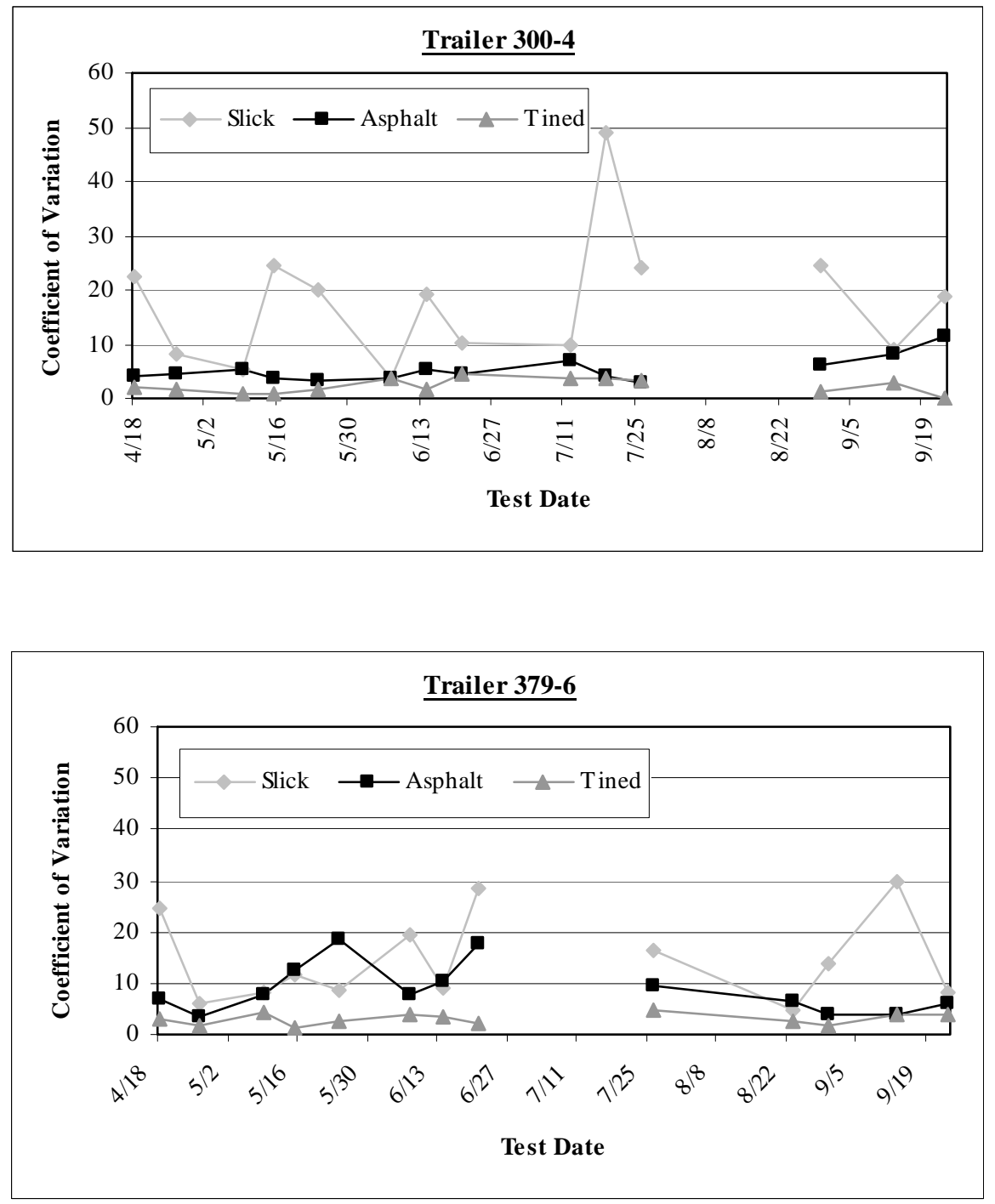

Figure 4.2 Coefficients of Variations of Friction Measurements on the Test Track

To further examine the frictional variations due to potential system errors with different tires, this study measured friction numbers on the test track using both the standard smooth and ribbed tires. The computed standard deviations and coefficients of variation are presented in Figures 4.3 and 4.4, respectively. The standard deviations vary with trailers and the type of surfaces. No consistent trends can be observed. However, it appears that the coefficients of variation may provide some valuable information about the variability of the test system due to the test tire. It is demonstrated that the smooth tire tends to provide greater variations than the ribbed tire. One of the possible reasons is that the smooth tire is more sensitive to the surface texture than the ribbed tire does. 

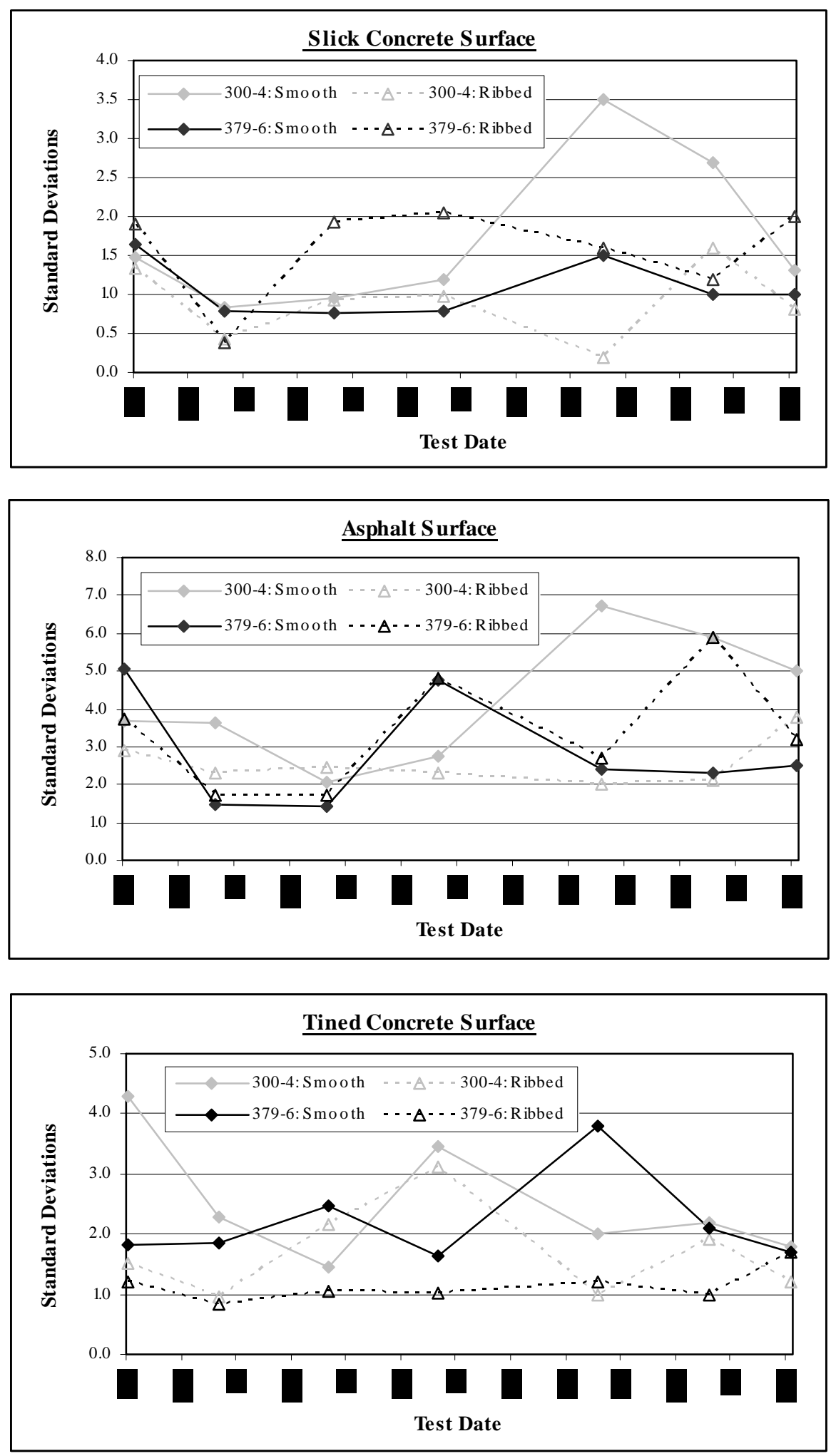

Figure 4.3 Standard Deviations with Smooth and Ribbed Tires 

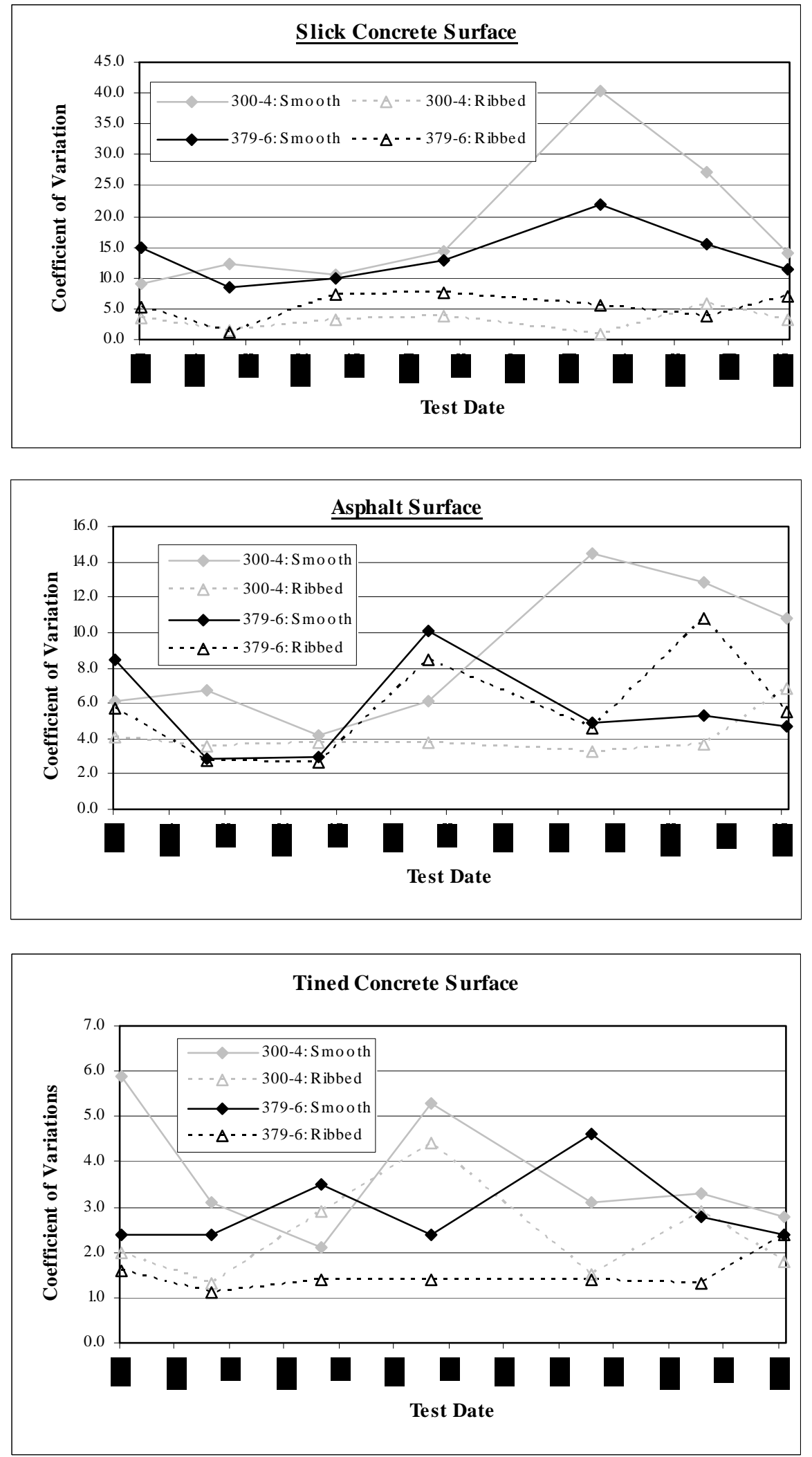

Figure 4.4 Coefficients of Variations with Smooth and Ribbed Tires 


\subsection{Seasonal Variations}

\section{Variations of Friction with Air Temperature}

INDOT annual pavement inventory friction test begins in spring and ends in fall, lasting for about seven months. During this period, air temperature may vary significantly. It is necessary to evaluate its effect on the real-life friction measurements because temperature is one of the principal variables in describing the dynamic nature of rubber tire. As shown in the preceding chapters, friction force decreases with increasing test temperature. It is possible friction test may generate greater friction numbers in spring than in summer. Some studies investigated this issue and developed models for applying seasonal corrections for friction measurements with the rib tire $(37,38)$. In order to evaluate seasonal variations involved in friction measurements with the smooth tire, this study has conducted extensive friction tests on the friction test track throughout the test season. As discussed in the preceding sections, it is easier to design tests on the test track so as to investigate the effect of a certain factor on friction measurements.

The surface friction characterization should remain constant. Also, the test measurements can be taken on the same spot because the friction test track is not open to any traffic. This makes it possible to minimize the effect of other factors and attribute the friction variations mainly to the test temperature or test season. Figure 4.5 shows the friction numbers measured with the smooth tire on the test track. Plotted in Figure 4.5(a) are the variations of friction measurements with the air temperature. It is observed that as the air temperature increases, the friction numbers does not necessarily decrease. No consistent trends exist. In some cases, the friction increased as the air temperature increased. In other cases, the friction decreased as the air temperature increased. Similar observations can be made from Figure 4.5(b) which gives the variations of friction measurements with the test month. It is illustrated that on all the three surfaces, the friction numbers varied over the year. However, the variations are random and follow a similar pattern on all the three surfaces. Also, it appears that the variations are negligible. 


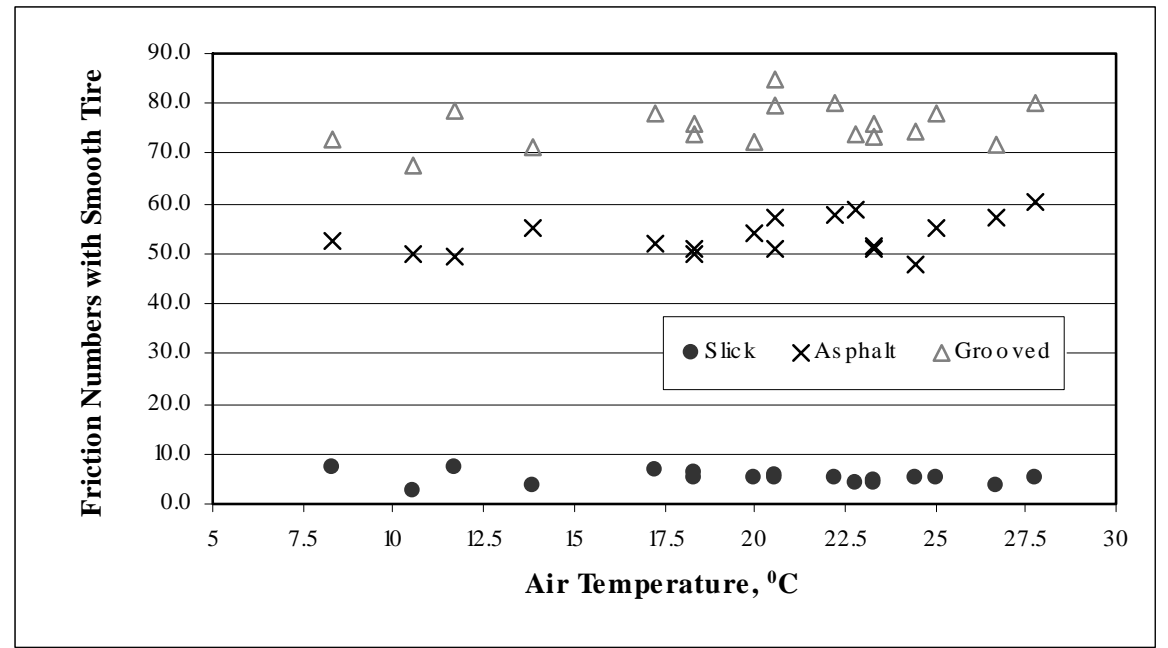

(a) Variations of Friction with Air Temperature

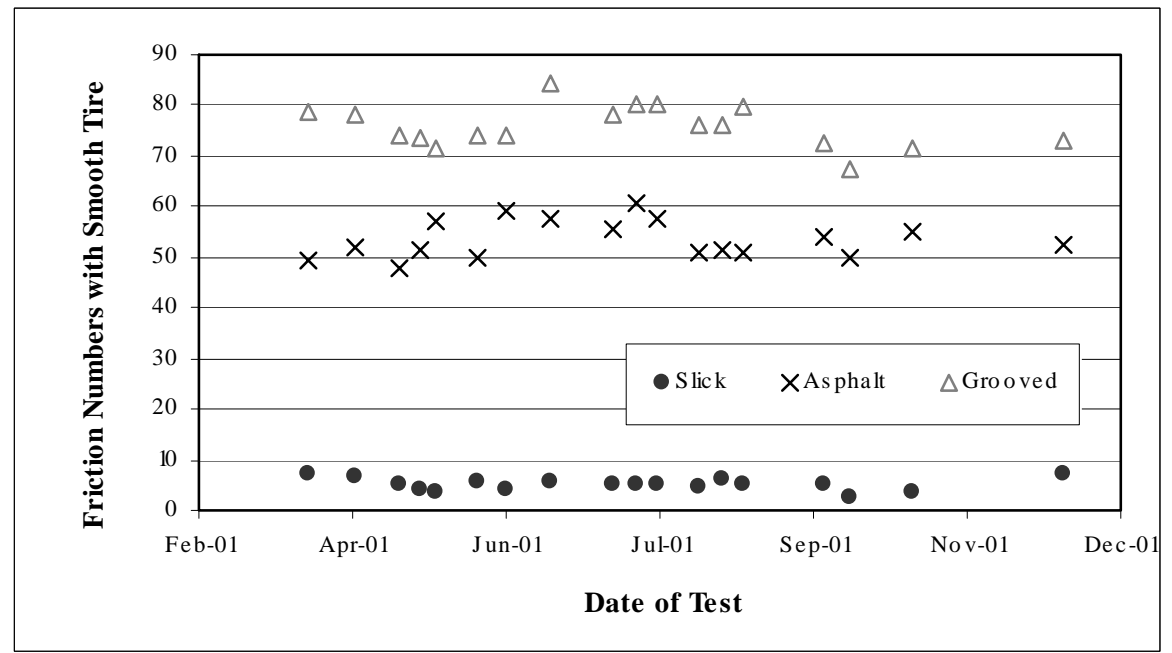

(b) Variations of Friction Measurements with Test Season

Figure 4.5 Friction Measurements in Different Seasons

\section{Significance Test of Air Temperature Effect}

In order to verify the above observations, a significance test was performed to further examine the potential correlations between friction measurements and air temperatures. Significance test consists of setting up hypotheses and testing the hypotheses. The hypotheses for the significance t-test are given below 
$\mathrm{H}_{0}$ : The population correlation between friction measurements and air temperatures is zero

$\mathrm{H}_{1}$ : The population correlation between friction measurements and air temperatures is not zero

The hypothesis of $\mathrm{H}_{0}$ is the so-called null hypothesis and the hypothesis of $\mathrm{H}_{1}$ is the socalled alternative hypothesis. In order to test the hypotheses, Pearson correlation coefficients and the corresponding p-values were computed as shown in Table 4.1. In the t-test, a low p-value (arbitrarily and by convention, p-value less than 0.05) means that there is evidence to reject the null hypothesis. It is shown that in Table 4.1, all computed p-values are greater than 0.05 , which indicates that there is no evidence to reject the null hypothesis $\mathrm{H}_{0}$. Also, it is indicated that by the Pearson correlation coefficients or the values of R-squared, the correlations between the friction measurements and the air temperatures are poor. However, it is interesting to note that the p-value on the asphalt surface is less than those on the slick and tined concrete surfaces and the Pearson correlation coefficient on the asphalt surface is greater than those on the slick and tined concrete surfaces. This implies that the friction measurements taken on asphalt pavements are more sensitive to the air temperature than those on concrete pavements.

Table 4.1 Results of Pearson Correlation Analysis

\begin{tabular}{|c|c|c|c|}
\hline Surface & $\begin{array}{c}\text { Pearson Correlation } \\
\text { Coefficient }\end{array}$ & R-Squared & p-Value \\
\hline Slick Concrete & -0.2777 & 0.0771 & 0.2645 \\
\hline Asphalt & 0.4583 & 0.2355 & 0.0541 \\
\hline Tined Concrete & 0.3231 & 0.1044 & 0.1910 \\
\hline
\end{tabular}

It should be pointed out that the above observations made from Figure 4.5 and Table 4.1 do not necessarily contradict the fundamentals of rubber tire friction phenomenon, i.e., the temperature-dependency of rubber friction. Strictly speaking, the test temperature refers to the tire temperature and the pavement temperature, rather than the air temperature. The tire and pavement temperatures depend on many factors such as air temperature, solar radiation, and wind speed which vary from time to time (as shown in Figure 4.6) and location to location. In order to apply seasonal or temperature correction properly, pavement engineers need to measure 
the tire and pavement temperatures. This is not practical for network pavement inventory friction test. However, the above observations made from Figure 4.5 and significance test can be extended to conclude that seasonal correction based solely on the air temperature can not guarantee a better friction measurement. For these reasons, INDOT does not apply seasonal or temperature corrections to friction measurements.
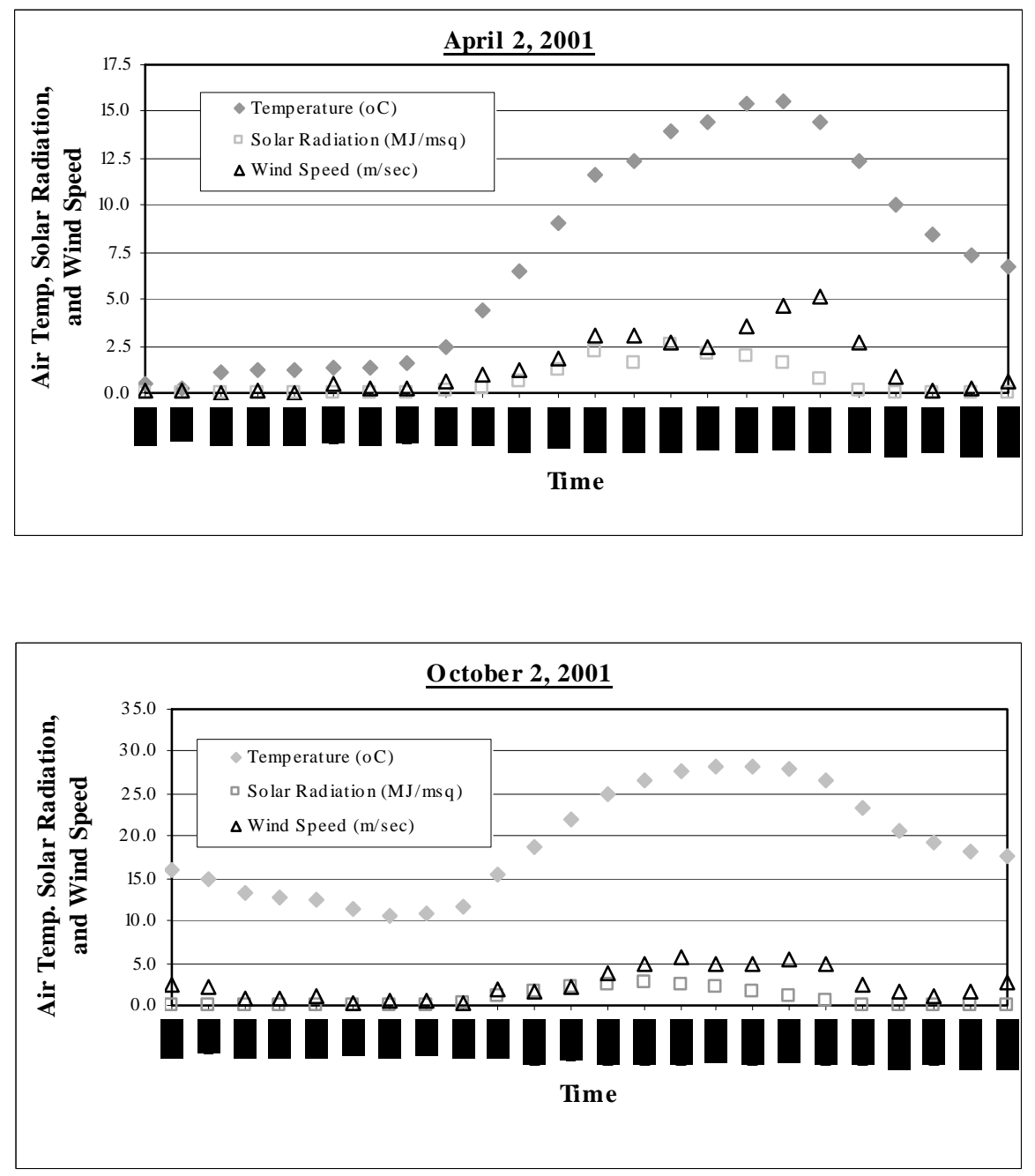

Figure 4.6 Variations of Air Temperature, Solar Radiation and Wind Speed with Time in West Lafayette 


\subsection{Spatial Variations}

\section{$\underline{\text { Lateral Friction Variations }}$}

Pavement friction exhibits significant lateral variations such as directional variations, lane variations, and wheel-track variations. Lateral variations are mainly caused by traffic pounding and polishing. Kummer et al. (18) pointed out that the repeated pounding of traffic reduces the large-scale texture of the pavement by breaking and removing aggregates. Continuous polishing wears down the small-scale texture of the aggregates exposed to traffic. The pounding and polishing actions on the pavement varies in space because traffic has two critical spatial characteristics such as directional distribution and lane distribution. In order to identify the test location for the network pavement friction inventory test, it is of importance to investigate the lateral friction variations.

During any particular time or at any particular location, traffic volume may be greater in one direction than that in the other direction. This is especially true on those urban routes serving strong directional demands. Therefore, pavements in different directions may carry different traffic volumes, which results in different surface characterizations and directional friction variations. Also, pavement types may add additional variations to friction measurements. Figure 4.7 shows the friction measurements with smooth tires in both directions on several selected roads. The largest variation was obtained on SR-121 and was about 16. Based on the network test results, it was also found that the State and U.S. roads tend to produce greater directional variations than the interstates.

When two or more lanes are provided to traffic in one direction, the traffic lane distribution may vary greatly with traffic regulations, volume, speed, and composition. When traffic volume is normal, most traffic may use the driving lane. As traffic volume increases, more traffic tends to use the passing lane. Consequently, the surface characterizations and friction measurements may vary widely from lane to lane. This study measured friction numbers using smooth tires on selected sections on I-65 and I-69. The results are presented in Figure 4.8. On I65, friction measurements were made in two sections, one with three lanes in a single direction

and the other with two lanes in a single direction. It is demonstrated that the passing lane has the 
greatest friction and the driving has the smallest friction. The friction variation between the passing and driving lanes is about 10 . In the second section on I-65, the lane variation is 5 . The tested section on I-69 has two lanes in a single direction. It is demonstrated that the lane variation is up to 13 .

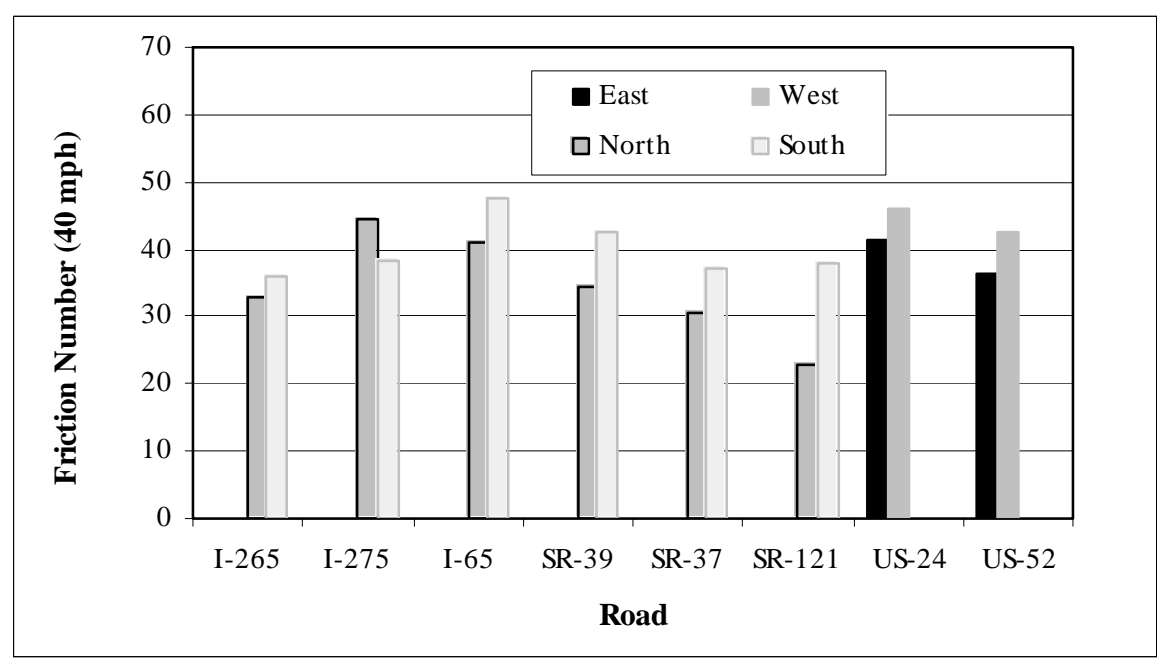

Figure 4.7 Directional Friction Variations

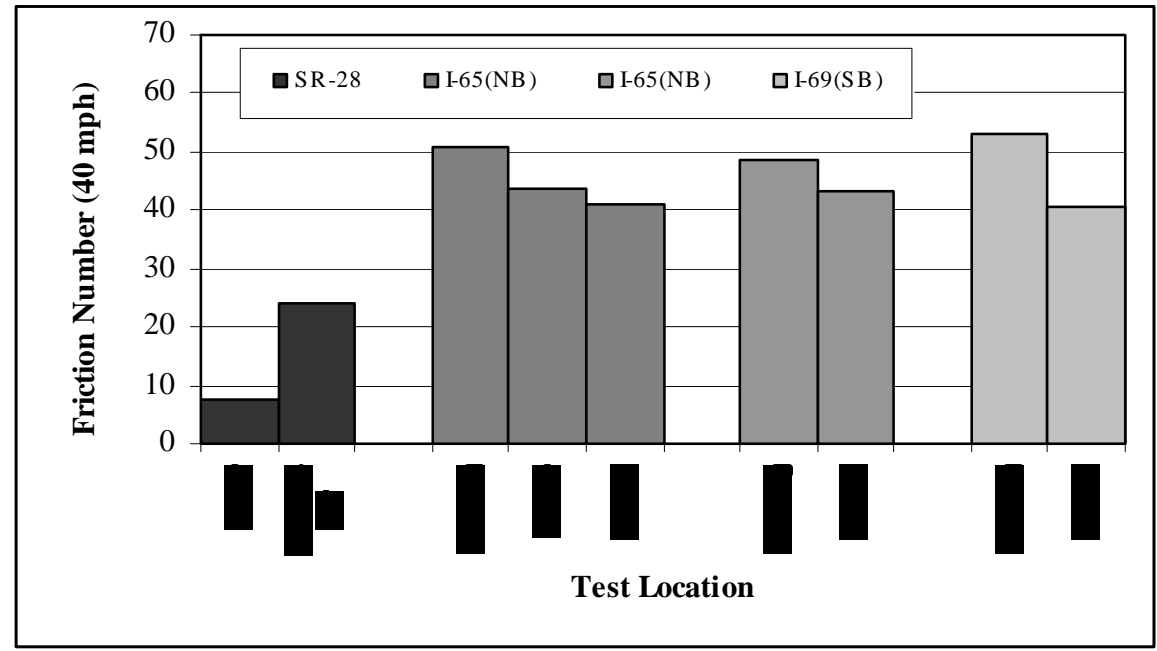

Figure 4.8 Friction Variations due to Test Location

Also presented in Figure 4.8 are the friction numbers measured with smooth tires on SR28. The friction number, In-WP, was measured in the left wheel track and the friction number, Outside-WP, was measured outside the wheel track and located between the two wheel tracks. 
The variation is about 16. In general, the pavement in a wheel track experiences more traffic pounding and polishing. Therefore, the friction number measured in the wheel track is usually much less than that measured outside the wheel track. When the wheel track has experienced rutting, the friction number in the wheel track may be further reduced.

\section{Longitudinal Friction Variations}

Friction measurements vary not only with lateral test locations, but also with longitudinal locations. The longitudinal friction variations arise due mainly to traffic distribution, pavement type, and surrounding conditions. In order to provide physical evidences for determining test spacing for the network pavement inventory friction test, this study took friction measurements in several selected sections and addressed the issue of longitudinal friction variations. The selection of test sections was set to cover concrete and asphalt pavements, different highway classifications, and different sections along the same road.

Two consecutive 1.0-mile sections were selected on I-65. One section is concrete pavement and the other is asphalt pavement. The friction measurements could provide a good illustration of the longitudinal friction variations under the same traffic conditions because the two test sections have no access and exit points. The friction measurements were taken with the smooth tire at 0.1-mile spacing, as shown in Figure 4.9. It is demonstrated that in general, the friction measurements are consistent within a one-mile section, especially the asphalt pavement section. The standard deviation is 4.2 for the concrete section and 1.7 for the asphalt section. The scale of variations is equivalent to that of the system variations as given earlier.

Figure 4.10 and Figure 4.11 show the longitudinal friction variations on interstates and other roads such as State and US roads, respectively. In Figure 4.10, I-465 is a full circular road with three to 4 lanes in one direction around the city of Indianapolis, Indiana. Along I-465, the daily traffic volume varies from approximately 74,000 to 147,000 from location to location. I-65 is a four-lane (except for the segment within the city of Indianapolis) road running through Indiana from north to the south. I-90 is a toll road running through Indiana from Ohio to Illinois. In Figure 4.11, SR-109 is a two-lane road connecting I-69 and I-70. SR-19 is also a two-lane road running from Noblesville to the southern Michigan. US-41 is a four-lane highway located in 
the west of Indiana and runs through Indiana from south to north. It is demonstrated that the friction measurements vary significantly along the roads. It appears that most friction measurements on interstates, State roads, and US roads are greater than 20 because a friction flag value of 20 with the standard smooth tire is used for the inventory friction testing. For a single road, the friction variations in both directions are quite consistent.

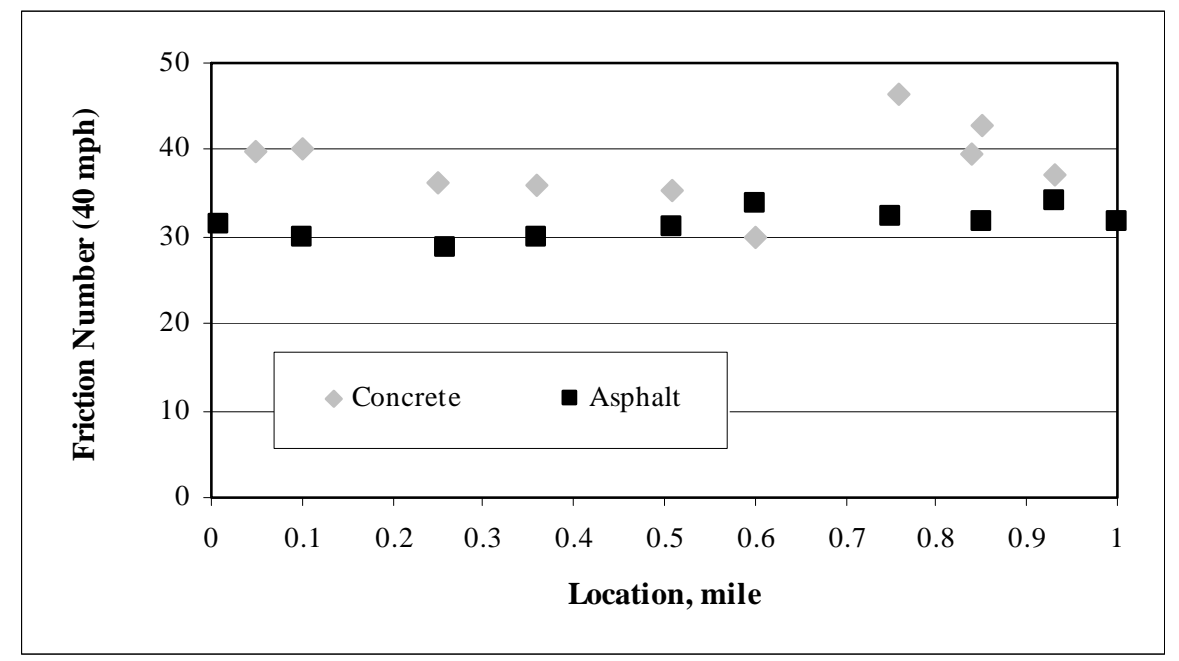

Figure 4.9 Friction Variations on Asphalt and Concrete Pavements

\subsection{Temporal Variations}

Because of the repeated traffic applications, periodic change of surrounding environment, and deterioration of pavement materials, pavement surface characterization may vary in time. It is desirable to measure pavement friction as frequently as possible so as to provide realistic pavement friction information. However, INDOT maintains a highway network consists of approximately 1300 miles of interstates and 7500 miles of paved State and US roads. Due to the constraint of the resources available, it is impractical to test the whole highway network every year. In order to realize the possible trends of temporal friction variations to determine a costeffective friction test cycle for INDOT network pavement inventory testing program, this study measured friction data on various selected pavements, including new pavements, old pavements, concrete pavements, and asphalt pavements. 

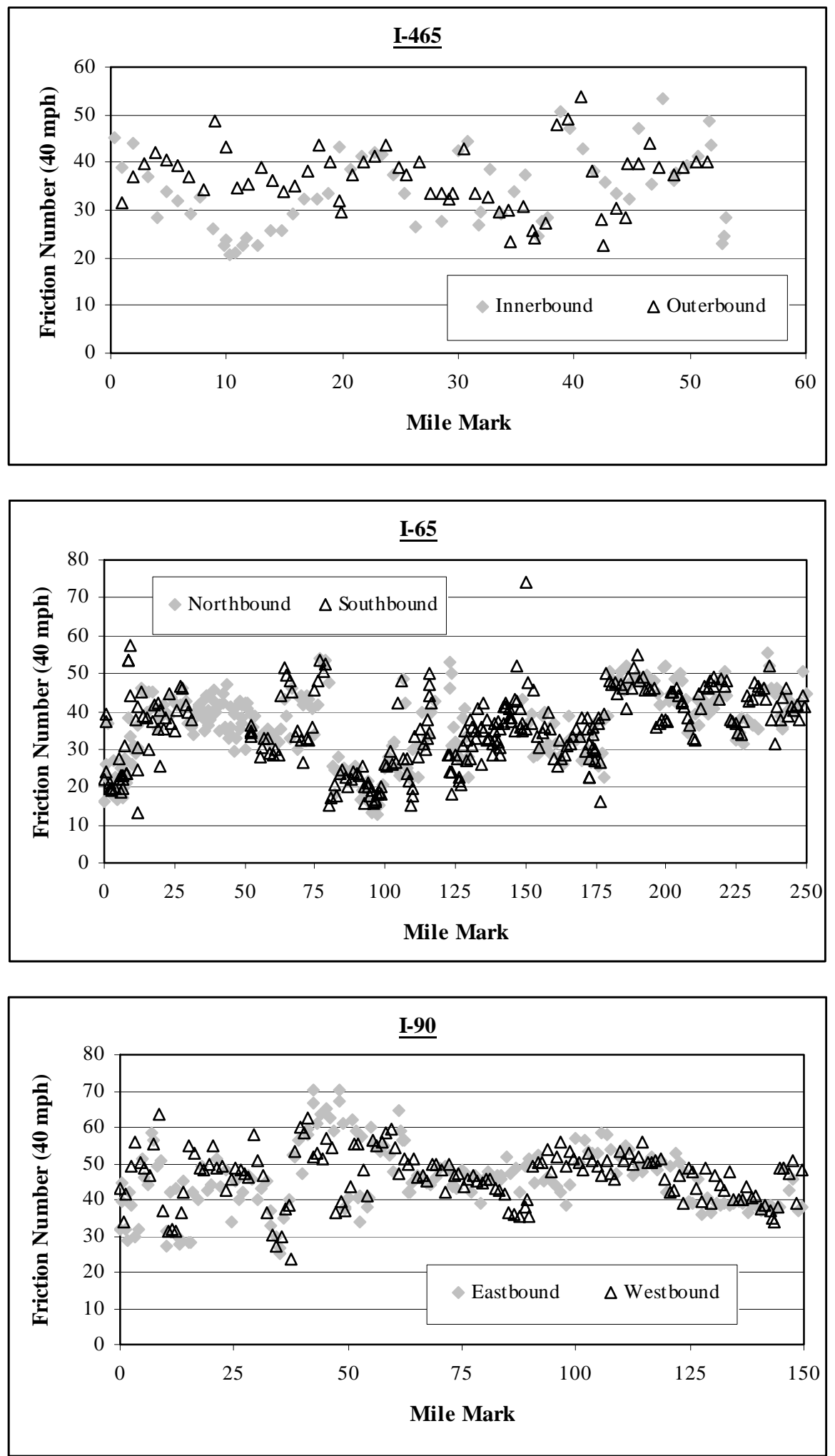

Figure 4.10 Longitudinal Friction Variations on Interstates 

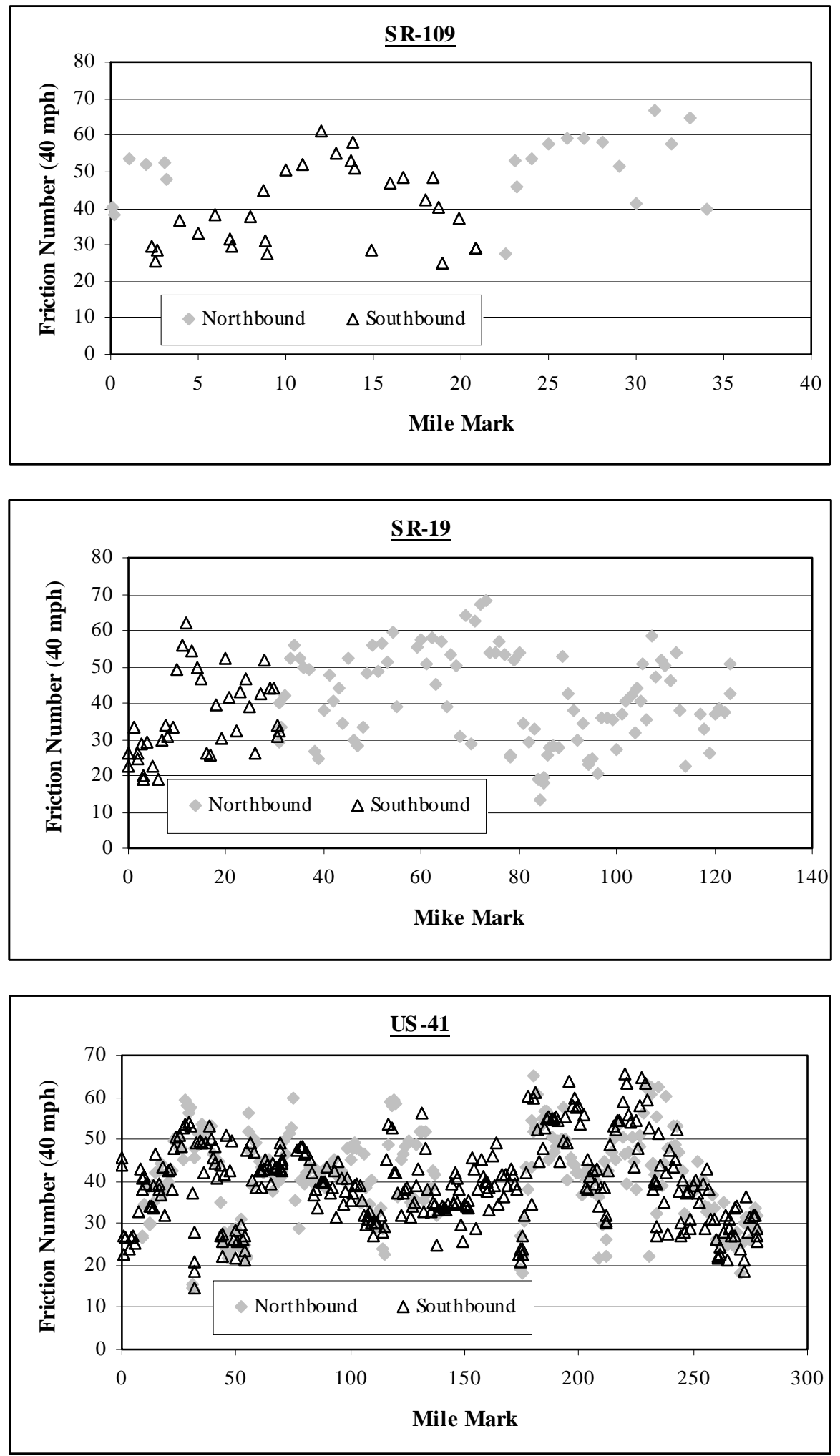

Figure 4.11 Longitudinal Friction Variations on State and US Roads 


\section{Variations of Friction with Time in New Pavements}

It was thought that new pavements have no surface distresses and the frictional variations may solely reflect the effect of traffic. Also, because of the differences in materials and structures, concrete and asphalt pavements may experience different trends of frictional variations with time. In order to verify this, this study measured friction numbers on two new Hot Mix Asphalt (HMA) pavement sections and two new concrete pavement sections on two interstates, respectively, as shown in Figure 4.12. The two selected new HMA pavement sections were located on I-65 and I-74, respectively. It is observed that in the first year, the two new HMA pavements experienced very low friction numbers. This is probably due to the effect of asphalt binder on the surfaces. The friction numbers increased significantly in the second year. The friction numbers peaked in the third year and then decreased slowly with time. The frictional variations on I-65 followed a trend similar to that on I-74.

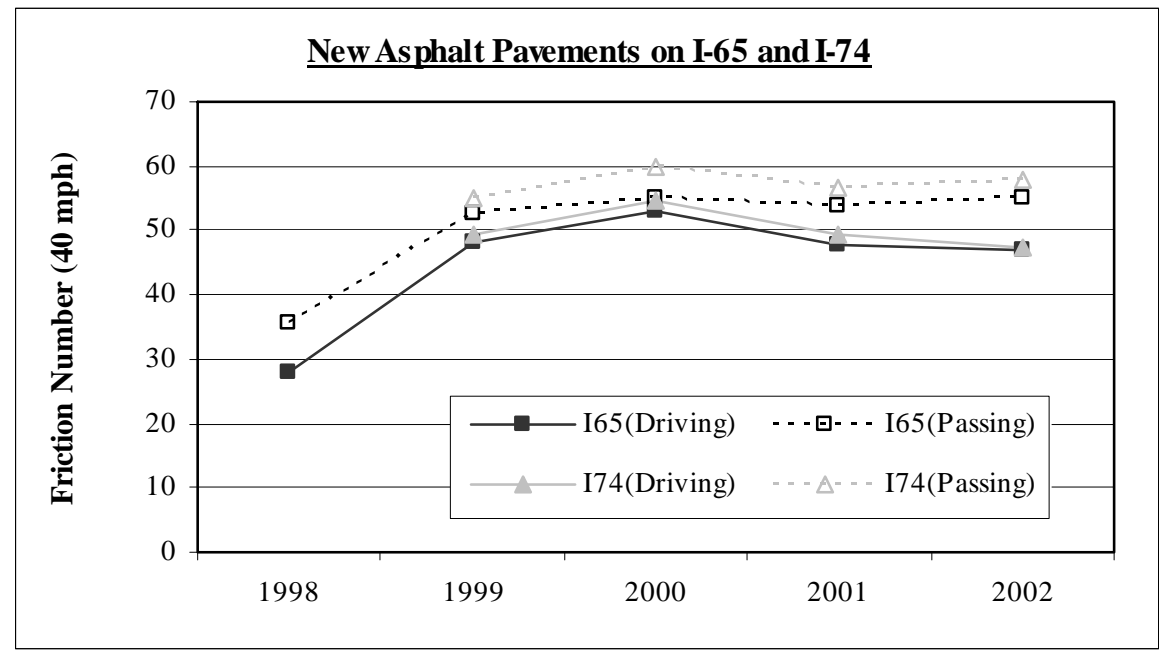

Figure 4.12 Frictional Variations on New HMA Pavements

Concrete pavements have very high rigidity and transverse joints. For new concrete pavements as shown in Figure 4.13, the friction numbers dropped significantly in the second year. This is probably because of the significant effect of polishing by traffic. The friction numbers grew in the third year and then fluctuated and decreased with time. The two new concrete pavement sections followed a similar trend. Because of differences in material properties and structures, the frictional variations of new concrete pavements differ from those of new HMA pavements in time. 


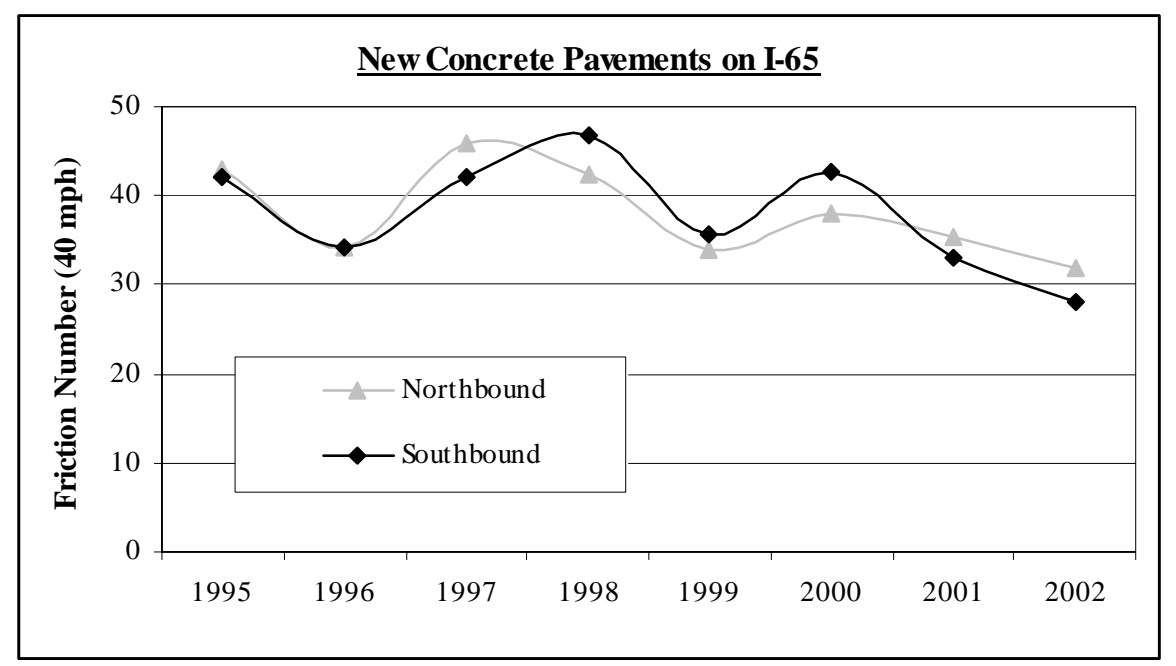

Figure 4.13 Frictional Variations on New Concrete Pavements

\section{Variations of Friction with Time in Old Pavements}

In general, pavement friction decreases with increased traffic applications. Old pavements may have distresses such as cracking and rutting. It has been widely accepted that the distress of rutting in asphalt pavements will further decrease pavement friction. As shown in Figure 4.14 are the friction numbers measured in a selected pavement section on SR-28 in 1998 and 2001, respectively. This pavement section solely experienced rutting on the surface. However, distresses such as cracking and raveling may cause rougher surfaces and result in greater friction numbers. Figure 4.15 shows the friction measurements in an asphalt pavement section on I-65. Because of cracking and raveling, an increase in pavement friction was observed with time. Therefore, pavements with different surface conditions may experience different frictional variations with time.

In addition, a specific road may consist of various types of pavements such as asphalt pavement and concrete pavement. As a result, it becomes very difficult to identify a typical trend of frictional variations in old pavements. In order to provide physical evidences for determining a realistic test cycle, it will be advisable to identify the variations of network pavement friction conditions rather than individual cases. It was thought that network pavement conditions not only reflect the overall variations of pavement conditions, but also reflect to some extent the effect of new pavement construction and resurfacing on the network pavement conditions. 


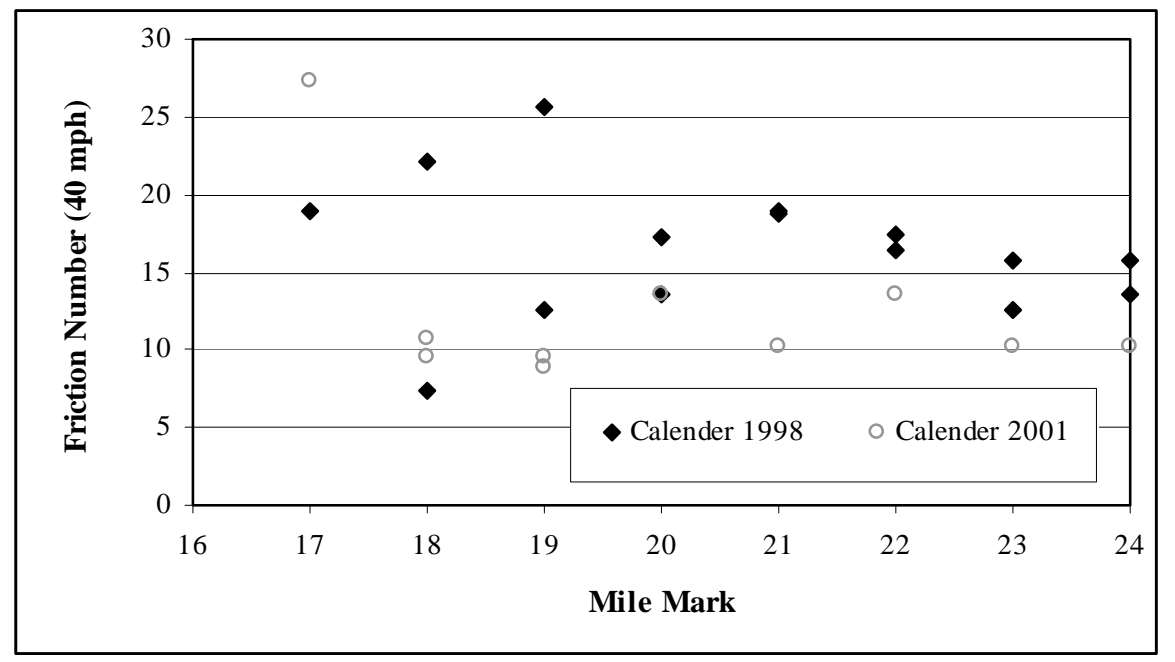

Figure 4.14 Frictional Variations in Asphalt Pavement with Rutting

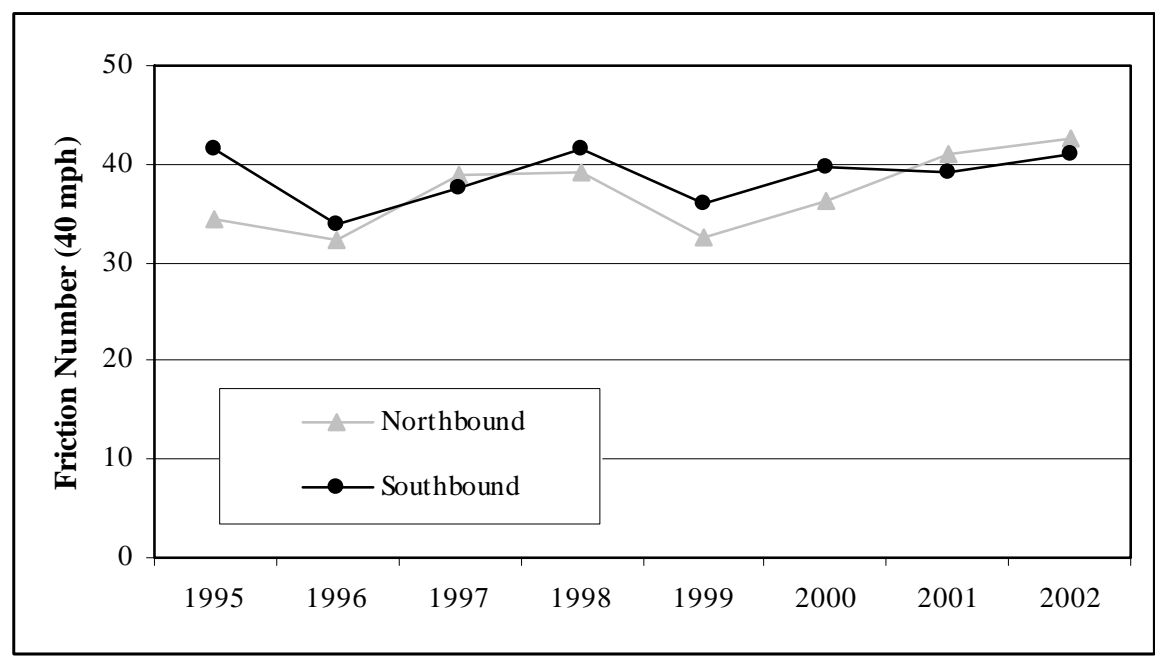

\section{Figure 4.15 Frictional Variations in Asphalt Pavement with Cracking and Raveling}

Figure 4.16 shows the variations of network pavement friction conditions with time in the past seven years. The friction variations are divided into two categories: (1) Interstates, and (2) State and US roads. Two observations are obtained by careful inspection of Figure 4.16. First, the frictional variations for these two categories of pavements almost follow a similar trend. The network pavement frictions increased from 1996 to 2000. The possible reason is that INDOT witnessed a large amount of new pavement construction and resurfacing during this period. Next, the network pavement frictions decreased after 2000 and the interstate pavements decreased 
faster than the State and US roads. The largest decreases occurred in 2002 for both categories. For interstate pavements, the largest annual decrease is approximately 7.0. For State and US roads, the largest annual decrease is about 4.0.

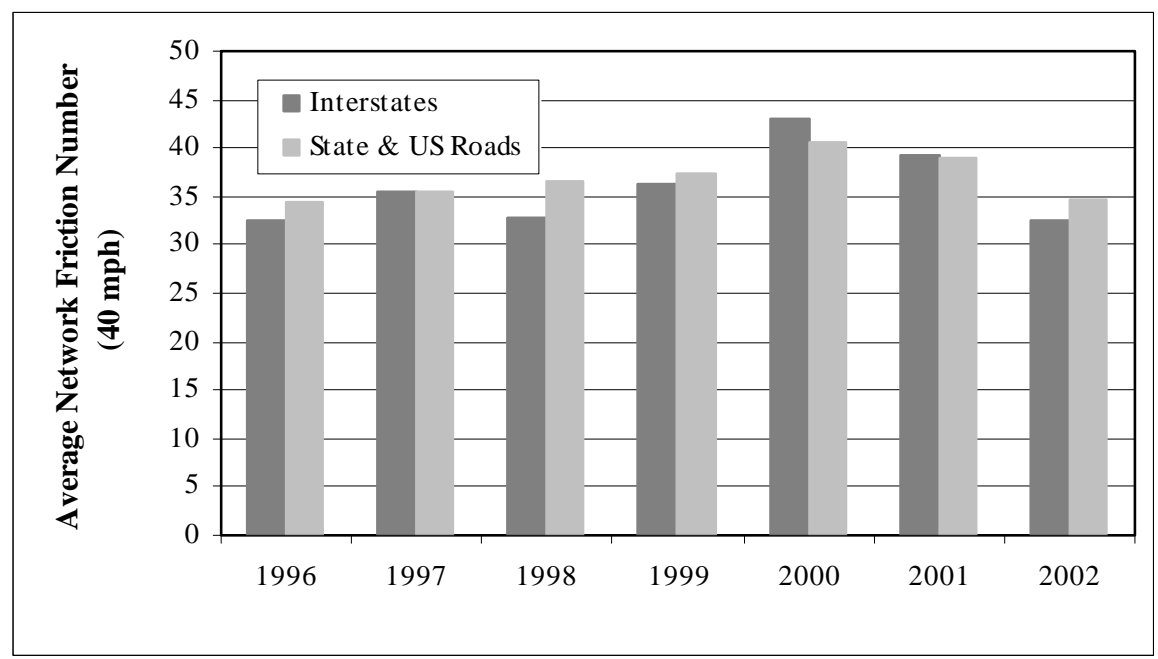

Figure 4.16 Variations of INDOT Network Pavement Friction Conditions 


\section{Chapter 5}

\section{THE INDOT NETWORK PAVEMENT INVENTORY FRICTION TEST PROGRAM}

\subsection{Friction Testing System Calibration and Performance Verification}

\section{Calibration of Transducers and Subsystems}

INDOT has two identical friction testing systems, i.e., the locked wheel trailers which were assembled in-house in accordance with ASTM E-274. Both systems have dual wheel friction test capability with a smooth tire installed on the left side and a ribbed tire on the right side of the trailer. It is well-known that the true friction number for a specific pavement has long been a puzzle to highway agencies. In order to acquire reliable friction data and maintain the system integrity, testing system calibration plays a great role in pavement friction test. System calibration mainly includes calibration of force-measuring transducer, calibration of pavement wetting subsystem, and calibration of speed-measuring transducer. The procedures for calibrating the friction testing system have been standardized by FHWA Technical Advisory T5040.17 (39) and ASTM E-274. However, the use of those standard calibration procedures requires great experience.

INDOT has established an in-house force plate calibration platform as shown in Figure 5.1. The force plate transducers are calibrated annually before test season or any time significant changes have occurred by the National Institute of Standards and Technology. The pavement wetting subsystem is calibrated to examine the flow of water supplied by the nozzle. It usually requires two operators because the whole procedure is exhausting and may be hazardous. The calibration of speed-measuring transducer is conducted annually on a selected straight highway section with a specific length between two reference posts. The detailed procedures are documented elsewhere (40). Calibration of force transducers is labor intensive and time consuming. INDOT calibrates force transducers every month and anytime if significant changes have been identified with the system. 


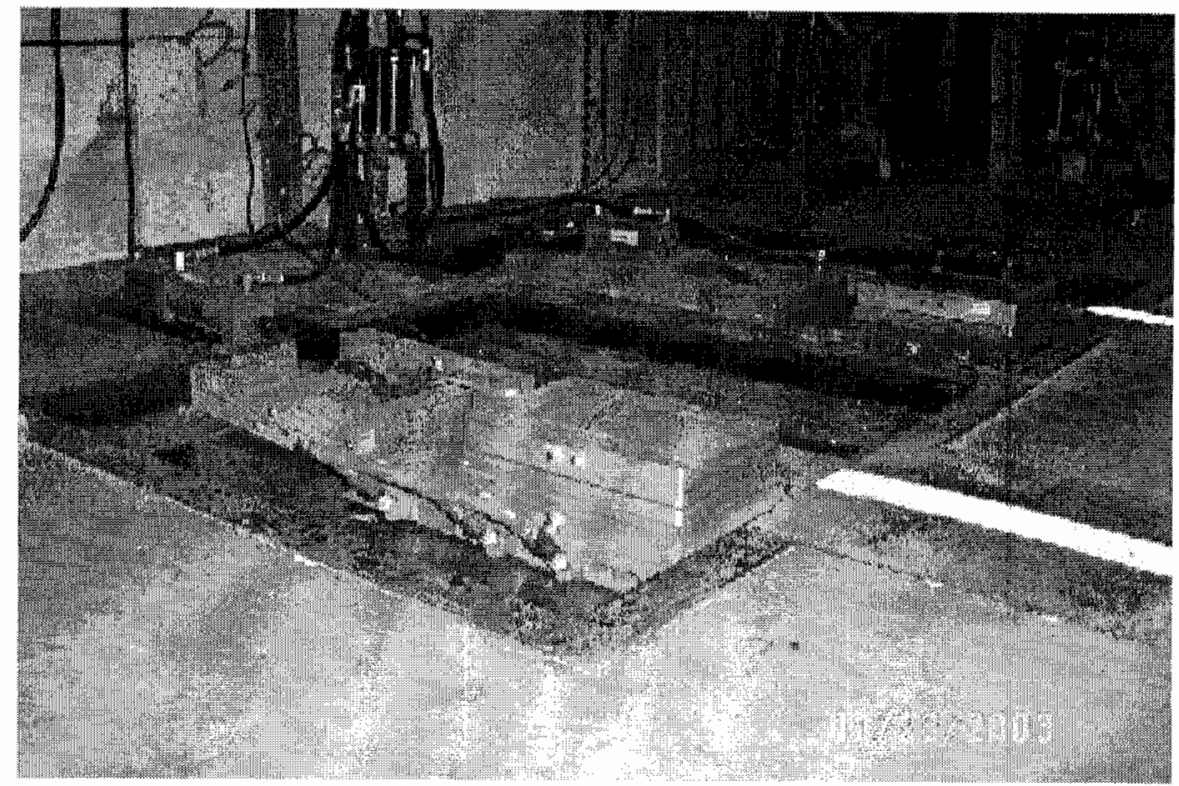

Figure 5.1 INDOT In-House Force Plate Calibration Platform

\section{System Performance Verification}

There exist many cases where the testing system may fail to function properly even after all transducers are properly calibrated. For example, water may enter into transducers during testing and result in low friction numbers. Therefore, it is necessary to verify the performance of the whole testing system periodically. The verification of system performance is conducted on the INDOT friction test track as shown in Figure 5.2. The friction test track consists of three 3.0meter wide sections: slick concrete pavement, asphalt pavement, and tined concrete pavement. The surfaces of the three test sections were prepared so that they could provide distinctive friction features which may be observed in highway pavements. For example, pavements with severe rut usually have very low friction in the wheel path and grooved concrete pavements have very high friction.

Table 5.1 shows the detailed information about the three test sections. For the tined concrete surface, transverse grooves are 0.12 in. $(3 \mathrm{~mm})$ wide, 0.12 in. $(3 \mathrm{~mm})$ deep, and spaced between $0.7 \sim 0.8 \mathrm{in}$. $(18 \sim 20 \mathrm{~mm})$. The test track has an approaching section and an exiting section so that the operator can adjust the test speed and maintain a safe operation. Good drainage system is also provided on both sides of the test track. The system performance verification is performed weekly during the test season and any time after the force plate is 
calibrated. Friction numbers are measured on all three test sections. The results are used to promptly identify potential significant changes occurred to the system performance. The surface friction features of the test track are also measured by the British Pendulum Tester so as to provide a reference to avoid any significant changes on the three surfaces.

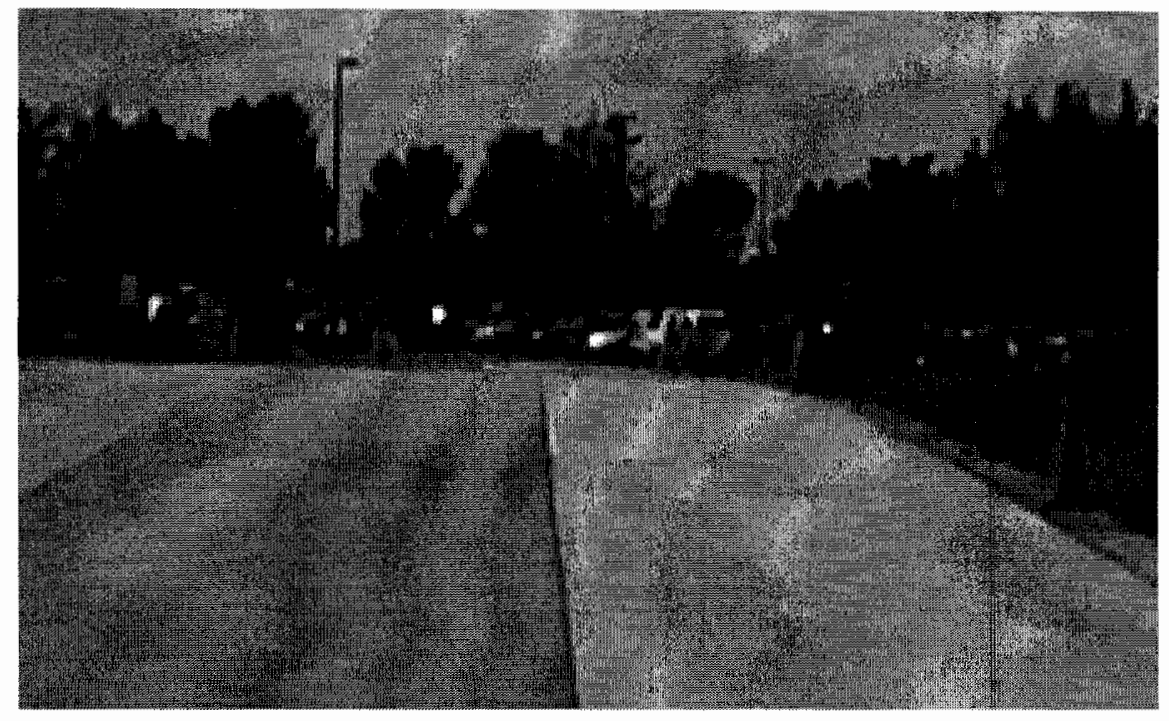

Figure 5.2 The INDOT Friction Test Track

Table 5.1 Surface Features of the Three Test Sections

\begin{tabular}{lcccc}
\hline \multicolumn{1}{c}{ Section } & Length & $\begin{array}{c}\text { Method of } \\
\text { Surface Finish }\end{array}$ & $\begin{array}{c}\text { Friction Number } \\
(40 \mathrm{mph}, \text { smooth tire })\end{array}$ & $\begin{array}{c}\text { British Pendulum } \\
\text { Number (BPN) }\end{array}$ \\
\hline Slick Concrete & $100 \mathrm{ft}$. & Fine finished & $<10.0$ & 27 \\
Asphalt & $395 \mathrm{ft}$. & Normal & $30.0 \sim 50.0$ & 49 \\
Tined Concrete & $100 \mathrm{ft}$. & Wire drag & $>60.0$ & 48 \\
\hline
\end{tabular}
$1 \mathrm{ft} .=0.305 \mathrm{~m}$.

The system performance verification is to estimate the standard deviations of friction measurements due to system errors and establish a confidence interval for examining system consistency. In order to avoid misleading estimates, a minimum number of test runs should be conducted. In general, the following equation provides a rough estimate of the minimum number of test runs (41):

$$
N=\left(\frac{\sigma Z_{a / 2}}{\varepsilon}\right)^{2}+\varepsilon_{N}
$$


where $\mathrm{N}=$ minimum number of test runs;

$\sigma=$ population standard deviation of the friction test results;

$\varepsilon=$ allowable error for friction test;

$\mathrm{Z}_{\alpha / 2}=\mathrm{Z}$-value from two-tailed standard normal distribution at a confidence level of 1- $\alpha$; and $\varepsilon_{\mathrm{N}}=$ adjustment factor equal to 2,3 , and 4 with respect to a confidence of $90 \%, 95 \%$, and $99 \%$, respectively.

The standard deviations and the allowable errors can be estimated in light of the historical verification test data. The standard deviation by the smooth tire is approximately $1.5,4.0$, and 2.5 for the slick concrete, asphalt, and tined concrete sections, respectively. With the ribbed tire, the standard deviation is about $1.0,4.0$, and 1.2 for the three sections, respectively. There are many factors that may influence friction test results. As shown in Chapter 4, friction measurements for system performance verification were made on the same spot so as to reflect frictional variations due to system errors. Figure 5.3 and Figure 5.4 show the variations of the friction numbers measured on the test track using both the smooth and ribbed tires. It is very interesting to note that for the two tires, the test results measured on the asphalt surface experienced the greatest variations and those on the tined concrete surface the smallest variations. As the number of test runs increased the standard deviation converged to a specific value, especially after five test runs. Statistically, a minimum of three tests should be conducted. For the INDOT friction test program, five test runs are recommended for the system performance verification test.

\subsection{Test Frequencies and Test Locations}

\section{Test Frequencies}

Determination of the friction test frequencies for network pavement inventory friction test program relies mainly on the resources available and the frictional variations with time. Based on the survey results published by Henry (5), most of the state highway agencies conduct friction tests annually or every two years. On the one hand, it is desirable to conduct pavement friction test more frequently so as to provide timely and realistic pavement friction information. Occasional tests may not identify potential significant friction changes. On the other hand, more frequent tests will incur more costs. It requires a compromise to determine cost-effective test 
frequencies. However, there are no simple approaches for determining cost-effective test frequencies due to the fact that it is very difficult to measure the impact of timely friction information on safety and pavement maintenance and resurfacing. A practical approach is to select test frequencies based on the temporal friction variations in conjunction with test operation cost.

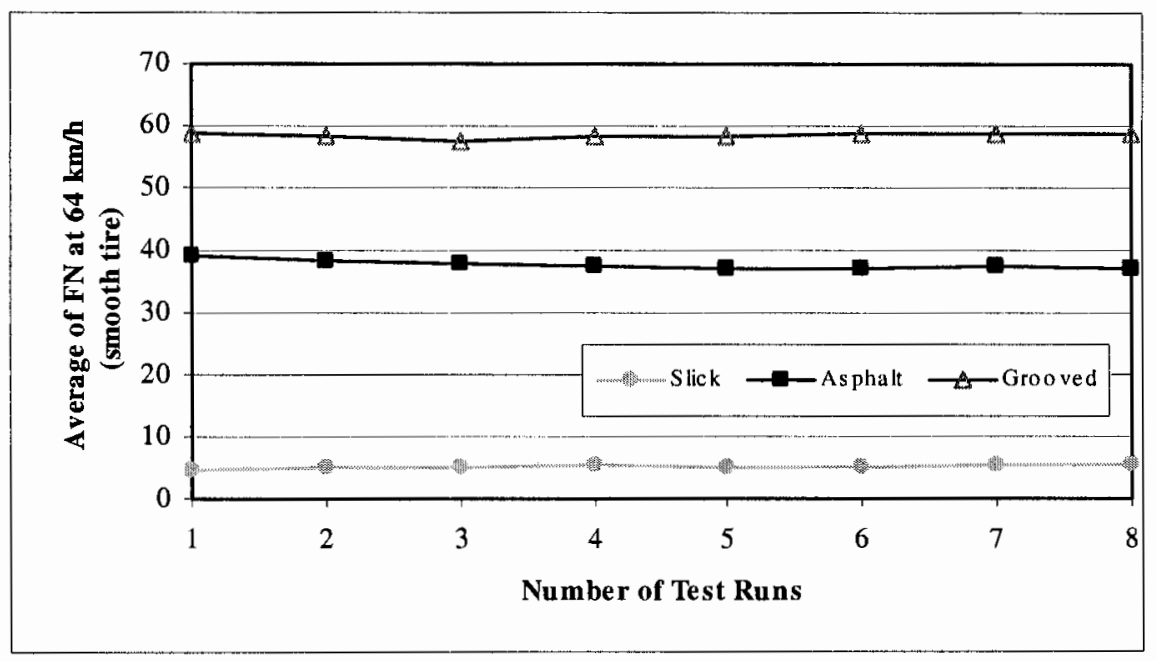

(a) Average Friction Measurements with a Smooth Tire

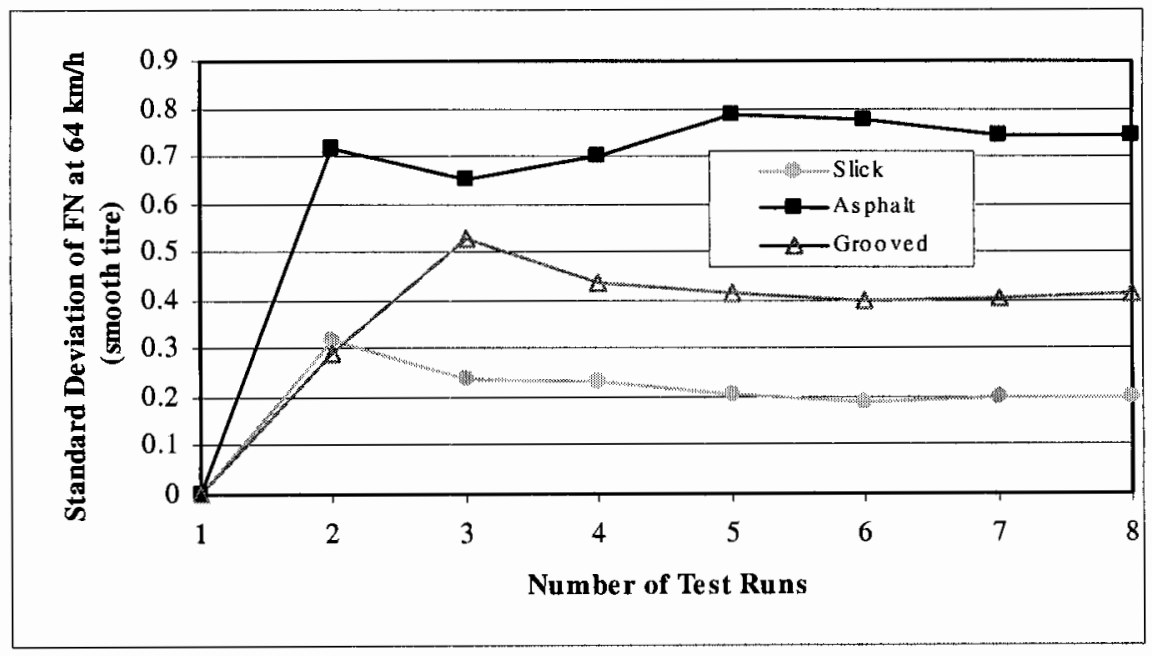

(b) Standard Deviations of Friction Measurements with a Smooth Tire

Figure 5.3 Effect of Sample Size on System Verification Test with the Smooth Tire 


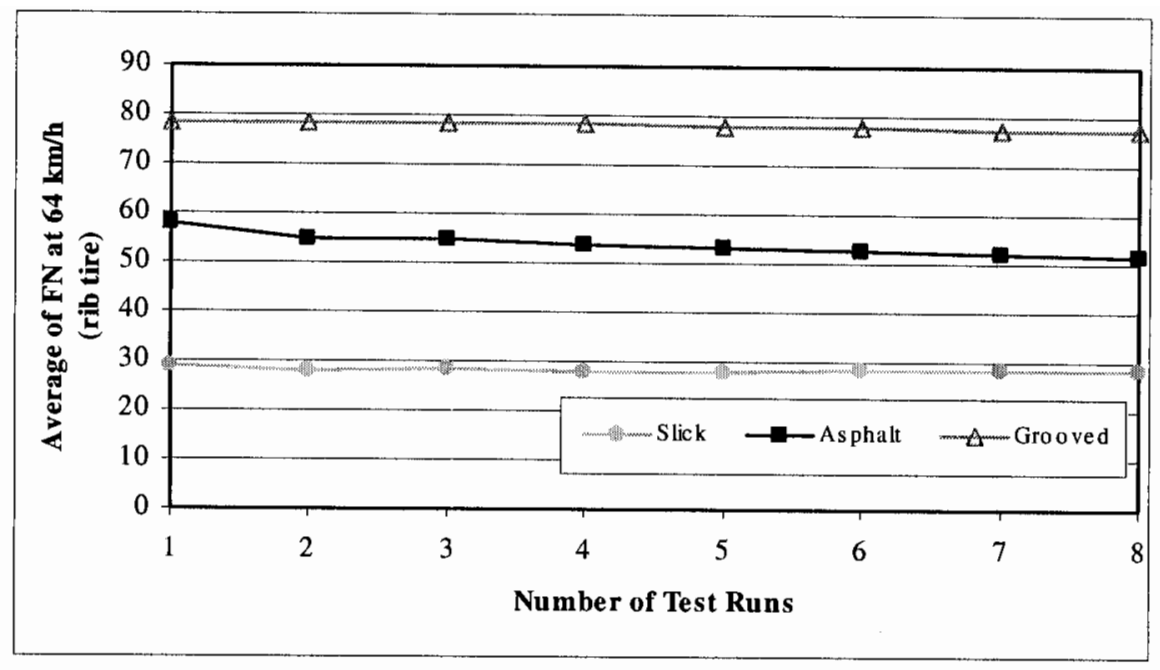

(a) Average Friction Measurements with a Ribbed Tire

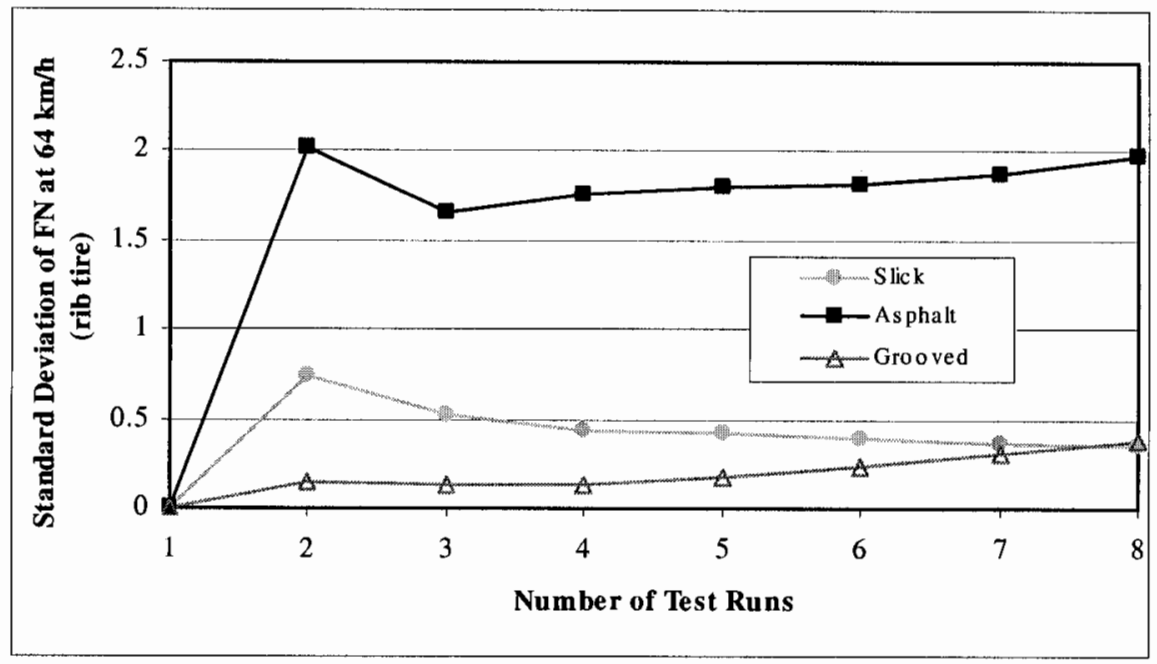

(b) Standard Deviations Friction Measurements with a Ribbed Tire

Figure 5.4 Effect of Sample Size on System Verification Test with the Ribbed Tire

(Test Track, Ribbed Tire)

As shown in Chapter 4, pavement friction varies in time. For new HMA pavements, their frictions usually increase with time in the first three years. For new concrete pavements, their frictions fluctuate in the first three years. For old pavements, pavement frictions usually decrease but may increase due to the effect of surface conditions. At the network level, pavement friction 
conditions also depend on new pavement construction and pavement resurfacing. In general, the average annual pavement friction variation is approximately 7.0 for all interstates and 4.0 for all State and US roads. The former exceeds the system variations and the latter is less the system variations. This simply implies that interstates should be tested more frequently than State and US roads. In addition, conventional friction tests are usually tested over an 8-month period. When temperature is low, the wetting system may not work properly.

In consideration of the temporal friction variations over INDOT network pavements, time constraints, availability of water, and geographical locations, INDOT annually conducts pavement inventory friction test on all interstates and on State and US roads every three years. As a result, INDOT conducts network inventory friction tests for approximately 6,700 lane-miles (11,000 lane-kilometers) each year. As an estimate, it usually takes about 100 days to complete all inventory friction tests. The operation cost for friction test is about $\$ 300$ per day. This cost includes only expenditures and salary for the operator and does not include any time and money for data processing, data analysis, system calibration and maintenance, and parts.

\section{Test Locations}

Friction test locations refer to both lateral and longitudinal locations. All factors considered in determination of the test frequencies, such as timely and realistic information and cost, also apply to determination of the test locations. However, it is relatively easier to determine the lateral test locations by considering the lateral friction variations. As shown in Chapter 4, the lateral friction variations are very consistent. The driving lane usually experiences lower friction numbers than other lanes. The friction number measured in the wheel track is much less than those measured outside the wheel track. INDOT conducts inventory friction tests in the wheel track of the driving lane in each direction so as to identify the worst friction conditions.

In order to determine the longitudinal test locations, it is necessary to take into account not only the longitudinal friction variations, but also other factors such as potential costs and traffic conditions. The results of the survey conducted by Henry (5) indicated that most state highway agencies conduct friction tests at $0.5-$ mile $(0.81-\mathrm{km})$ spacing or $1.0-\mathrm{mile}(1.61-\mathrm{km})$ 
spacing. There is no doubt that the 0.5 -mile spacing may generate more realistic results than the 1.0-mile spacing. However, a spacing of 0.5 miles almost doubles the amount of test work at a spacing of 1.0 mile $(1.61 \mathrm{~km})$. As mentioned earlier, INDOT has approximately 6,700 lane-miles in inventory friction testing. This number is calculated at 1.0-mile test spacing. A spacing of 0.5mile will simply generate 13,000 lane-miles friction testing. It will take about 200 days to complete all tests. As a result, a dramatic increase in the operation costs will occur.

Short test spacing not only generates much more test work, but also causes difficulties and safety issues to the operator. This is because the friction testing is usually conducted at the desired speeds without traffic control. The operator needs sufficient time and distance to adjust and maintain the trailer's speed in light of traffic conditions. When the test spacing is short, the operator needs to adjust the trailer's speed frequently. This may create mental and physical tensions to the operator, especially when traffic volume is large and travel speed is high. Longer test spacing will result in easier and safer operation. Without scarifying too much accuracy, it is desirable to select longer test spacing for network pavement inventory friction testing.

In addition, the longitudinal friction variations within one-mile uniform pavement section are very consistent, as shown in Figure 4.9 in Chapter 4. To further distinguish between 0.5-mile spacing and 1.0-mile spacing, friction measurements taken in one SHRP test site in Indiana, Site 20, are plotted in Figure 5.5. This section is a 5.0-mile long asphalt pavement on I-65. Eleven friction numbers were measured using the standard ribbed tire approximately at a spacing of 0.5 miles. The averages and standard deviations were computed in two scenarios. In the first scenario, all eleven friction numbers were used to compute the average and standard deviation. This scenario is equivalent to the 0.5 -mile spacing. The second scenario was set to reflect friction testing at 1.0-mile spacing. Therefore, only six out of the eleven friction measurements, approximately spaced at 1.0 mile, were picked to compute the average and standard deviation. At 0.5 -mile spacing, the average is 42.2 and the standard deviation is 4.0. At 1.0-mile spacing, the average is 42.5 and the standard deviation is 4.1 . The differences are negligible. Therefore, a test spacing of 1.0 mile is justified for INDOT network pavement inventory friction testing program. 


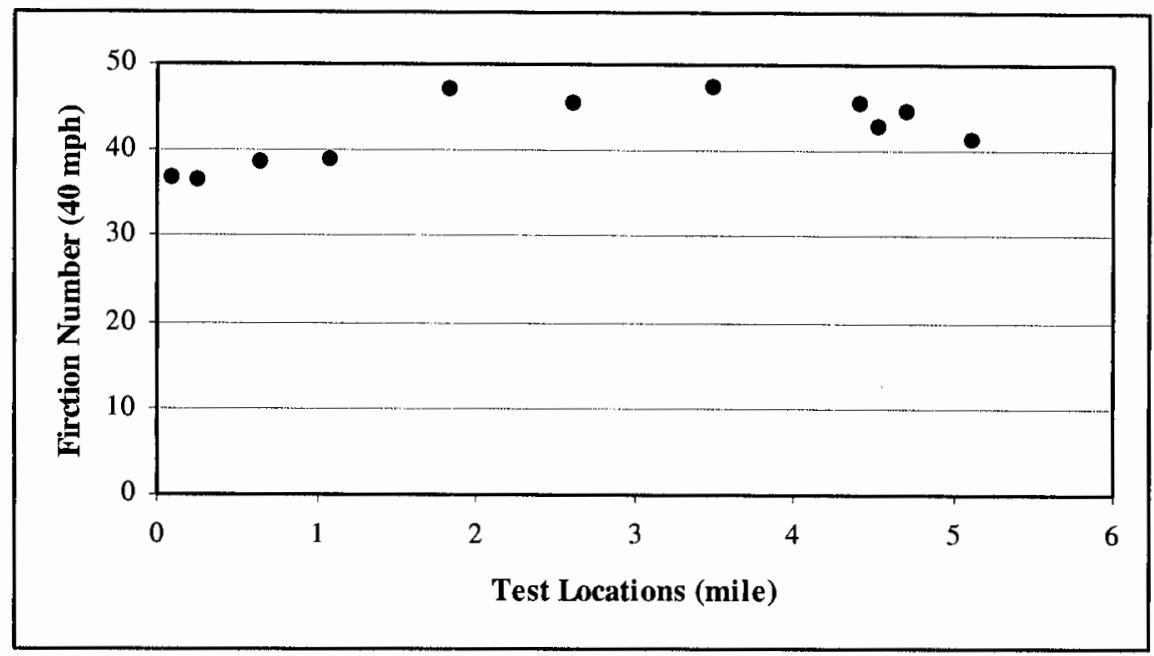

Figure 5.5 Friction Measurements Taken in Indiana SHRP Friction Test Site 20

\subsection{Test Tires}

\section{Differences between the Ribbed and Smooth Tires}

Because of the differences of construction between the smooth and ribbed tires, the interaction between the smooth tire and the contacting pavement is different from that between the ribbed tire and the contacting pavement. The fundamental principle for measuring pavement friction using the locked wheel trailer is the classic Coulomb's friction law as expressed in Equation 2.2. Ultimately, the resultant differences between the pavement friction measurements with the smooth and ribbed tires are reflected by the measured forces. In order to identify the differences between the smooth and ribbed tires, this study conducted a great number of friction tests on the INDOT friction test track and highway pavements using both tires. During tests, both the vertical and horizontal forces were measured.

INDOT Friction Test Track: Figure 5.6 shows the measured vertical and horizontal forces on the three surfaces with both ribbed and smooth tires over a period of nine months. It is demonstrated that the vertical forces measured with the smooth tire are very close to those measured with the ribbed tire on all three surfaces, respectively, no matter when the test was conducted. This is because the vertical force depends only on the weight applied onto the wheel and the geometry of the test track. At the same location, the measured vertical forces should remain close to each other. However, differences arose between the horizontal forces measured 
with the two tires. It is very interesting to note that as the surface becomes rougher, the differences between the measured horizontal forces decrease. The greatest differences occurred on the slick concrete surface. The differences became much smaller on the asphalt surface. On the tined concrete surface, the differences became negligible. As a result, the friction numbers measured with the smooth tire was approximately 17,12, and 0 less than those measured with the ribbed tire on the slick concrete surface, asphalt surface and tined concrete surface, respectively.

Highway Pavements: Friction measurements were also taken with both tires on highway pavements in two scenarios. In the first scenario, a 40.0-miles (72.0-kilometers) long pavement section on SR-37 was selected and both the vertical and horizontal forces were measured during testing. The results are plotted in Figure 5.7. Plotted in Figure 5.7(a) is the relationship between the frictional differences and the differences between the horizontal forces. The frictional differences and the horizontal force differences were computed by subtracting those measured with the smooth tire from the corresponding ones measured with the ribbed tire. It is demonstrated that there exists a very good linear relationship between the frictional differences and the horizontal force differences. This implies that the frictional differences between the two tires are due mainly to the horizontal forces. It is also observed that in Figure 5.7(b), the frictional differences are very consistent over the selected section and the average difference is 20.

In the second scenario, this study investigated frictional differences between the two tires over the network pavements. As shown earlier by the results on the test track, the frictional differences may vary with the surface roughness. It is very difficult to investigate all potential surface roughness. Therefore, this study focused on those locations with low friction numbers which reflect the worst friction conditions. Figure 5.8 shows the frictional differences in the pavement network. The frictional differences are plotted in two categories: (1) Interstates and (2) State and US roads. It appears that the frictional differences on State and US road pavements are very close to those on Interstate pavements. The frictional differences fluctuated in the whole network. The average frictional difference is approximately 23 on interstates and 20 on State and US roads, respectively. 

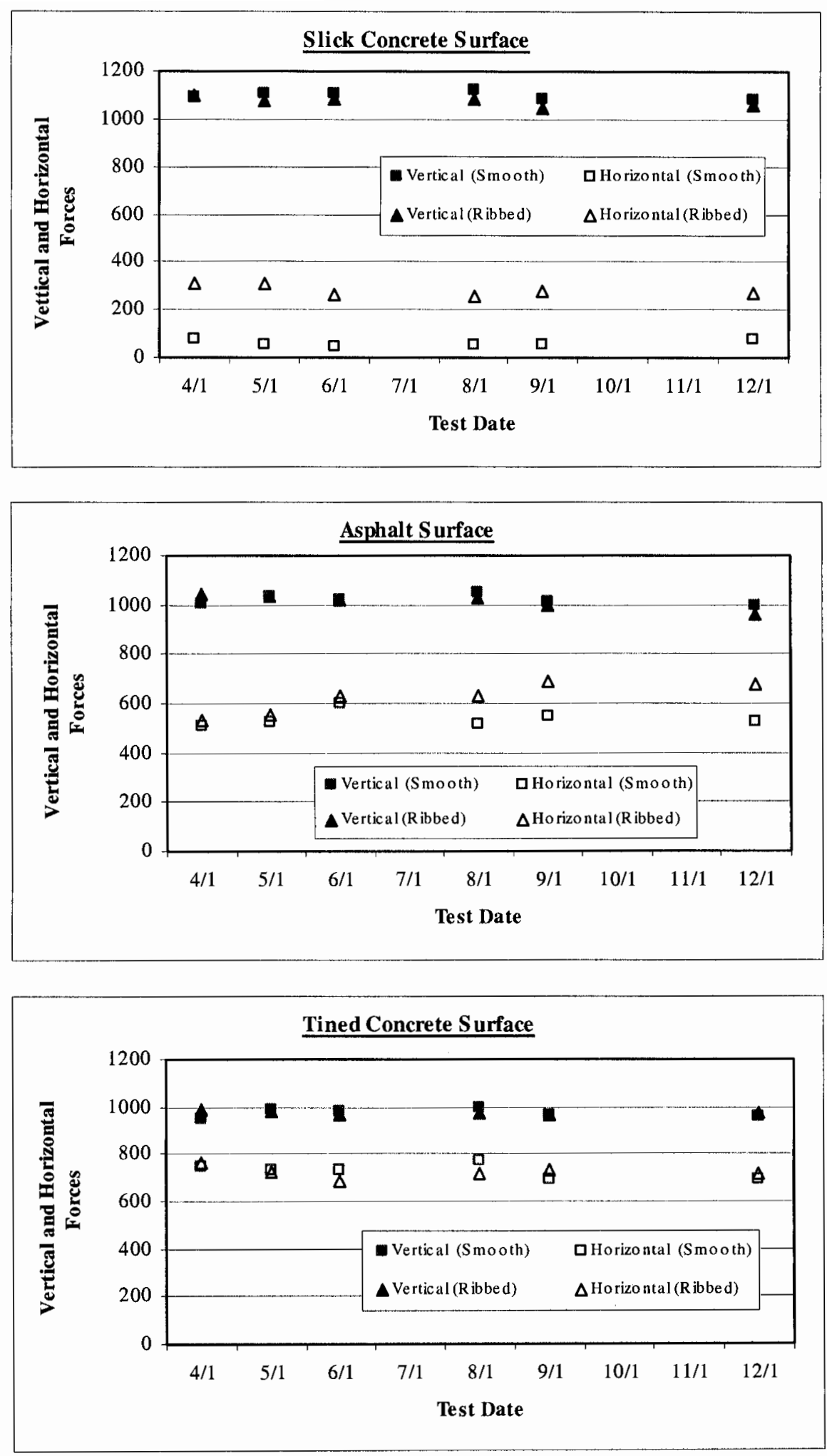

Figure 5.6 Friction Measurements with Smooth and Ribbed Tires on INDOT Friction Test Track 


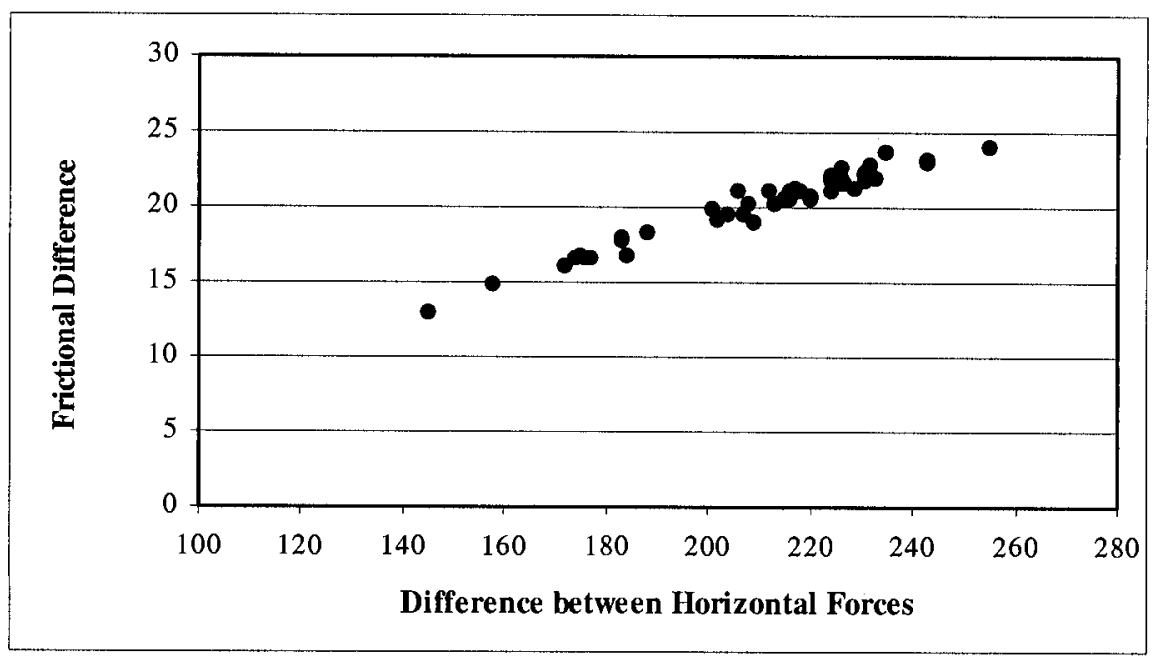

(a) Relationship between Frictional Differences and Horizontal Force Differences

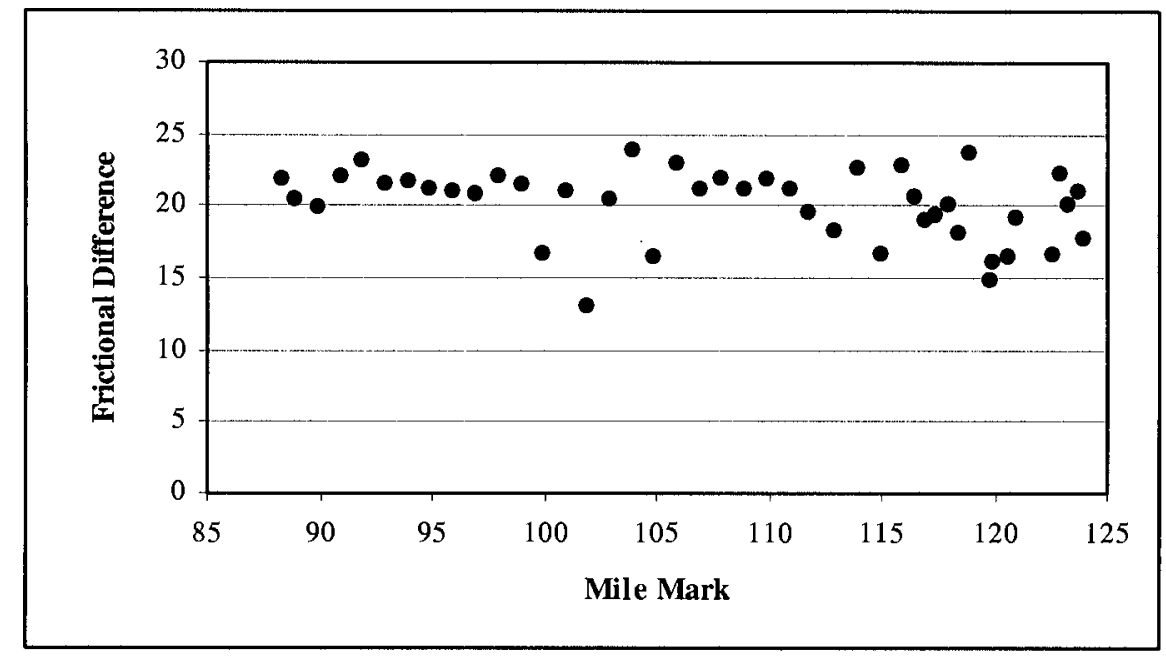

(b) Frictional Differences

Figure 5.7 Frictional Differences Measured on SR-37

\section{Use of the Ribbed and Smooth Tires}

Initially, ASTM E-274 solely required the ribbed tire in the 1960s. In the 1970s, the smooth tire was adopted as an alternative for friction testing. In the 1990s, ASTM E-501 and E524 were developed for the standard ribbed tire and smooth tire, respectively. This indicates an increased interest in use of the smooth tire in the country. Based on the published reports $(5,27)$, none of the 49 state highway agencies surveyed in 1990 used the smooth tire in pavement 
friction tests and 12 of 26 state highway agencies which responded in 2000 used the smooth tire or both tires. INDOT has been using the smooth tire for inventory friction tests since 1996.

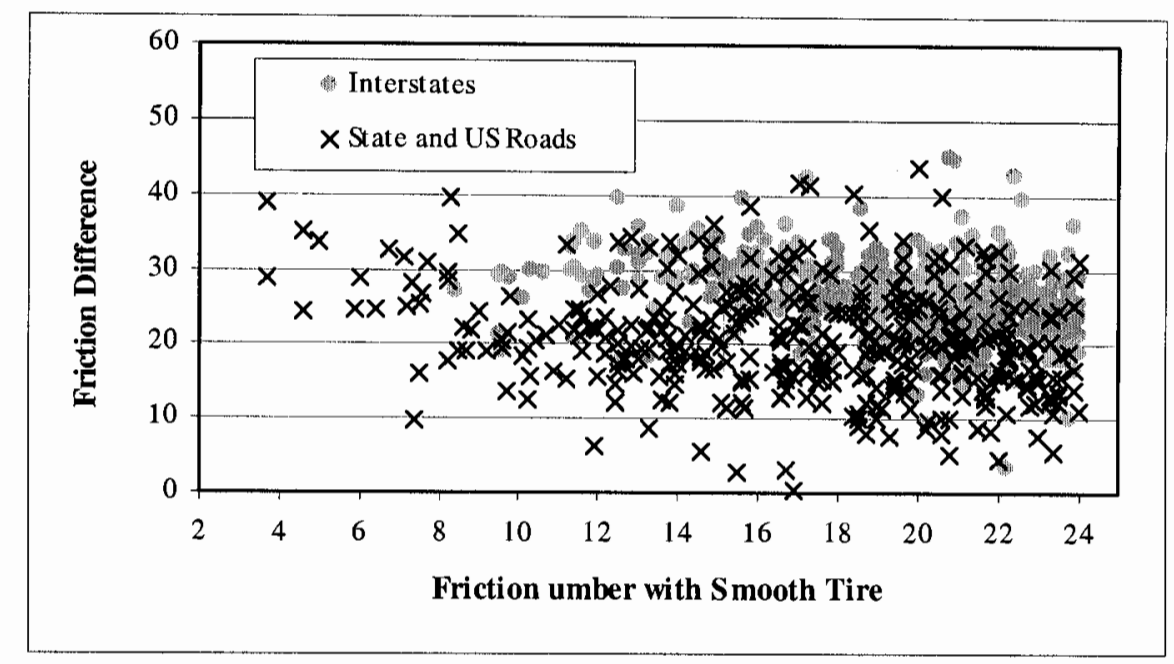

Figure 5.8 Frictional Differences in the Pavement Network

As demonstrated in the preceding chapters, pavement friction is relevant and is the result of tire-pavement interaction. Theoretically, pavement friction can be measured with either the ribbed tire or the smooth tire. The possible difference is that the test results may have different scales. However, Henry questioned the use of the ribbed tire for evaluating wet-pavement safety (42). He further concluded that the ribbed tire was not sensitive to pavement surface macrotexture but are dominated by the microtexture (5). This is because the grooves in the ribbed tire provide channels much larger than the macrotexture for water flow. Therefore, it is required to measure the macrotexture while measuring friction using the ribbed tire. Friction tests with the smooth tire are sensitive to both microtexture and macrotexture. The results can be directly used in calculating the so-called international friction index (IFI) without knowing the macrotexture.

Another study by Connecticut DOT study (6) has shown that "a good correspondence between low smooth-tire skid numbers and accident experience can be seen, but ribbed-tire correspondence was quite poor." Furthermore, the study found out that pavements with friction numbers greater than 25 with smooth tire experienced fewer wet skidding accidents. Therefore, it is evident that use of the smooth tire can provide more advantages than use of the ribbed tire. 
Henry pointed out that agencies are reluctant to use the smooth tire possibly because the friction number with the smooth tire is much lower and the ribbed tire is the original standard tire for friction test, changing to the smooth tire would produce data that could not be compared with historical data. The smooth tire is recommended to be used by the INDOT network pavement inventory friction test program.

\subsection{Test Speeds}

The standard speed for pavement friction tests is $40 \mathrm{mph}(64 \mathrm{~km} / \mathrm{h})$ as recommended by ASTM E-274. However, INDOT Network pavement friction testing is conducted without traffic control in most cases. Because of the effect of traffic, it is very difficult for the operator to conduct friction tests at $40 \mathrm{mph}$, especially when the post speed is high and traffic volume is large. In order to assure safe operation, the operator needs to adjust the test speed in light of the traffic conditions. As shown in the preceding chapters, pavement friction measurements may vary with the test speed. Therefore, it is recommended to convert all friction measurements taken at other test speeds to those taken at $40 \mathrm{mph}$ so as to make the friction measurements comparable and useful. To fulfill this, it requires establishment of correlations between friction measurements taken at different test speeds, i.e., the speed gradient curves introduced in ASTM E-274.

Great attention should be given to friction data conversion in light of the test speed. There is no a unique speed correlation equation. To illustrate this, friction measurements were taken at various test speeds over the three surfaces in the friction test track and the speed gradient curves were established as shown in Figure 5.9. Three observations can be made through careful inspection of Figure 5.9. First, as the test speed increases from $15 \mathrm{mph}(24 \mathrm{~km} / \mathrm{h})$ to $40 \mathrm{mph}(64$ $\mathrm{km} / \mathrm{h}$ ) the friction measurement decreases. When the test speed approaches $40 \mathrm{mph}$, the decreasing rate of friction slows down and the friction number decreases gradually. Next, the speed correlations for the three different surfaces differ from each other. The third observation is that the speed gradient curves with the smooth tire are different from those with the ribbed tire. 

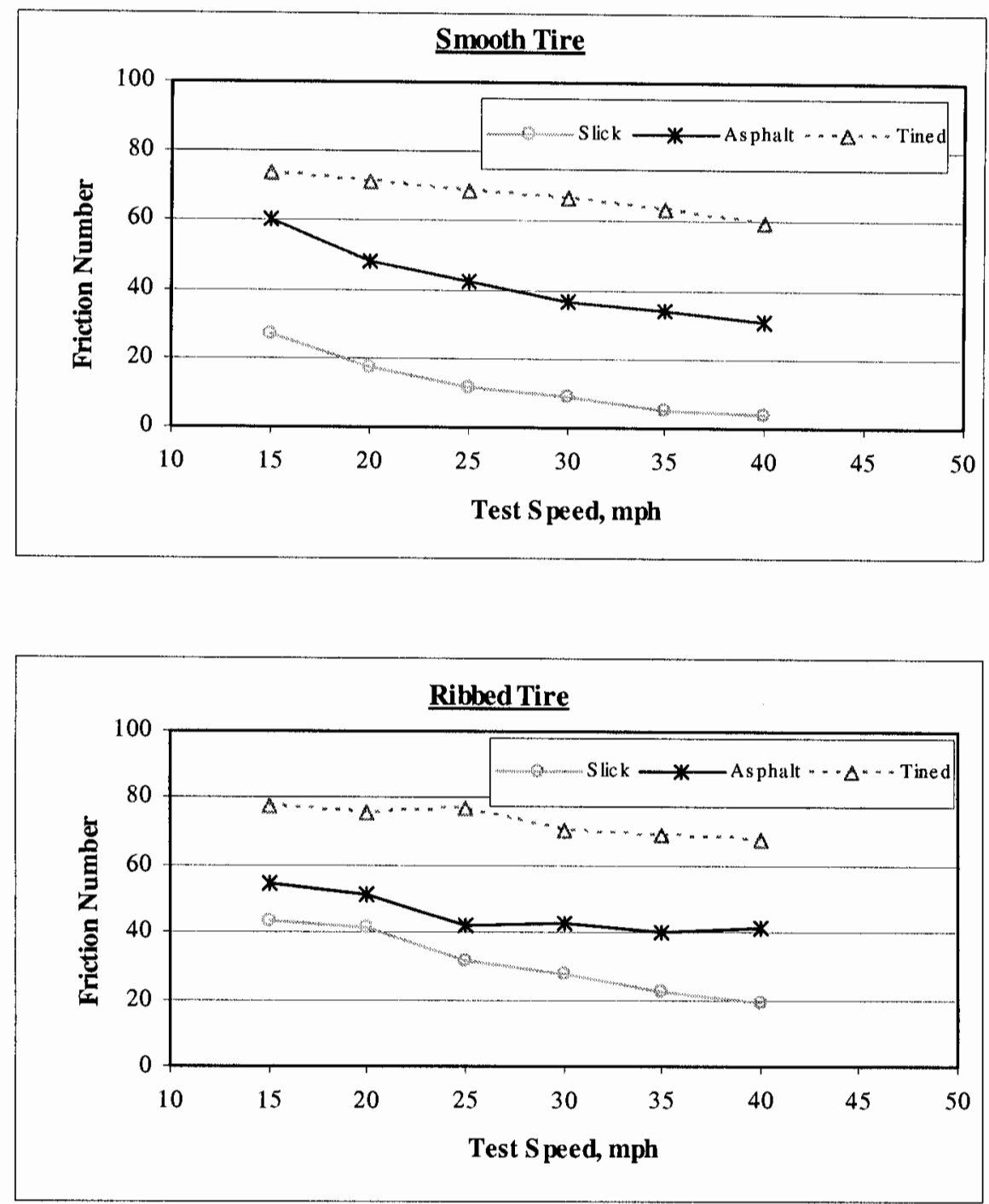

Figure 5.9 Speed Gradients with Smooth and Ribbed Tires on Different Surfaces

Therefore, the speed gradients vary with pavement surface features and test tires. In order to provide sufficient accuracies for friction data conversion in light of the test speed, it is required to establish speed gradients to cover all possible surface features. This is not practical. Pavement surface features vary from time to time and location to location. It is very difficult to include all potential surface features. In addition, if friction tests are conducted at various test speeds, it is costly and laborious to create the many speed gradients in light of surface features and speeds. As an attempt to make a compromise between the accuracy and incurred cost, three test speeds such as $30 \mathrm{mph}, 40 \mathrm{mph}$, and $50 \mathrm{mph}$ were selected for the INDOT network pavement inventory friction test program. Before each friction test season, three pavement 


\section{Chapter 6}

\section{NETWORK PAVEMENT FRICTION DATA MANAGEMENT}

Friction data management consists of data processing, reporting, distribution, and query. Data processing is to examine friction data so as to identify possible errors involved in the data. Data reporting includes low friction number reporting and annual friction data reporting. The low friction number reporting is to report all locations with friction numbers lower than the friction flag value to the individual districts which are responsible for further field investigation and action. The annual friction data reporting is to report all related friction data to the individual districts. Data query is to access, display and analyze friction history data by users.

\subsection{Friction Requirements}

\section{The Friction Flag Value}

The INDOT network pavement inventory friction testing program requires that all low friction numbers together with their locations be reported to the individual districts for further actions within one week after testing. The friction numbers less than the friction flag value are considered to be low friction numbers. The so-called friction flag value is a friction requirement which requires site investigation to further verify pavement surface friction. It is well-known that determination of the friction requirement should consider its impact on wet-pavement accidents and agency's budgets. On the one hand, a greater friction requirement may result in greater network pavement friction and less skidding accidents. On the other hand, as the friction requirement increases, more pavements may not meet the requirement. As a result, more pavements may need resurfacing treatment.

There are no direct approaches to correlate pavement friction and wet-pavement accidents and to correlate pavement friction and pavement resurfacing cost. Currently, there is no national standard or specification available to address this issue either. However, effort has been 
made to establish pavement friction requirements by many investigators $(18,29,30-32,43)$. For example, Kummer and Meyer (18) examined the normal frictional needs of traffic as derived from driver behavior studies. They recommended a friction number of 37 as the tentative minimum requirement for pavement friction on main rural highways. This requirement is determined with the standard ribbed tire at $40 \mathrm{mph}$ and has been widely used by many highway agencies in establishing their friction requirements. This tentative friction requirement was also utilized by INDOT in determining the friction requirement, i.e., the friction flag value. It is necessary to adjust the friction requirement by taking into account the natural differences between the smooth and ribbed tires because INDOT uses the smooth tire in the network pavement inventory friction testing,

As demonstrated in Chapter 5, pavement friction measured with the smooth tire is less than that measured with the ribbed tire and the differences depend on the pavement surface features as summarized in Table 6.1. On the tined concrete surface in the test track, the friction numbers measured with the smooth tire are close to those with the ribbed tire. In reality, the friction on tined concrete pavement surface is very high (usually $>60$ ). Even in rainy seasons, the tined pavement surface provides grooves for water flow and the wet-pavement friction on the tined surface is not an issue in comparison with other pavement surfaces. The pavement friction on the slick concrete surface is similar to the asphalt pavement surfaces with sever rutting and the concrete pavement surfaces experiencing sever polishing. Those pavements are more likely to experience wet-pavement skidding accidents and deserve great attention. In addition, the network pavements also reflect the real pavement friction conditions.

Table 6.1 Summary of Friction Differences between Ribbed and Smooth Tires

\begin{tabular}{|c|c|c|c|c|}
\hline \multicolumn{2}{|c|}{ INDOT Friction Test Track } & \multicolumn{2}{c|}{ Network Pavements } \\
\hline $\begin{array}{c}\text { Slick } \\
\text { Concrete }\end{array}$ & Asphalt & $\begin{array}{c}\text { Tined } \\
\text { Concrete }\end{array}$ & Interstates & $\begin{array}{c}\text { State \& US } \\
\text { Roads }\end{array}$ \\
\hline 17 & 12 & 0 & 23 & 20 \\
\hline
\end{tabular}

Thus, the result measured on the tined concrete surface was not used in determining the differences between the ribbed and smooth tires. The average friction difference for slick concrete surface, asphalt surface and network pavements is 18 . Subtracting 18 from the tentative 
friction requirement of 37 with the ribbed tire yield a friction requirement of 19 with the smooth tire. A friction number of 20 is therefore recommended as the friction flag value for INDOT network pavement inventory friction testing program. It is widely accepted that high-speed highways may require greater friction numbers. Divided highways such as interstates and multilane rural highways usually have higher posted speeds than those on two-lane highways. However, two-lane highways tend to experiences severer skidding accidents than divided highways $(29,30)$ and also require greater friction numbers. Therefore, the friction flag value of 20 applies to all INDOT highways.

\section{Effect of Friction Requirement on Pavement Maintenance and Resurfacing}

A greater friction requirement will result in better network pavement friction performance but cost more resources. INDOT pavement friction testing program requires that all friction numbers less than the friction flag value of 20 should be reported together with their locations to individual districts for further actions such as field visit to double-check the pavement conditions and resurfacing if necessary. It is apparent that the friction requirement has an impact on pavement maintenance and resurfacing activities. The greater the flag value, the more the resultant pavement maintenance and resurfacing work. In return, pavement maintenance and resurfacing activities may have an impact on network pavement friction performance. Therefore, it is of significance to balance the needs of pavement friction and the resources available.

A complete analysis of economic impact of friction requirement includes estimates of all benefits and costs due to a specific friction requirement, such as agency costs and benefits from reduction of wet-pavement accidents. Unfortunately, no accurate cost and benefit data are currently available associated with pavement friction. One of the main reasons is that it is very difficult to distinguish between pavement friction and other causes which might have caused skidding accidents. In addition, pavement maintenance and resurfacing activities are usually determined on the basis of overall pavement performance which is a result of combined effect of pavement structural capacity, roughness, and friction. It is very hard to differentiate the costs unless the project is solely to restore pavement friction. In order to provide an estimate of possible economic impact associated with pavement friction requirement, this study focused on 
the potential network pavement maintenance and resurfacing which might have been caused due to different friction requirements as follows:

- It is first assumed that any pavements with friction measurements less than the minimum friction requirement are defined as friction-failed pavements and all frictionfailed pavements require immediate and appropriate treatments such as resurfacing.

- Next, a minimum friction requirement is assumed and all friction-failed pavements in the whole network can be filtered out using the assumed friction requirement. The percentage of the friction-failed pavements can then be computed.

- Applying different minimum friction requirements generates various percentages of the friction-failed pavements. Those percentages reflect the amount of pavement maintenance and resurfacing work incurred due to different friction requirements.

Figure 6.1 shows the computed percentages of friction-failed pavements together with the corresponding friction requirements. In 2000, for example, a minimum friction requirement of 25 will generate approximately $7.6 \%$ of the network pavements which may require maintenance or resurfacing so as to restore the pavement friction. It is demonstrated that in general, the percentage of friction-failed pavements increases as the minimum friction requirement increases. Careful inspection of these curves further generates an interesting observation. When the friction requirement is less than 20 22.5, the curves vary slowly and smoothly. When the friction requirement exceeds 20 22.5, the curves grow more rapidly, especially the four curves for 1996, 1997, 1998, and 2002. However, the percentages of the friction-failed pavements for 1999, 2000, and 2001 are much less than those for the other years. One possible reason is that a lot of new construction and overlay projects were completed during this particular period. As a result, the pavement friction conditions were significantly improved (see Figure 4.16).

The above observations imply that a minimum friction requirement greater than $20 \sim 22.5$ may result in a dramatic increase in the friction-failed pavements and therefore, may incur significant increase in pavement maintenance and resurfacing. When the minimum friction requirement is less than 20 22.5, an increase in the friction requirement has no significant impact on the pavement maintenance and resurfacing. For example, if the minimum friction 
requirement is increased from 22.5 to 25 , the pavement maintenance and resurfacing will experience an additional increase of $6 \%$ of the total network pavements. If the friction requirement increases form 17.5 to 20 , the additional increase is about $3 \%$. It can be concluded that a minimum friction requirement of 20 with the smooth tire is economically reasonable for the INDOT network pavement inventory friction test program.

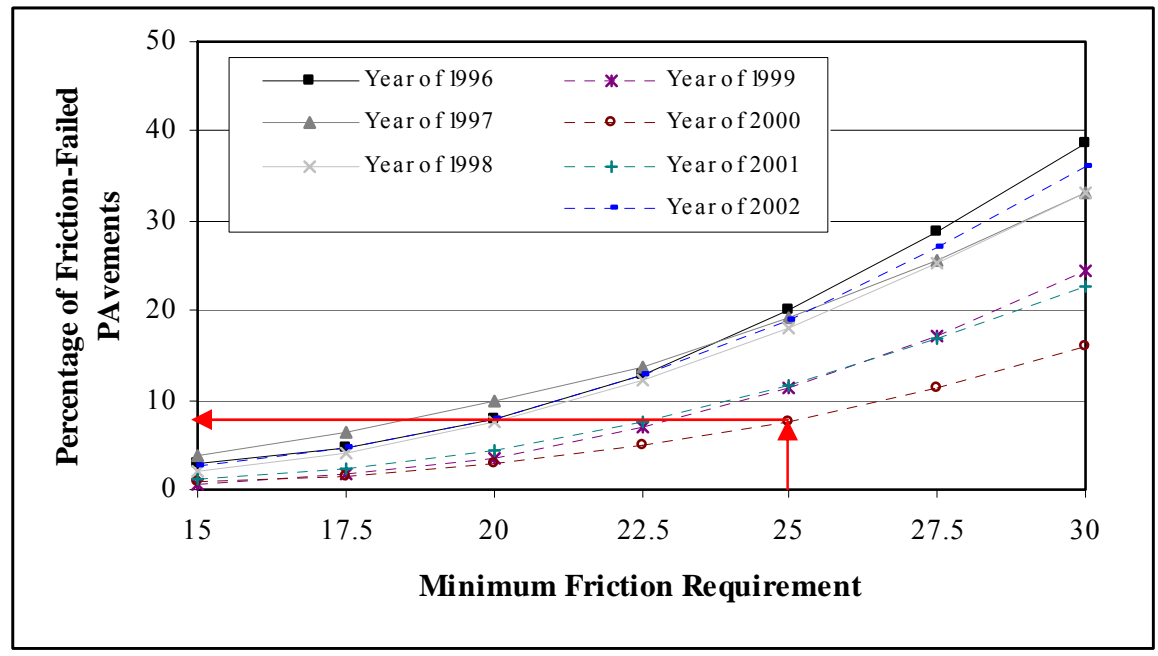

Figure 6.1 Friction-Failed Pavements vs. Minimum Friction Requirement

\section{Impact of Pavement Friction on Wet-Pavement Accidents}

It has been widely accepted that great pavement friction may enhance wet weather travel safety. As friction requirement increases, wet-pavement skidding accidents may decrease. In order to evaluate the impact of pavement friction on wet-pavement skidding accidents, this study analyzed the Indiana wet-pavement accident data in the FARS database developed by the National Highway Traffic Safety Administration (NHTSA) (14). However, it should be noted that a very high friction requirement does not necessarily result in zero accident. In many cases, wet-pavement skidding accidents are results of combined effect of human, vehicle, and pavement factors. Because of the difficulties to distinguish between these factors, the accident data was used in the analysis in light of only one criterion, i.e., wet or dry pavement. A parameter, wetpavement accident rate, was employed to study the correlation between wet-pavement accidents and network pavement friction conditions. The wet-pavement accident rate refers to the ratio of the number of wet-pavement accidents to the number of accidents on both dry and wet pavements and has already been used to evaluate wet-pavement accidents (42). 
It should be highlighted that in the FARS database, the pavement surface conditions are divided into seven categories such as dry, wet, snow/slush, ice, sand (dirt, oil), other and unknown. Since snow and ice are different issues, only accidents in the dry and wet surface conditions are used since the surface conditions. Figure 6.2 shows the wet-pavement accident rates for Indiana and all states during the period of 1996 through 2002, respectively. The wetpavement accident rates are further categorized into two groups so as to distinguish between interstates and State and US roads. It is demonstrated that on the national level, the variations of the wet-pavement accident rates for interstates are similar to those for the State and US roads. The wet-pavement accident rates on State and US roads in Indiana are different from those in the whole country, and are higher than those on interstates in Indiana.

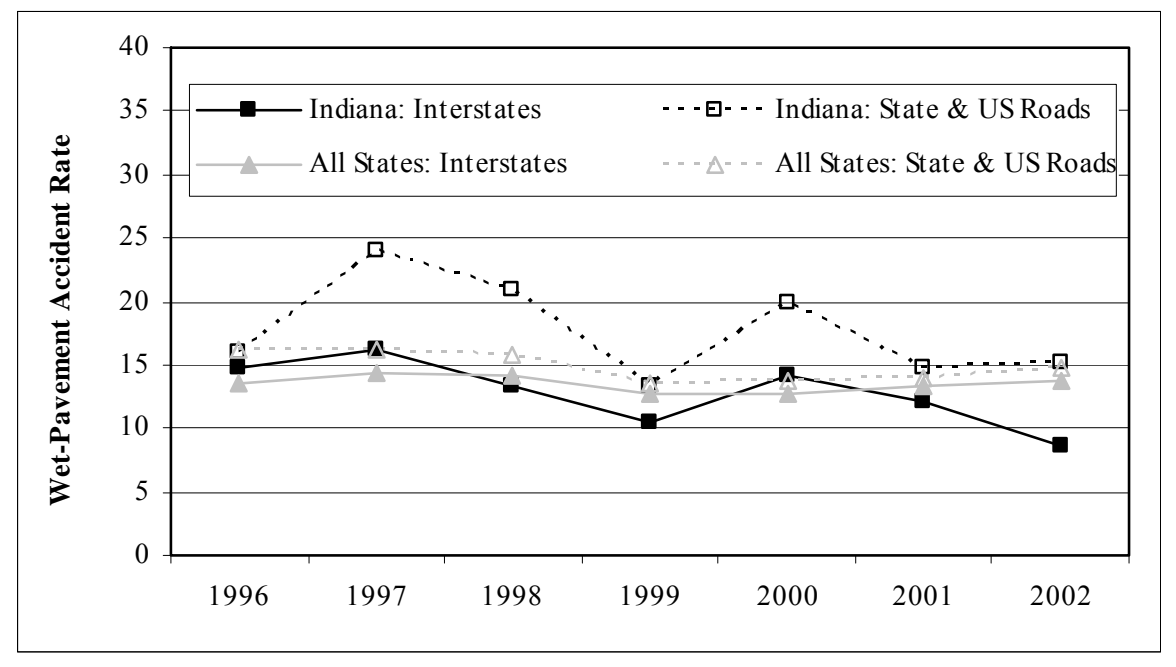

Figure 6.2 Wet-Pavement Accidents

In order to present the effect of the pavement friction on the wet-pavement accidents, Figure 6.3 shows the network pavement frictions and the corresponding wet-pavement accident rates in Indiana. It is shown that no consistent trend can be observed on interstates and on State and US roads. Statistics analysis was also performed to investigate the correlation between wetpavement accident rates and network pavement frictions. The R-squared value is extremely low and the correlation between the wet-pavement accident rates and the network pavement frictions is very poor. On possible reason is that as mentioned earlier, the wet-pavement accidents are results of many factors. The causes of those wet-pavement accidents are not specific in the database. However, this study attributed all wet-pavement accidents solely to pavement friction. 
As a result, no good correlations between the wet-pavement accidents and network pavement frictions could be identified.

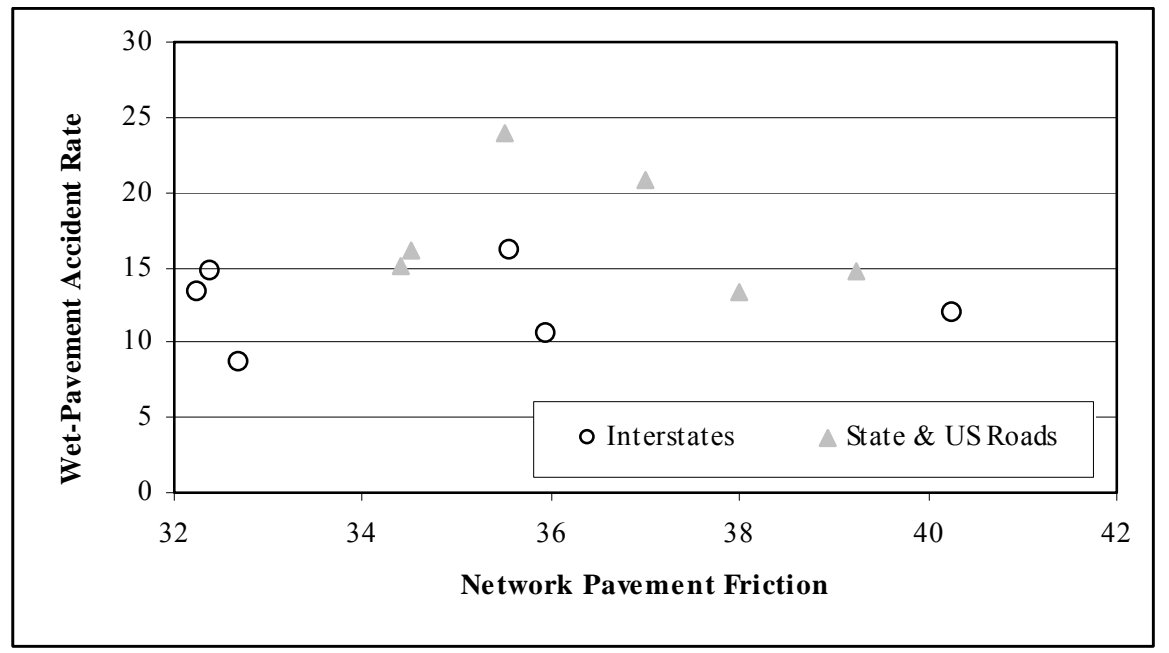

Figure 6.3 Correlations between Network Wet-Pavement Accidents and Pavement Frictions

\subsection{Friction Data Reporting}

Friction data reporting includes low friction reporting and annual network pavement friction reporting. The low friction reporting is to immediately report all friction numbers lower than the minimum friction requirement, 20 at $40 \mathrm{mph}$, and the corresponding locations to individual districts which are responsible for further field investigation and action. The annual network pavement friction is to report all necessary friction data to the Division of Program Development and individual districts so as to provide a full picture of pavement friction conditions for planning pavement maintenance and resurfacing activities. The low friction reporting is required be completed within one week after testing. The annual network pavement friction reporting is completed in the end of each year. All data must be processed in accordance with ASTM E-274 and converted into those at $40 \mathrm{mph}$.

The low friction reporting consists of a summary of low friction numbers and other important road information. The road information covers road name, direction, test lane, and reference post so as to allow individual districts to easily identify the locations for field 
investigation. The low friction reporting also provides other information such district, city, and test date. Table 6.2 is an illustration of the low friction reporting table. The annual network pavement friction reporting consists of two reports, Summary of Inventory Friction Test and Inventory Friction Test Report for each individual district. Table 6.3 shows an illustration of the Summary of Inventory Friction Test which summarizes the average friction number, standard deviation, and number of tests for each tested road. It also provides the total number of friction measurements lower than 20 on each road. The Inventory Friction Test Report provides all individual test results and a plot of friction number-reference post on each tested road. This provides not only the detailed pavement friction conditions, but also a simple visualization of the pavement friction conditions on each road as shown in Table 6.4.

Table 6.2 Illustration of Low Friction Report

\begin{tabular}{|c|c|c|c|c|c|c|c|}
\hline Road & Direction & Lane & $\mathrm{RP}$ & District & City Name & Date & FNS@40 \\
\hline SR-227 & South & Driving & 13.92 & Greenfield & Wayne & 16-Jul-02 & 16.5 \\
\hline SR-227 & South & Driving & 14.65 & Greenfield & Wayne & 16-Jul-02 & 8.7 \\
\hline SR-227 & South & Driving & 15.02 & Greenfield & Wayne & 16-Jul-02 & 15.5 \\
\hline SR-227 & South & Driving & 15.92 & Greenfield & Wayne & 16-Jul-02 & 16.5 \\
\hline SR-227 & South & Driving & 20.92 & Greenfield & Wayne & 16-Jul-02 & 19.5 \\
\hline SR-227 & South & Driving & 29.97 & Greenfield & Randolph & 16-Jul-02 & 17.6 \\
\hline SR-227 & South & Driving & 32.88 & Greenfield & Randolph & 16-Jul-02 & 16.9 \\
\hline SR-32 & East & Driving & 74.06 & Greenfield & Hamilton & 15-Jul-02 & 11.4 \\
\hline SR-32 & East & Driving & 75.05 & Greenfield & Hamilton & 15-Jul-02 & 19.3 \\
\hline SR-32 & East & Driving & 73.07 & Greenfield & Hamilton & 15-Jul-02 & 14.6 \\
\hline SR-32 & East & Driving & 77.11 & Greenfield & Hamilton & 15-Jul-02 & 12.5 \\
\hline SR-44 & West & Driving & 32.94 & Greenfield & Shelby & 16-Jul-02 & 16.7 \\
\hline SR-44 & West & Driving & 56.95 & Greenfield & Rush & 16-Jul-02 & 12.2 \\
\hline SR-44 & West & Driving & 65.87 & Greenfield & Fayette & 16-Jul-02 & 12 \\
\hline SR-44 & West & Driving & 68.42 & Greenfield & Fayette & 16-Jul-02 & 12.2 \\
\hline US-35 & South & Driving & 7.97 & Greenfield & Wayne & 15-Jul-02 & 12.7 \\
\hline US-35 & South & Driving & 38.97 & Greenfield & Delaware & 15-Jul-02 & 19.8 \\
\hline
\end{tabular}


Table 6.3 Illustration of Summary of Inventory Friction Test for Individual Districts

\begin{tabular}{|c|c|c|c|c|c|}
\hline Test Section & $\mathbf{R P}$ & $\begin{array}{l}\# \text { of } \\
\text { Test }\end{array}$ & $\#$ of $\mathbf{F N}<\mathbf{2 0}$ & Average FN & Standard Dev. \\
\hline I-164East & From 0.1 To 20.08 & 21 & 0 & 37.1 & 6.8 \\
\hline I-164West & From 0.9 To 20.36 & 21 & 0 & 40.3 & 5.6 \\
\hline I-64East & From 0.3 To 91.03 & 84 & 8 & 31 & 8.1 \\
\hline I-64West & From 0.8 To 90.67 & 92 & 1 & 34.1 & 9.8 \\
\hline SR-145North & From 0.1 To 45.06 & 42 & 1 & 32.1 & 6.9 \\
\hline SR-154West & From 0.9 To 13.12 & 15 & 7 & 20.3 & 6.2 \\
\hline SR-166East & From 0.1 To 6.1 & 8 & 2 & 26.7 & 13.4 \\
\hline SR-237North & From 0.0 To 5 & 6 & 3 & 23.6 & 7.2 \\
\hline SR-364East & From 0.0 To 3.04 & 6 & 0 & 33.2 & 4.9 \\
\hline SR-43North & From 0.2 To 12.03 & 14 & 0 & 31.2 & 4 \\
\hline SR-43South & From 0.9 To 11.88 & 13 & 0 & 44.2 & 6.7 \\
\hline SR-445East & From 0.0 To 1.04 & 3 & 0 & 50 & 5.2 \\
\hline SR-458North & From 0.0 To 0.07 & 1 & 0 & 38.6 & 6.5 \\
\hline SR-45North & From 0.1 To 5.05 & 7 & 1 & 33.4 & 8.7 \\
\hline SR-45South & From 5.8 To 22.97 & 14 & 0 & 30.6 & 4.9 \\
\hline SR-48East & From 0.1 To 29.12 & 31 & 3 & 34.3 & 11.1 \\
\hline SR-54West & From 0.9 To 55.12 & 54 & 6 & 31.9 & 10.8 \\
\hline SR-58East & From 0.0 To 88.06 & 73 & 0 & 37.9 & 6.1 \\
\hline SR-61South & From 0.8 To 64.46 & 67 & 20 & 23 & 7.7 \\
\hline SR-63South & From 0.0 To 15.92 & 17 & 0 & 34.8 & 3.8 \\
\hline SR-650East & From 0.0 To 0.97 & 3 & 1 & 22.3 & 2.2 \\
\hline SR-66East & From 0.1 To 121.0 & 123 & 21 & 29.7 & 9.9 \\
\hline SR-66North & From 129 To 152.1 & 22 & 0 & 34.6 & 4.8 \\
\hline SR-69North & From 0.1 To 25.13 & 25 & 6 & 27.2 & 11 \\
\hline US-150West & From 112 To 147.9 & 38 & 0 & 33.5 & 6 \\
\hline US-50East & From 43. To 76.05 & 38 & 7 & 28.8 & 7.6 \\
\hline
\end{tabular}


Table 6.4 Illustration of Inventory Friction Test Report for Individual Districts

\begin{tabular}{|c|c|c|c|c|c|c|c|}
\hline Date & $\underline{\text { Road }}$ & Dir & Lane & $\underline{\text { County }}$ & $\underline{\text { RP }}$ & $\underline{\text { FN40good }}$ & FN40bad \\
\hline $7 / 9 / 2002$ & I-90 & East & Driving & Lake & .6 & 29 & \\
\hline $7 / 9 / 2002$ & I-90 & East & Driving & Lake & 1.3 & 27.6 & \\
\hline $6 / 18 / 2002$ & I-90 & East & Driving & Lake & 1.4 & & 18.1 \\
\hline $6 / 18 / 2002$ & I-90 & East & Driving & Lake & 2. & 34.1 & \\
\hline $7 / 9 / 2002$ & I-90 & East & Driving & Lake & 2.1 & 53 & \\
\hline $6 / 18 / 2002$ & I-90 & East & Driving & Lake & 3. & 21 & \\
\hline $7 / 9 / 2002$ & I-90 & East & Driving & Lake & 4. & 29.5 & \\
\hline $6 / 18 / 2002$ & I-90 & East & Driving & Lake & 4. & 24.8 & \\
\hline $7 / 9 / 2002$ & I-90 & East & Driving & Lake & 5. & 46.4 & \\
\hline $6 / 18 / 2002$ & I-90 & East & Driving & Lake & 5.1 & 35 & \\
\hline $6 / 18 / 2002$ & I-90 & East & Driving & Lake & 6. & 35.9 & \\
\hline $7 / 9 / 2002$ & I-90 & East & Driving & Lake & 6.2 & 37.6 & \\
\hline $7 / 9 / 2002$ & I-90 & East & Driving & Lake & 7.1 & 53.6 & \\
\hline $6 / 18 / 2002$ & I-90 & East & Driving & Lake & 7.1 & 40.8 & \\
\hline $6 / 18 / 2002$ & I-90 & East & Driving & Lake & 8. & 38.8 & \\
\hline $7 / 9 / 2002$ & I-90 & East & Driving & Lake & 8.1 & 41.2 & \\
\hline $7 / 9 / 2002$ & I-90 & East & Driving & Lake & 9. & 48.2 & \\
\hline $6 / 18 / 2002$ & I-90 & East & Driving & Lake & 9.3 & 33.7 & \\
\hline $6 / 18 / 2002$ & I-90 & East & Driving & Lake & 10. & 35 & \\
\hline $7 / 9 / 2002$ & I-90 & East & Driving & Lake & 10.1 & 26.8 & \\
\hline $7 / 9 / 2002$ & I-90 & East & Driving & Lake & 11.1 & 27.2 & \\
\hline $6 / 18 / 2002$ & I-90 & East & Driving & Lake & 11.1 & 34.9 & \\
\hline $7 / 9 / 2002$ & I-90 & East & Driving & Lake & 12. & 32.7 & \\
\hline $6 / 18 / 2002$ & I-90 & East & Driving & Lake & 12.1 & 38.6 & \\
\hline $6 / 18 / 2002$ & I-90 & East & Driving & Lake & 13. & 28.8 & \\
\hline
\end{tabular}

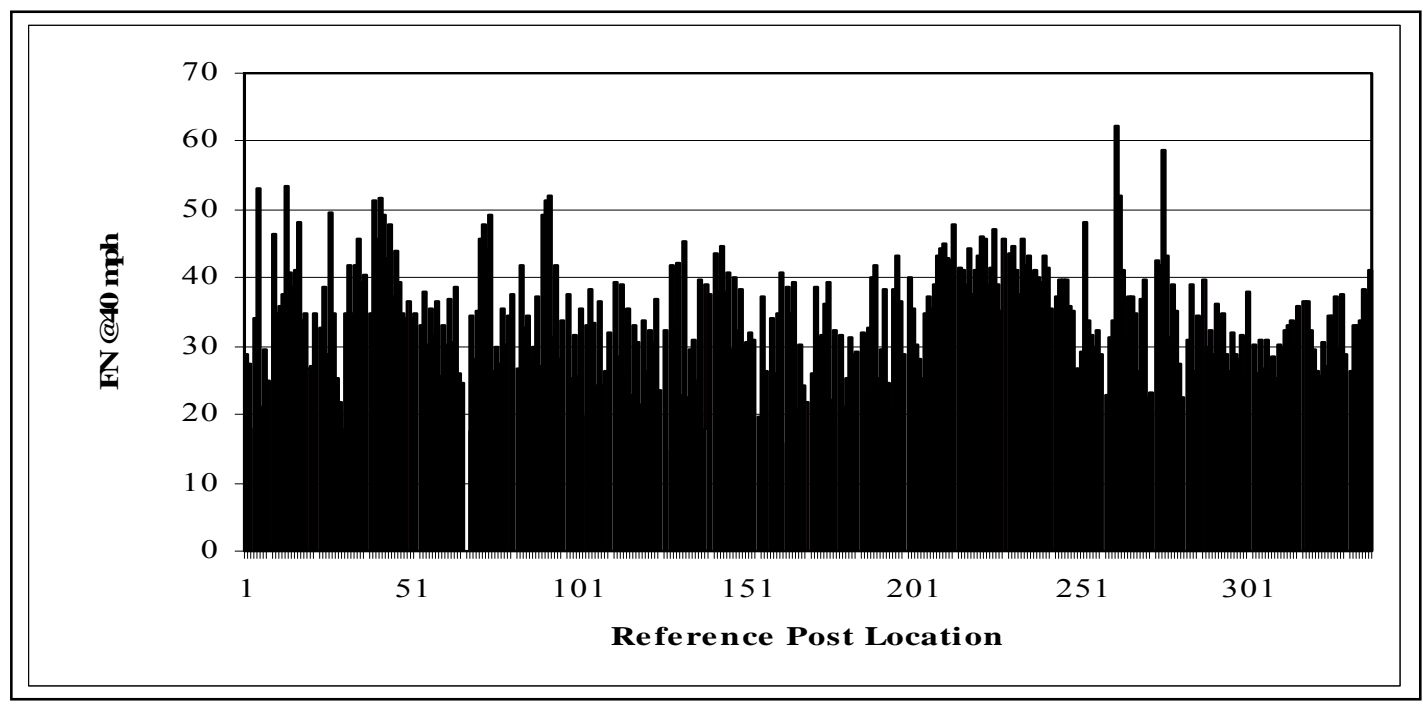




\subsection{Friction Data Distribution and Query}

INDOT has been conducting annual pavement friction testing for approximately 6500 to 7000 lane-miles on the Indiana highway network each year. The large amount of data presents a challenge for efficient and effective data management. In the past many years, INDOT inventory pavement friction data was distributed in the form of written reports and computer disks containing Microsoft Access database files. Information retrieval was inconvenient. Timely data distribution could not be guaranteed. The users needed to search through the written report or execute a query within the Microsoft Access program to find out the desired information. Therefore, finding information was a cumbersome and time-consuming task. In addition, dealing with Microsoft Access data requires working knowledge of the Microsoft Access program and an understanding of the database structure.

A research study was completed to utilize geographic information system (GIS) technology as a tool for INDOT friction data management (44). A computer program was developed to integrate the friction database, a graphic user interface, network, and the GIS technology for friction data distribution and query. All friction data are consolidated into one single database, allowing users to retrieve and make comparisons with historical data. The graphic user interface (GUI) provides an easy and intuitive way for users to retrieve and analyze data from the database. The GIS technology was utilized in the form of an embedded map in the graphic user interface. The map component provides a powerful tool for data presentation and analysis, by revealing patterns that can not be easily identified with other methods. Network technology was utilized to provide real-time distribution of the friction data.

The primary users of the computer program, as shown in Figure 6.4, will be INDOT districts and Program Development Division. However, the program was designed in such a way that virtually anyone is capable of using it with minimal training. No previous knowledge of database, GIS, or computer programming is necessary for a user to run the program. The computer program can be installed on a user's computer from a shared drive in the INDOT wide area network. Installation $\mathrm{CD}$ is also available if needed. Once the program is installed, the 
friction data are automatically updated every time a user runs the program. No user intervention is necessary for data updates.

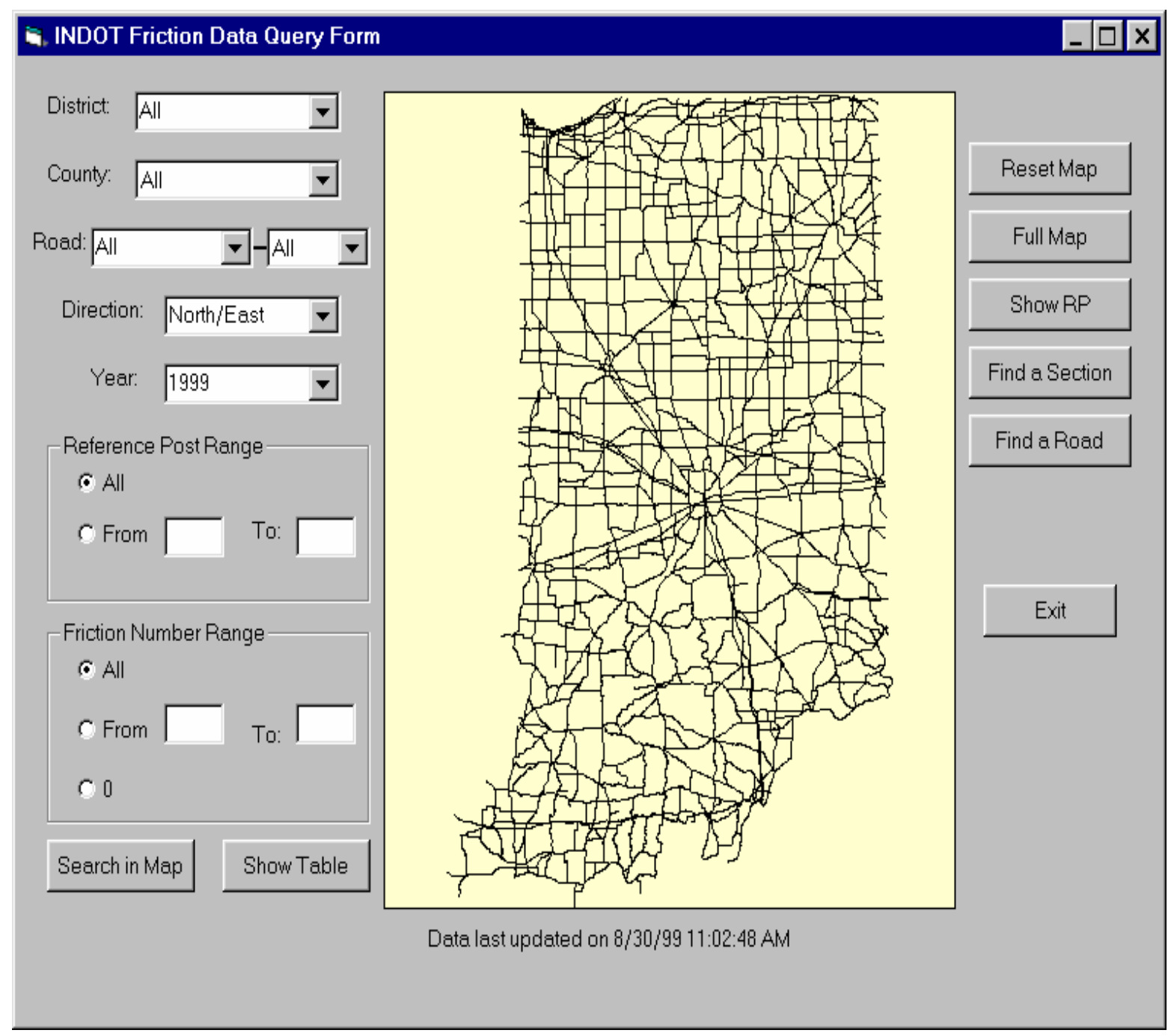

Figure 6.4 INDOT Network Pavement Inventory Friction Data Query Program 


\section{Chapter 7}

\section{FINDINGS AND RECOMMENDATIONS}

\subsection{Findings}

This study conducted literature review to examine the latest technologies and progress associated with pavement friction testing and evaluation. This study reviewed other DOTs' friction testing programs including calibration, testing, and friction requirements. This study also reviewed the relevant standards, specification, and other documents published by FHWA, ASTM, AASHTO, TRB, ASCE, SAE, and PIARC for guiding pavement friction testing and evaluation. The locked wheel trailer is currently the most popular test device used by highway agencies in pavement inventory friction testing. The primary purposes for pavement friction testing are pavement inventory, implementation of friction requirements for new construction, and accident investigation. While there is no specification or standard currently available for determining the minimum friction requirement, many highway agencies established their friction requirements based on the recommendation by NCHRP Report-37.

Researchers in Pennsylvania State University have developed many models to evaluate pavement friction. It has been accepted that pavement friction force arises at the interface due to the interaction between the rolling tire and the contacting surface and are mainly consist of two components: adhesion force and hysteresis force. The dynamic nature of the friction of rubber is considered to be a molecular-kinetic thermal process due to the thermal motion of molecular chains against the contacting surface. This study utilized 3-D FEM program, ABAQUS/Explicit, to investigate the fundamental friction phenomenon in light of energy dissipation during friction process. It was shown that pavement friction is the result of tire-pavement interaction process and depends on many factors such as test tire, test speed, surrounding conditions, pavement surface texture, and pavement type. 
A great amount of friction data has been collected on both the INDOT friction test track and network pavements so as to investigate variations involved in pavement friction measurements and their effects on friction testing and data processing. This study investigated the frictional variations due to testing system errors. It was found that the system variations depend on the characteristics of pavement surface. As pavement surface texture scale increases, the coefficient of variations in friction decreases. The standard deviations due to system errors are usually less than 5.0. The smooth tire tends to provide greater variations than the ribbed tire since the smooth tire is more sensitive to the surface texture than the ribbed tire.

This study also investigated the effects of test seasons or air temperature on pavement friction testing. It was found that as the air temperature increases, the friction number does not necessarily decrease. Also, no consistent trends could be identified to establish relationship between friction measurements and test seasons. While the friction measurements on asphalt pavements are more sensitive to the air temperature than those on concrete pavements, the seasonal friction variations are negligible on both types of pavements. The statistical $t$-test results confirmed these observations. However, this does not necessarily contradict the fundamentals of rubber tire friction phenomenon, i.e., the temperature-dependency of rubber friction. Test temperature refers to the tire and pavement temperatures, rather than the air temperature. The tire and pavement temperatures depend on many factors such as air temperature, solar radiation, and wind speed. In order to apply seasonal or temperature correction properly, pavement engineers need to measure the tire and pavement temperatures. This is not practical for network pavement inventory friction testing.

Pavement friction exhibits significant lateral variations in directions, lanes, and wheeltracks. Lateral variations are mainly caused by traffic pounding and polishing. Pavements in different directions may carry different traffic volumes, which results in different surface characterizations and directional friction variations. The largest directional variation is 16 with the smooth tire on a State road. The State and U.S. roads tend to produce greater directional variations than the interstates. Pavement friction measurements vary from lane to lane. The driving lane usually has lower friction than other lanes because traffic intends to use the driving lane. It was observed that on I-65, the friction variation between the passing and driving lane is 
about 5 in a section with three lanes in a single direction and increases to 10 in a section with two lanes in a single direction. A lane variation of 13 was observed in a section with two lanes in one direction on I-69. The greatest lateral variation may arise due to the effect of wheel track. In general, the pavement in a wheel track experiences more traffic pounding and polishing. The friction in the wheel track is usually much less than that outside the wheel track. The friction number in the wheel track is 16 less than that outside the wheel track in a section on SR-28.

Pavement friction also varies longitudinally with traffic distribution, pavement type, and surrounding conditions. It was found that all pavements have experienced significant longitudinal variations regardless of highway classifications. However, the friction measurements are very consistent in one-mile uniform section, especially in asphalt pavement. It was also found that the friction measurements measured at 1.0-mile spacing are very close to those measured at 0.5 -mile spacing in terms of average and standard deviation. The longitudinal friction variations are very similar in both directions.

Pavement friction varies from time to time because of the traffic applications, periodic changes of surrounding environment, and deterioration of pavement materials. For new HMA pavement, the initial pavement friction is quite low probably because of the effect of asphalt binder. It then increases within the first 2-3 years, and then decreases. For new concrete pavement, the friction number drops significantly in the second year probably because of the effect of polishing by traffic. In general, old pavement friction decreases with increased traffic applications. Rutting will further decrease pavement friction. It was observed that the frictional variations with time on interstates follow a trend similar to that on US and State roads. However, pavement frictions on interstates may decrease faster than those on US and State roads. On the network level, the largest annual friction decrease is approximately 7.0 on interstates, but does not exceed 4.0 on US and State roads.

A British Pendulum Tester was purchased in order to provide reference friction numbers in the friction test track. This can enhance the testing system calibration. System calibration plays an important role in pavement friction testing. The force transducers are calibrated every month and the whole system performance is verified on the test track every week so as to identify 
potential significant performance changes. A minimum of three tests must be conducted for system calibration. In general, three to five test runs are recommended for the system performance verification test.

Ribbed tire is not sensitive to pavement surface macrotexture but are dominated by the microtexture. It is required to measure the macrotexture while measuring friction with the ribbed tire. Friction tests with the smooth tire are sensitive to both microtexture and macrotexture. In addition, a good correspondence between low smooth-tire skid numbers and accident experience was identified by some investigators. This study investigated the differences between the standard smooth and ribbed tires. It was found that the primary difference arise from the horizontal force. In general, the friction number measured with the ribbed tire is greater than that measured with the smooth tire. However, the differences decrease as the surface texture becomes rougher. On the slick concrete surface, the friction number with the ribbed tire is approximately 17 greater than that with the smooth. The friction number with the ribbed tire is 12 greater than that with the smooth on the asphalt surface. On the tined concrete surface, the differences became negligible. On the network highway pavements, the average friction with the ribbed tire is approximately 23 greater than that with the smooth tire on interstates and is 20 on US and State roads, respectively.

Pavement friction measurements vary with test speed. Pavement friction test using the locked wheel trailer is usually conducted without traffic control. In order to assure safe operation, the operator needs to adjust the test speed in light of the real traffic conditions. Therefore, it is very difficult to conduct friction test at the standard test speed, $40 \mathrm{mph}$. This is especially true when the traffic speed is high and traffic volume is large. However, the correlations between test speed and friction measurements also vary with surface features. If friction tests are conducted at many different speeds, it is necessary to conduct a great number of tests so as to develop speed gradients to cover different surface features. In order to reduce the amount of work for developing speed gradients without scarifying operation safety, several speeds should be selected for inventory friction testing. 
Friction requirement is still an issue. It is well-known that determination of the minimum friction requirement should consider its impact on wet-pavement accidents and agency's budgets. On the one hand, a greater friction requirement may result in greater network pavement friction and less skidding accidents. On the other hand, as the friction requirement increases, more pavements may not meet the requirement and need some treatments to restore surface friction. NCHRP Report-37 recommended a friction number of 37 with the standard ribbed tire at $40 \mathrm{mph}$ as the minimum friction requirement. Taking into account the differences between the ribbed and smooth tires identified by this study, a friction number of 20 at $40 \mathrm{mph}$ is established as the

friction flag value for the network pavement inventory friction testing. It was found that this requirement is economically reasonable in light of the network pavement maintenance and resurfacing. Also, this requirement applies to interstates, State roads, and US roads. It should be pointed out that the friction flag value is a requirement for site investigation to verify pavement friction for further action. The friction flag value does not imply any correlation between pavement friction and wet-pavement accidents.

Friction data reporting is one of the important components for the network pavement inventory friction testing. INDOT network pavement inventory friction testing includes low friction reporting and annual network pavement friction reporting so as to provide accurate friction information for individual districts to take immediate action if necessary and provide a full picture of network pavement friction information for planning maintenance and resurfacing. INDOT has been conducting annual pavement friction testing for approximately 6,500 to 7,000 lane-miles on the Indiana highway network each year. A computer program developed using the GIS technology has been used for efficient friction data distribution and query. Network technology was utilized to provide real-time updating and distribution of the friction data.

\subsection{Recommendations}

\section{Recommendations for Implementation}

The blocked wheel friction testing with the ASTM E-274 trailer is still the best practice for network pavement inventory friction testing. With this practice, pavement friction testing can be undertaken at traffic speeds without traffic control. Therefore, it is safe and efficient for field 
operation. The smooth tire can provide more realistic results of pavement friction. Friction testing with the smooth tire depends not only on the pavement surface microtexture, but also the macrotexture. This study recommends the standard smooth tire for INDOT network pavement inventory friction testing. In addition, this study also recommends the smooth tire for both warranty project friction testing and special project friction testing.

In order to maintain the consistency of testing system so as to provide meaningful and comparable test results, the transducers should be calibrated frequently. It is recommended that the force transducers should be calibrated at least once a month. The whole testing system should be verified more frequently so as to identify potential performance changes. This study recommends that the whole testing system be verified at least once a week on the three surfaces in the INDOT friction test track, i.e., the slick concrete surface, asphalt surface and tined concrete surface, so as to evaluate the system performance on different surfaces. Three to five test runs are recommended for a single testing system on each surface. It is very important to note that the verification testing should be undertaken at the same spot on each surface. A BPT tester has been utilized to monitor the possible changes of surface characteristics of the friction test track.

The current network pavement inventory friction testing is conducted annually on all interstates, and every three years on all US and State roads. This study found out that these two testing periods can basically identify potential significant changes in pavement friction. It is not necessary to change the testing periods. Friction testing should be conducted in the wheel paths in the driving lanes in both directions. For special or warranty project, friction testing should be conducted at the standard speed, $40 \mathrm{mph}(64 \mathrm{~km} / \mathrm{h})$. Because of the safety concern, the inventory friction testing should be conducted at a speed in light of the real traffic conditions. Three speeds, 30, 40, and $50 \mathrm{mph}$, have been recommended for the network inventory friction testing. Before each friction test season, three pavement sections with three different friction conditions (friction number $\leq 20$, friction number $=30$ to 40 , and friction number $\geq 50$ ) should be selected to develop speed correlations between the selected test speeds. Also, the 1.0-mile test spacing can essentially provide realistic information on the network pavement friction condition. No seasonal correction is recommended for the network pavement inventory friction testing. 
The current friction flag value of 20 with the smooth tire at $40 \mathrm{mph}$ was established on the basis of NCHRP Report-37 and the differences between the smooth and ribbed tires. It appears that this requirement is reasonable for the network pavement inventory friction testing and can provide consistent network friction performance without incurring unanticipated increase in pavement maintenance and resurfacing activities. No correlation has been identified between the requirement and wet-pavement accidents based on the data stored in the FARS database created by the National Highway Traffic Safety Administration. The establishment of a friction flag value is also an effort to further enhance pavement friction performance.

The current INDOT friction testing and calibration documents should be standardized and upgraded accordingly. INDOT is one of the very few state highway agencies utilizing the standard smooth tire in network pavement inventory friction testing. The interest in the smooth tire has been growing in the past years. We are ready to share our experience and expertise with other state highway agencies.

\section{Recommendations for Further Research}

It is realized by the SAC members and investigators that the network inventory friction testing results have not yet been integrated into the INDOT PMS. The main reason is that the inventory friction testing on the US and State roads is conducted every three years, i.e., only one third of the US and State roads can be tested each year. Consequently, there is no timely and accurate friction information on two thirds of the US and State roads. Currently, it is not practical for the Program Development Division to use the network pavement friction data in INDOT PMS. Pavement distresses, ride quality, friction and structural capacity are key pavement condition items which should be considered by a PMS. There is a need to develop sound models that will enable the Program Development Division to evaluate and predict pavement friction realistically.

It was observed that pavement surface friction did not necessarily decrease with time possibly due to the variations of pavement surface texture. Pavement surface texture data is part of the data collected at the network level for PMS purposes. This is the data that has not been utilized due to the lack of models to correlate it to pavement friction or distress types (such as raveling, stripping or disintegration). It is needed to investigate the correlation between pavement surface friction and 
texture so as to allow the Program Development Division and districts to evaluate pavement friction performance from the surface texture data and inventory friction data.

No friction model has been fully verified. Friction results obtained with different testing devices are not fully exchangeable. The use of ABAQUS/Explicit program by this study is the first effort of its type to investigate tire-pavement friction interaction in the country. It is believed that the use of FEM simulation programs not only enable us to find food for thought, but also enable us to minimize laborious field experiment. Further effort is necessary for us to fully interpret and verify the simulation results. In addition, further evaluation of the friction-temperature trend is required. 


\section{References}

1. Indiana Pavement Friction Testing Program, Division of Research, Indiana Department of Transportation, 1995.

2. ASTM Designation E274-97, Standard Test Method for Skid Resistance of Paved Surfaces Using a Full-Scale Tire, Annual Book of ASTM Standards, Vol. 04. 03, 1997.

3. ASTM Designation E501-94, Standard Specification for Standard Rib Tire for Pavement SkidResistance Tests, Annual Book of ASTM Standards, Vol. 04. 03, 1994.

4. ASTM Designation E524-88 Standard Specification for Standard Smooth Tire for Pavement Skid-Resistance Tests, Annual Book of ASTM Standards, Vol. 04. 03, 1988.

5. John J. Henry, Evaluation of Pavement Friction Characteristics, NCHRP Synthesis 291, Transportation Research Board, National Research Council, 2000.

6. Ganung, G. A. and F. J. Kos, Wet Weather, High-Hazard Accident Locations: Identification and Evaluation, FHWA-CT-RD403-F-794, Connecticut Department of Transportation, Wethersfield, Connecticut, 1979.

7. Kummer, H. W., Unified Theory of Rubber and Tire Friction, Engineering Research Buletin B-94, The Pennsylvania State University, State College, 1966.

8. Leu M. C., and J. J. Henry, "Prediction of Skid Resistance as a function of Speed from Pavement Texture," TRR 946, Transportation Research Board, National Research Council, Washington D.C., 1983.

9. Rado Z. Analysis of Texture Profiles, PTI Report 9510, Pennsylvania Transportation Institute, State College Park, Pa., 1994.

10. The World Road Association, International PIARC Experiment to Compare and Harmonize Texture and Skid Resistance Measurements, PIARC Report 01.04.T, Paris, 1995.

11. Singer, I. L., "Friction and Energy Dissipation at the Atomic Scale: A Review," Journal of Vacuum Science and Technology, A 12(5), pp. 2605-2616, 1994.

12. ABAQUS Version 6.3 Release Notes, Hibbitt, Karlsson \& Sorensen, Inc., 2002.

13. Titus, G. I. and S.D. Tayabji, Assessemnt of LTPP Friction Data, FHWA-RD-99-037, Fedearl highway Administration, U.S. Department of Transportation, 1999.

14. Fatality Analysis Reporting System (FARS), http://www-fars.nhtsa.dot.gov/, National Highway Traffic Safety Administration, U.S. Department of Transportation. 
15. European Tire School, Module 6: Dynamic Mechanical Properties of Elastomers. http://www.tut.fi/plastics/tyreschool/, Accessed October 28, 2002.

16. French, I., Tire Technology, Ed. Adam Hilger, Bristol, 1989.

17. PIARC, Optimization of Pavement Surface Characteristics, PIARC Technical Committee on Surface Characteristics, Report to the XVIIIth World Road Congress, Brussels, Belgium, 1987.

18. Kummer, H. W., and W. E. Meyer, Tentative Skid-Resistance Requirements for main Rural Highways, NCHRP -37, Highway Research Board, National Research Council, 1967.

19. Bueche, F., Physicl Properties of Polymers, Interscience Publishers, New York, 1962.

20. John J. Henry, Evaluation of Pavement Friction Characteristics, NCHRP Synthesis 291, Transportation Research Board, National Research Council, 2000.

21. ASTM Designation E303-93, Standard Test Method for Measuring Surface Frictional Properties Using the British Pendulum Tester, Annual Book of ASTM Standards, Vol. 04. 03, 1998.

22. ASTM Designation E1911-98, Standard Test Method for Measuring Paved Surface Frictional Properties Using the Dynamic Friction Tester, Annual Book of ASTM Standards, Vol. 04. 03, 2002.

23. Nippo Sangyo Co., Ltd., Dynamic Friction Tester, http://www.nippou.com/productle.html, Accessed September 04, 2003.

24. Schallamach A., Proceedings of the Royal Society of London, B66, pg. 386-392, 1953.

25. Schallamach A., “A Theory of Dynamic Rubber Friction,” Wear, Vol. 6, No. 5, pg. 375-382, 1963.

26. James C. W., E. A. Charles, J. J. Henry, and Z. Rado, International PIARC Experiment to compare and Harmonize Texture and Skid Resistance Measurements, Final Report, The World Road Association, Paris, 1995.

27. Sabir H. M., and L. G. Wade, Wet-Pavement Safety Programs, NCHRP Synthesis of Highway Practice 158, Highway Research Board, National Research Council, 1990.

28. Thad Tibbles, Friction Test Survey, Office of Pavement Engineering, Ohio Department of Transportation, in 2002 (not published).

29. Stephen N. R. and D. C. Maphone, Critique of Tentative Skid-Resistance Guidelines, TRR 633, Transportation Research Board, National Research Council, Washington D. C., 1977. 
30. Ronald L. R., J. L. Burchett, and L. A. Warren, Relation of Accidents and Pavement Friction on Rural, Two-Lane Roads, TRR 633, Transportation Research Board, National Research Council, Washington D. C., 1977.

31. Farber E., M. S. Janoff, S. Cristinzio, J. G. Blubaugh, W. Reisener, and W. Dunning, Determining Pavement Skid Resistance Requirements at Intersections and Braking Sites, NCHRP Report 154, Transportation Research Board, National Research Council, Washington D. C., 1974.

32. Zuieback J. M., "Methodology for Establishing Frictional Requirements." TRR 623, Transportation Research Board, National Research Council, Washington D.C., 1977.

33. Persson, B. N. J., Sliding Friction: Physical Principles and Applications, Springer, Heidelberg, 1998.

34. Huemer T., W. Liu, J. Eberhardsteiner, and H. A. Mang, A 3D Finite Element Formulation of the Friction Behavior of Rubber on Ice and Concrete Surfaces, Engineering Computations, Vol. 18, No. 3/4, pp. 417-436, 2001.

35. Hofstetter K., J. Eberhardsteiner, and H. A. Mang, Thermo-Mechanical Investigation of a Rubber Friction Process, Institute for Strength of Materials, Vienna University of Technology, Austria.

37. Henry, J. J., K. Saito, and R. Blackburn, Prediction Model for Seasonal Variations in Skid Resistance, Vol. II Comprehensive Report, FHWA/RD-83/005, Final Report, 1984.

38. Wambold J. C., J. J. Henry, C. E. Antle, B. T. Kulakowski, W. E. Meyer, A. J. Stocker, J. W. Button, and D. A. Anderson, Pavement Friction Measurements Normalized for Operational, Seasonal, and Weather Effects, FHWA-RD-88-069, 1989.

39. FHWA, Skid Accident Reduction Program, Technical Advisory, T5040.17, Federal Highway Administration, U.S. Department of Transportation, 1980.

40. Manual for Pavement Friction Test, Revised Edition, The Research Division, Indiana Department of Transportation, West Lafayette, Indiana, 2003.

41. Shuo Li, Karen Zhu, van Gelder, John Nagle and Carl Tuttle, "Reconsideration of sample size requirements for field traffic data collection using GPS devices." TRR 1804, Transportation Research Board, National Research Council, Washington D.C., pp. 17-22., 2002. 
42. Henry J. J., "Use of Blank Tire and Ribbed Test Tires for Evaluating Wet Pavement Friction," Transportation Research Record 788, Transportation Research Board, National Research Council, Washington D.C pp.1-6, 1981.

43. Carl-Gustaf Wallman and Henrik Åström. Friction Measurement Methods and Correlation between Road Friction and Traffic Safety: A Literature Review, Swedish National Road and Transport Research Institute, 2001.

44. Karen Zhu, Utilizing GIS Technology to Improve INDOT Pavement Friction Data Management and Distribution, FHWA/INDOT/SPR-2154 Final Report, Indiana Department of Transportation, 1999. 